Fábbio Anderson Silva Borges

\title{
Extração de Características Combinadas com Árvore de Decisão para Detecção e Classificação dos Distúrbios de Qualidade da Energia Elétrica
}


Fábbio Anderson Silva Borges

\section{Extração de Características Combinadas com Árvore de Decisão para Detecção e Classificação dos Distúrbios de Qualidade da Energia Elétrica}

Dissertação de mestrado apresentada à Escola de Engenharia de São Carlos da Universidade de São Paulo, sendo parte dos requisitos para obtenção do título de Mestre em Ciências, Programa de Engenharia Elétrica.

Área de Concentração: Sistemas Dinâmicos.

Orientador: Prof. Dr. Ivan Nunes da Silva

São Carlos

2013

Trata-se da versão corrigida da dissertação. A versão original se encontra disponível na EESC/USP que aloja o Programa de Pós-Graduação de Engenharia Elétrica. 


\begin{abstract}
AUTORIZO A REPRODUÇÃO TOTAL OU PARCIAL DESTE TRABALHO, POR QUALQUER MEIO CONVENCIONAL OU ELETRÔNICO, PARA FINS DE ESTUDO E PESQUISA, DESDE QUE CITADA A FONTE.
\end{abstract}

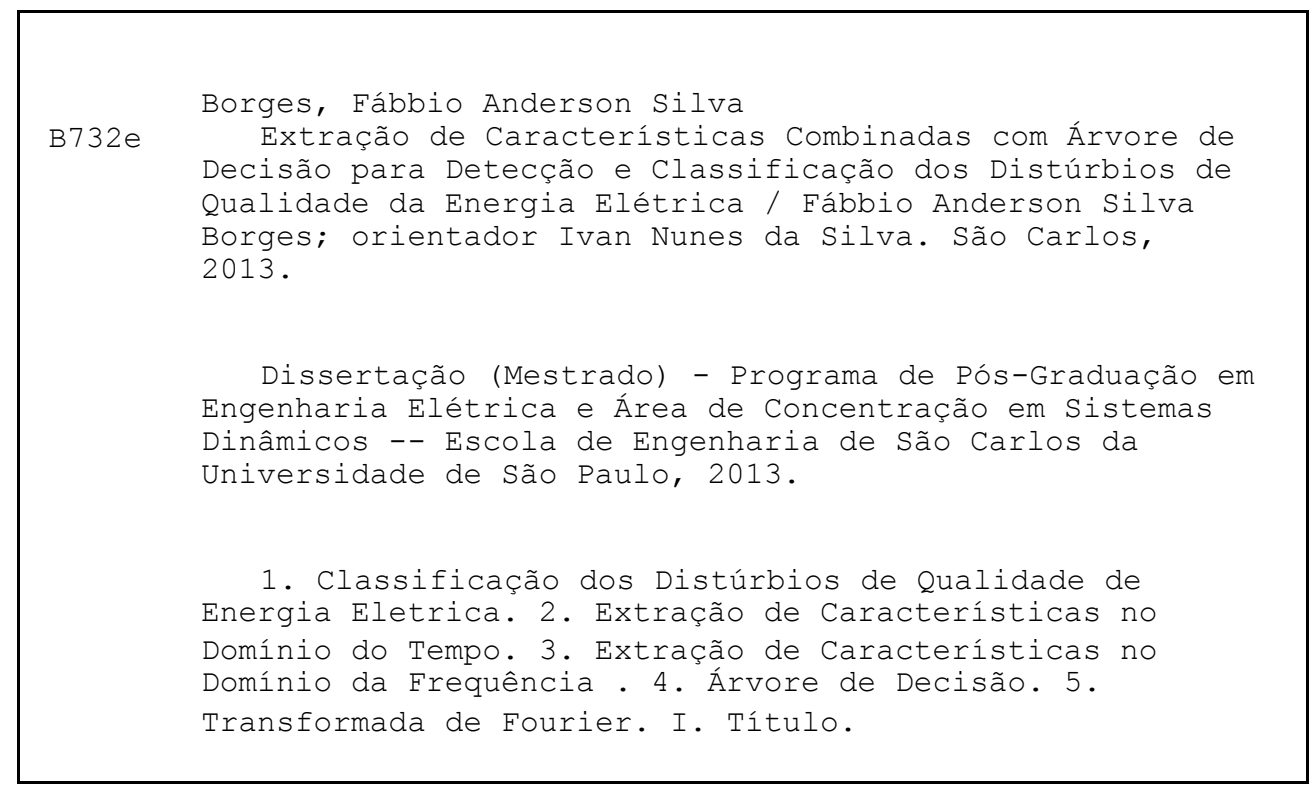





\section{FOLHA DE JULGAMENTO}

\section{Candidato: Bacharel FÁBBIO ANDERSON SILVA BORGES}

Título da dissertação: "Extração de características combinadas com árvore de decisão para detecção e classificação dos distúrbios de qualidade da energia elétrica".

Data da defesa: 11/07/2013

\section{Comissão Julgadora:}

Prof. Associado Ivan Nunes da Silva (Orientador)

(Escola de Engenharia de São Carlos/EESC)

Prof. Dr. Ricardo Augusto Souza Fernandes (Universidade Federal de São Carlos/UFSCar)
Resultado:
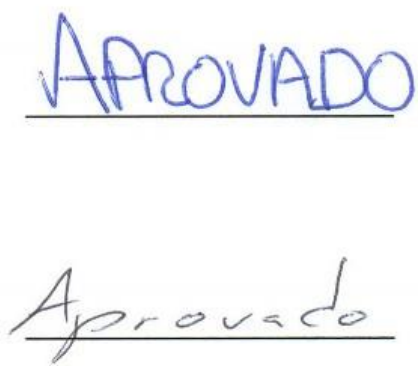

A $320 \mathrm{~A} D O$

Prof. Dr. Dionízio Paschoareli Júnior

(Universidade Estadual Paulista "Júlio de Mesquita Filho"/UNESP-Ilha Solteira)

Coordenador do Programa de Pós-Graduação em Engenharia Elétrica e Presidente da Comissão de Pós-Graduação:

Prof. Titular Denis Vinicius Coury 


\section{Agradecimentos}

Primeiramente, quero agradecer À Deus pela vida e pela saúde.

À todas as dificuldades que enfrentei; não fosse por elas, eu não teria saído do lugar.

Aos meus pais, Antônio Humberto e Maria Lídia, pelas oportunidades oferecidas e pelos conselhos, que com certeza me tornaram uma pessoa melhor. Agradecendo também todos os esforços que eles fazem sempre para que eu possa alcançar meus objetivos. Sem esquecer é claro, do amor e por me fazer muito feliz. Amo Vocês. À minha irmã, Carla Lorena, pelo amor e afeto.

À Thayz quero agradecer principalmente pelo amor que me proporciona e por saber suportar todas as dificuldades que enfrentamos durante toda essa jornada que estivemos distantes. Sou muito grato pelo seu apoio nas horas difíceis, bem como nas felizes. Você é muito importante para mim. Amo você.

À toda minha família, que mesmo distante sempre demonstrou seu apoio, acreditando em mim, em especial aos meus avós Francisca, Déa e Nonato.

Ao meu orientador Ivan Nunes da Silva pela oportunidade e pelos ensinamentos que contribuíram para a conclusão deste trabalho.

Ao Prof. Dr. Ricardo Augusto Souza Fernandes que sempre se mostrou disposto a tirar as minhas dúvidas e pela orientação que desde o início ajudou no desenvolvimento do projeto.

Ao Prof. Dr. Mário Oleskovicz que participou da banca de qualificação, apresentando contribuições para o projeto.

Aos Professores que contribuíram para minha formação, em especial ao Prof. Dr Ricardo de Andrade Lira Rabêlo que foi meu orientador durante a graduação, e que contribuiu grandiosamente para o meu ingresso no mestrado. 
As amigos de São Carlos, Fabão, Remy, Camila, Raissa, Thais, Leandro, Yuri, Tati, Geyverson, Alexandre, sem esquecer os amigos da REP RGEM, Dudu, Alexandre, Patrick, Rafael, Marcelo, Elian, Renan e Gustavo, pelos momentos de diversão e pela ajuda que certamente contribuíram para minha formação.

Ao amigos de laboratório (LAIPS) Sergio Date Fugita, Marcelo Suetake, Danilo Hernane Spatti, Silas Alves, Renné Takao.

Aos funcionários da USP, em especial aos que trabalham secretaria da pós graduação, que sempre se mostraram dispostos a ajudar.

Registro também um muito obrigado ao CNPq (Conselho Nacional de Desenvolvimento Cientifico e Tecnológico), que apoiou financeiramente esta pesquisa. 


\section{SUMÁRIO}

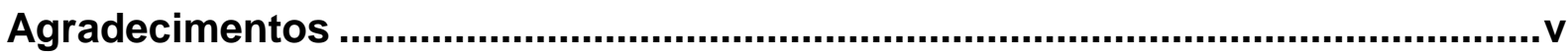

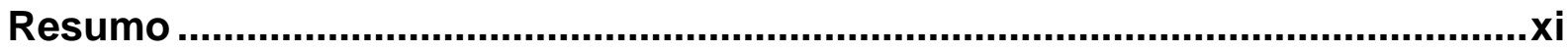

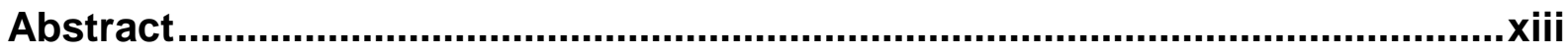

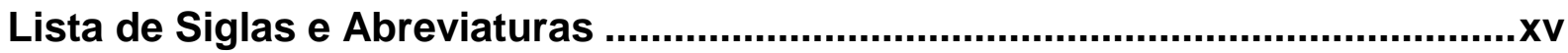

Lista de Figuras...................................................................................................

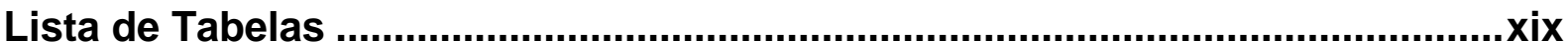

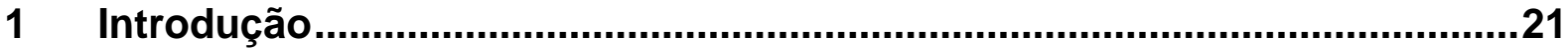

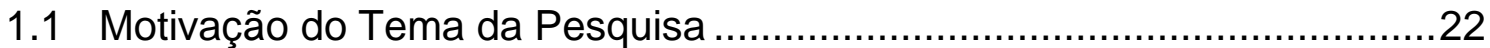

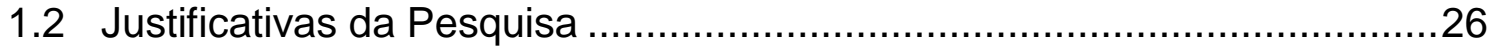

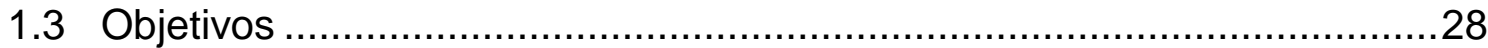

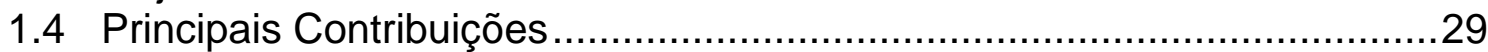

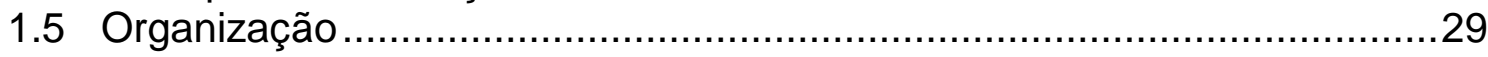

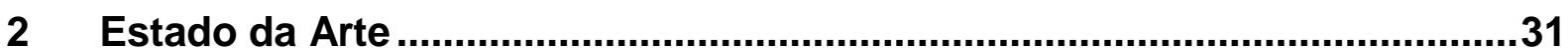

2.1 Métodos de Classificação de Distúrbios de QEE utilizando Transformada Wavelet ................................................................................. 31

2.2 Métodos de Classificação de Distúrbios de QEE utilizando Transformada-S

2.3 Métodos de Classificação de Distúrbios de QEE utilizando Multiplas Ferramentas de Pré-Processamento ...............................................42

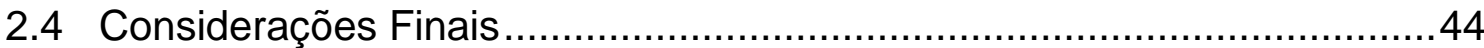

3 Modelagem e Processamento dos Distúrbios Relacionados à Qualidade da Energia Elétrica ........................................................................................47

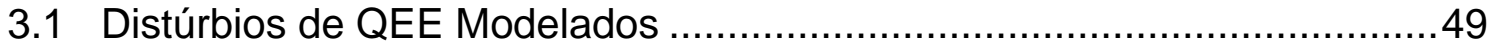

3.1.1 Transitórios Impulsivos .......................................................

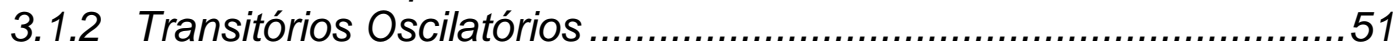

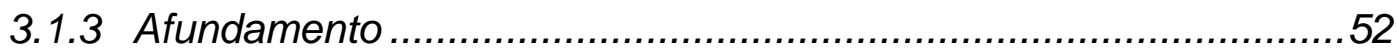

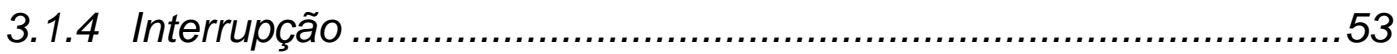

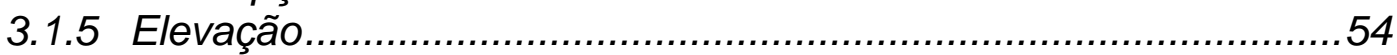

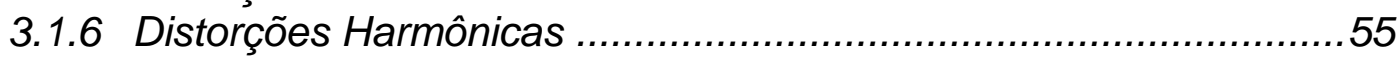

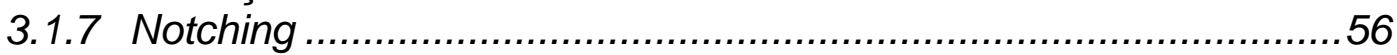

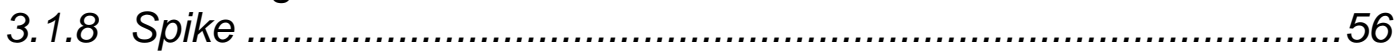

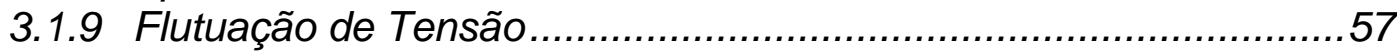

3.1.10 Distúrbios Combinados .....................................................58

3.2 Modelagem Matemática dos Distúrbios de Qualidade de Energia Elétrica ...

rocessamento e Montagem do Banco de Dados de QEE.......................64

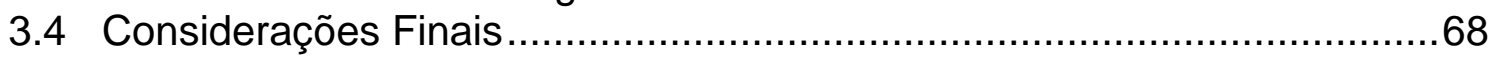

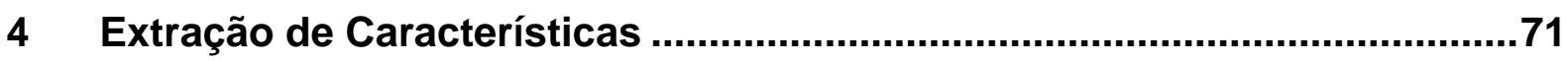

4.1 Aspectos da Extração de Características ...............................................71 
4.2 Características Extraídas no Domínio do Tempo ................................ 72

4.3 Características Extraídas no Domínio da Frequência............................... 76

4.4 Considerações Finais ............................................................ 79

5 Detecção dos Distúrbios da Qualidade de Energia Elétrica ...................... 81

5.1 Detecção do Distúrbio ................................................................ 81

5.2 Resultados obtidos pelo sistema de detecção dos distúrbios de QEE ..... 83

5.3 Considerações Finais ........................................................... 89

6 Classificação dos Distúrbios Relacionados à Qualidade da Energia

Elétrica..................................................................................................... 91

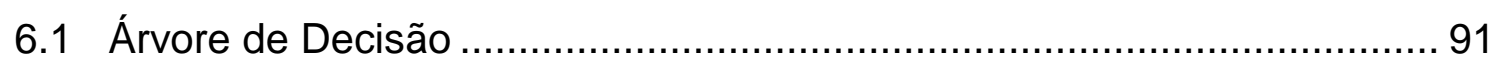

6.1.1 Escolha do atributo para cada nó ......................................... 94

6.1.2 Critérios de parada ......................................................... 95

6.1.3 Algoritmo C4.5 ............................................................... 96

6.2 Resultados Observados ............................................................... 97

6.2.1 Resultados para as janela do sinal com tamanho de um ciclo...... 97

6.2.2 Resultados para um sinal com tamanho de dez ciclos ................ 108

6.3 Considerações Finais ............................................................. 111

7 Conclusões e Trabalhos Futuros .......................................................... 113

Referências Bibliográficas............................................................................ 115 


\section{Resumo}

Este trabalho apresenta uma metodologia de detecção e classificação de distúrbios relacionados à qualidade da energia elétrica. A detecção é feita utilizandose somente uma regra para inferir na presença ou não do distúrbio em uma janela analisada. Para a classificação é proposto um método baseado em árvore de decisão. A árvore recebe como entrada as características do sinal extraídas tanto no domínio do tempo como no domínio da frequência, sendo a última obtida pela Transformada de Fourier. Destaca-se que toda a metodologia de extração de características foi idealizada como tentativa de se reduzir ao máximo o esforço computacional das tarefas de detecção e classificação de distúrbios. Em suma, verifica-se que os resultados obtidos são satisfatórios para a proposta desta pesquisa.

Palavras Chave: Identificação de Distúrbios, Qualidade de Energia Elétrica, Extração de Características, Árvores de Decisão. 

Abstract

This work presents a methodology for detection and classification of disturbance related to the electric power quality. The detection is performed using only one rule to infer in the presence or not of the disturbance in a window analyzed. For the classification is proposed a method based on decision tree. The tree receives as input features of the extracted signal both in time domain and in the frequency domain, being the last obtained by Fourier transform. It is emphasized that all the features extraction methodology was idealized as an attempt to reduce to the maximum the computational effort for the tasks of detection and classification of disturbances. In short, it is possible to verify that the results obtained are satisfactory for the purpose of this research.

Keywords: Identification of Disturbances, Power Quality, Feature Extraction, Decision Trees. 



\section{Lista de Siglas e Abreviaturas}

QEE

TW

$\mathrm{TF}$

TS

THD

IEEE

PRODIST

Qualidade de Energia Elétrica

Transformada Wavelet

Transformada de Fourier

Transformada-S

Total Harmonic Distortion

Institute of Electrical and Electronics Engineers

Procedimentos de Distribuição de Energia Elétrica no Sistema Elétrico Nacional

RNA Redes Neurais Artificiais

DFT

Discrete Fourier Transform

SVM

Suport Vector Machine

PNN

Probabilistic Neural Network

PMC

Perceptron Multicamadas

TWD

Transformada Wavelet Discreta

RMS

Root Mean Square 


\section{Lista de Figuras}

Figura 1.1 - Relação entre quantidade de artigos revisados para cada distúrbio 23

Figura 2.1 - Decomposição Realizada pela Transformada Wavelet................ 32

Figura 3.1-Exemplo de Transitório Impulsivo. ……………………................ 51

Figura 3.2-Exemplo de Transitório Oscilatório. ………………………….... 52

Figura 3.3-Exemplo de Afundamento de Tensão............................................ 53

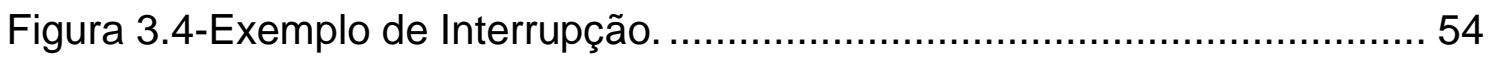

Figura 3.5-Exemplo de Elevação de Tensão.................................................. 54

Figura 3.6-Exemplo de Distorção Harmônica................................................ 55

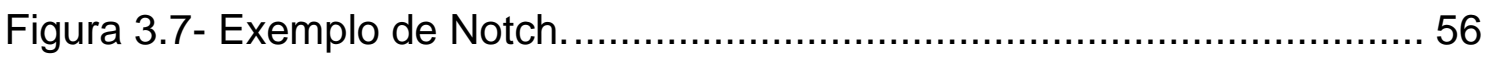

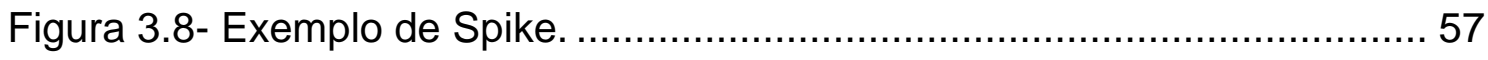

Figura 3.9- Exemplo de Flutuação de Tensão................................................ 58

Figura 3.10- Exemplo de Distorção Harmônica com Afundamento de Tensão. 59

Figura 3.11- Processo para formulação de um sinal com distúrbio Afundamento ( $a$ - Sinal senoidal puro, b - função degrau u(t), c - amplitude do distúrbio d - distúrbio gerado). 63

Figura 3.12 - Caracterização do disturbio transitório oscilatório sobre diferentes

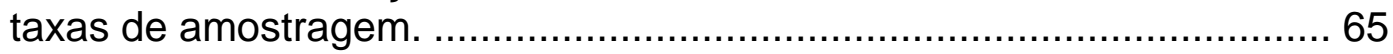

Figura 3.13 - Processo para formulação de um sinal com o ruído (a - Sinal senoidal puro, b - Janela de dados com distribuição normal, c - constante $\propto d$ - sinal gerado com ruído de 20DB)

Figura 3.14 - Processo de movimentação da janela........................................ 68

Figura 5.1 - Representação do método de detecção do distúrbio ..................... 81

Figura 5.2 - Desempenho do método de detecção para as janelas de transição adquiridas sobre uma taxa de amostragem de 16 amostras/ciclo 86

Figura 5.3 - Desempenho do método de detecção para as janelas de transição adquiridas sobre uma taxa de amostragem de 32 amostras/ciclo 86

Figura 5.4 - Desempenho do método de detecção para as janelas de transição adquiridas sobre uma taxa de amostragem de 64 amostras/ciclo 
Figura 5.5 - Desempenho do método de detecção para as janelas de transição adquiridas sobre uma taxa de amostragem de 128 amostras/ciclo

Figura 5.6 - Desempenho do método de detecção para as janelas de transição adquiridas sobre uma taxa de amostragem de 256 amostras/ciclo........... 88

Figura 6.1 - Estrutura de uma árvore de decisão..........................................92

Figura 6.2 - Processo de classificação de duas classes utilizando árvore de decisão: obtenção da primeira fronteira de decisão (a) e segunda fronteira de decisão (b) 93

Figura 6.3 - Caracterização do disturbio transitório oscilatório sobre diferentes niveis de ruído: (a) - sinal sem ruído; (b) - SNR 45 dB; (c) - SNR 40 dB; (d) - SNR 35 dB; (e) - SNR 30 dB; (f) - SNR 25 dB; (g) - SNR 20 dB. 103 


\section{Lista de Tabelas}

Tabela 1.1 - Comparação entre os diferentes métodos realizados 22

Tabela 3.1 - Categorias típicas de fenômenos eletromagnéticos definidos pelo IEEE. 48

Tabela 3.2 - Distúrbios de qualidade de energia elétrica modelados 49

Tabela 3.3 - Equações sintéticas que representam os distúrbios. 60

Tabela 5.1 - Resultado da Detecção para janelas adquiridas com taxa de amostragem de 16 amostras/ciclo 83

Tabela 5.2 - Resultado da Detecção para janelas adquiridas com taxa de amostragem de 32 amostras/ciclo 83

Tabela 5.3 - Resultado da Detecção para janelas adquiridas com taxa de amostragem de 64 amostras/ciclo 84

Tabela 5.4 - Resultado da Detecção para janelas adquiridas com taxa de amostragem de 128 amostras/ciclo .................................................. 84

Tabela 5.5 - Resultado da Detecção para janelas adquiridas com taxa de amostragem de 256 amostras/ciclo

Tabela 6.1 - Desempenho da Árvores de Decisão utilizando os distúrbios adquiridos com taxa de amostragem de 16 amostras/ciclo e SNR 40 $\mathrm{dB}$. 99

Tabela 6.2 - Desempenho da Árvores de Decisão utilizando os distúrbios adquiridos com taxa de amostragem de 16 amostras/ciclo e SNR 30 $\mathrm{dB}$. 100

Tabela 6.3 - Desempenho da Árvores de Decisão utilizando os distúrbios adquiridos com taxa de amostragem de 16 amostras/ciclo e SNR 20 $\mathrm{dB}$. 101

Tabela 6.4 - Resultados detalhado das janelas de Transição adquiridas a 16 amostras/ciclo 104

Tabela 6.5 -- Desempenho da Árvores de Decisão utilizando os distúrbios adquiridos com taxa de amostragem de 32 amostras/ciclo 105

Tabela 6.6 - Desempenho da Árvores de Decisão utilizando os distúrbios adquiridos com taxa de amostragem de 64 amostras/ciclo. 106

Tabela 6.7 - Desempenho da Árvores de Decisão utilizando os distúrbios adquiridos com taxa de amostragem de 128 amostras/ciclo. 106 
abela 6.8 106

Tabela 6.9 - Desempenho comparativo da árvore de decisão sobre diferentes taxas de amostragem.

Tabela 6.10 - Desempenho da Árvores de Decisão utilizando os distúrbios adquiridos com taxa de amostragem de 16 amostras/ciclo e duração de 10 ciclos. 109

Tabela 6.11 - Desempenho da Árvores de Decisão utilizando os distúrbios adquiridos com taxa de amostragem de 32 amostras/ciclo e duração de 10 ciclos. 109

Tabela 6.12 - Desempenho da Árvores de Decisão utilizando os distúrbios adquiridos com taxa de amostragem de 64 amostras/ciclo e duração de 10 ciclos.

Tabela 6.13 - Desempenho da Árvores de Decisão utilizando os distúrbios adquiridos com taxa de amostragem de 128 amostras/ciclo e duração de 10 ciclos

Tabela 6.14 - Desempenho da Árvores de Decisão utilizando os distúrbios adquiridos com taxa de amostragem de 256 amostras/ciclo e duração de 10 ciclos. 


\section{Introdução}

A Qualidade de Energia Elétrica (QEE) está relacionada a um conjunto de fenômenos eletromagnéticos que ocorrem no sistema elétrico, os quais impedem o funcionamento adequado dos equipamentos do consumidor. Atualmente, o cenário que envolve a análise da qualidade de energia elétrica tem recebido grande atenção por parte da comunidade científica, das concessionárias de energia e das indústrias, em consequência dos seguintes aspectos:

- Aumento no uso de equipamentos eletrônicos susceptíveis aos fenômenos eletromagnéticos;

- Proliferação das cargas não lineares;

- Conscientização dos consumidores;

- Regulamentação do setor elétrico.

Devido a estes fatores, os estudos envolvendo a QEE, que antes se preocupavam somente com a continuidade do serviço, passaram a descrever também diferentes terminologias que caracterizam as deformidades na forma de onda de corrente e/ou tensão.

Neste sentido, o Institute of Electrical and Electronics Engineers (IEEE) determinou, por meio da norma IEEE Std 1159-2009, técnicas para medir, quantificar e interpretar estes fenômenos eletromagnéticos, ou simplesmente distúrbios, que ocorrem nos sistemas de energia elétrica, dentre os quais se destacam as seguintes: as variações de tensão de curta duração (VTCD), as variações de tensão de longa 
duração (VTLD), as flutuações de tensão, os desequilíbrio de tensão, as variações de frequência, as distorções da forma de onda e os transitórios. No Brasil, os Procedimentos de Distribuição de Energia Elétrica do Sistema Elétrico Nacional (ANEEL, 2012), em seu oitavo modulo, é o documento responsável por estabelecer a padronização e regulamentação relativa aos distúrbios de QEE.

Os distúrbios de QEE, mencionado tanto nas norma já citadas, são ocasionados por diferentes tipos de fenômenos, tais como: chaveamento de banco de capacitores, cargas não lineares conectadas à rede, descargas atmosféricas, partidas de grandes cargas, os quais provocam então perdas consideráveis aos consumidores de energia elétrica. Em virtude disto, tanto as indústrias quanto as concessionárias de energia têm investido, a cada dia, em equipamentos que monitoram a qualidade de energia elétrica.

Após uma breve introdução à temática desta dissertação (deteç̧ão, e identificação dos distúrbios de QEE), serão apresentados a seguir os fatos que motivaram tal pesquisa (Seção 1.1), as justificativas para as motivações comentadas (Seção 1.2), os objetivos a serem atingidos (Seção 1.3), as principais contribuições advindas desta pesquisa (Seção 1.4) e, por fim, a organização do texto (Seção 1.5).

\subsection{Motivação do Tema da Pesquisa}

De acordo com o contexto apresentado, torna-se então indispensável garantir a qualidade da energia elétrica, eliminando a causa da ocorrência dos distúrbios, ocasionando-se desta forma, a diminuição de prejuízos ao consumidor final. Em vista disso, faz-se necessário primeiro detectar e classificar de forma rápida e precisa os distúrbios de QEE, podendo assim, apontar as possíveis causas do problema e, consequentemente, medidas de mitigação possam ser efetuadas. 
No entanto, a detecção e classificação dos distúrbios de QEE não são tarefas simples, apresentando inúmeras dificuldades, dentre as quais, destacam-se as características semelhantes existentes entre os vários distúrbios encontrados no sistema elétrico de potência.

Vale comentar que na literatura existe uma grande quantidade de pesquisas (Tabela 1.1) que propõem métodos para realizar a classificação de distúrbios de QEE, no entanto, a maioria dos artigos revisados, objetiva somente a classificação de alguns distúrbios simples, como: afundamento, elevação, interrupção, e somente dois distúrbios combinados que são afundamento com distorção harmônica e elevação com distorção harmônica. A Figura 1.1 apresenta uma relação, em forma de gráfico de barras, entre a quantidade de artigos que foram revisados que propõem a classificar cada distúrbio. Assim, dos 24 artigos revisados nesta dissertação apenas 3 desenvolvem métodos para classificar elevação com transitórios oscilatório, de forma contraditória os 24 artigos desenvolvem métodos para classificar o distúrbio elevação.

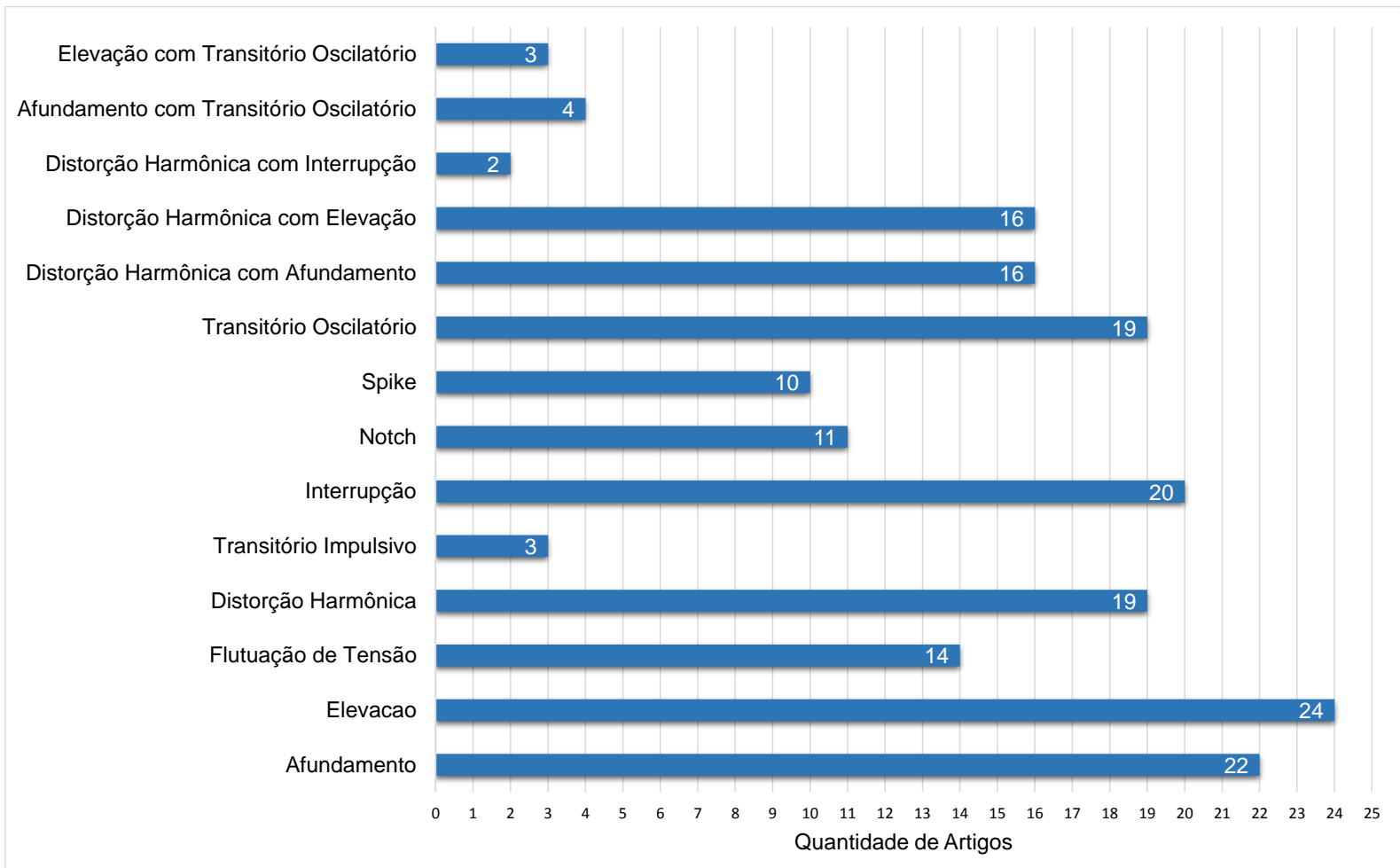

Figura 1.1 - Relação entre quantidade de artigos revisados para cada distúrbio 


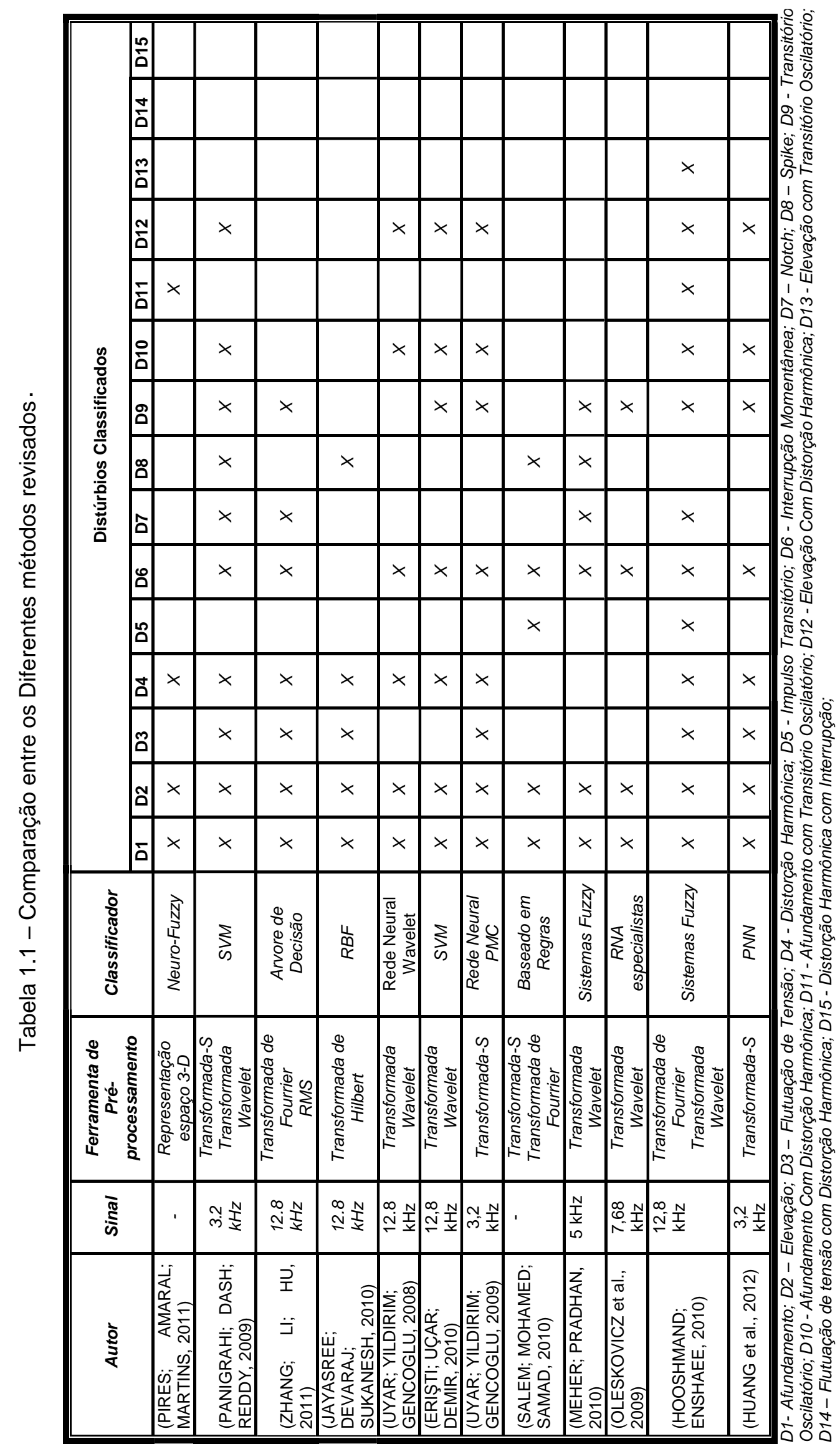




\begin{tabular}{|c|c|c|c|c|c|c|c|c|c|c|c|c|c|}
\hline \multirow{15}{*}{ 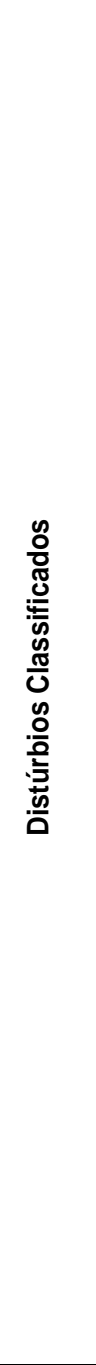 } & & $x$ & & & & & & & & & $x$ & & \\
\hline & & $x$ & & & & $x$ & & & & & $x$ & & \\
\hline & & & & & & $x$ & & & $x$ & & & & \\
\hline & $x$ & $x$ & $x$ & & & $x$ & $\times$ & $\times$ & $x$ & $x$ & $x$ & $x$ & \\
\hline & & & & & & $x$ & & & $x$ & & & & \\
\hline & $x$ & $x$ & $x$ & & & $x$ & $x$ & $x$ & $x$ & $x$ & $x$ & $x$ & \\
\hline & $x$ & $x$ & $x$ & $x$ & $\times$ & $x$ & $x$ & $\times$ & $x$ & $x$ & $x$ & & \\
\hline & $x$ & $x$ & $x$ & & & $x$ & $x$ & & & & $x$ & & \\
\hline & $x$ & $x$ & $x$ & & $x$ & $x$ & $x$ & & & & $x$ & & \\
\hline & $x$ & & $x$ & $x$ & $\times$ & $x$ & $x$ & $\times$ & $x$ & $x$ & & $x$ & \\
\hline & & & & & $\times$ & & & & & & & & \\
\hline & $x$ & & $x$ & $x$ & $\times$ & $x$ & $x$ & $\times$ & $x$ & $x$ & & $x$ & \\
\hline & $x$ & $x$ & $x$ & & $\times$ & $x$ & $x$ & $\times$ & & & $x$ & & \\
\hline & $x$ & $x$ & $x$ & $x$ & $\times$ & $x$ & $\times$ & $\times$ & $x$ & $x$ & $x$ & $x$ & \\
\hline & $x$ & & $x$ & $x$ & $\times$ & $x$ & $\times$ & $\times$ & $x$ & $x$ & & $x$ & \\
\hline 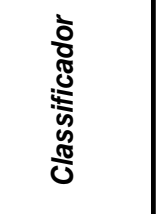 & $\sum_{a} \sum_{0} \sum_{0} z_{i}$ & 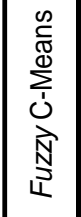 & $\varliminf_{a}$ & 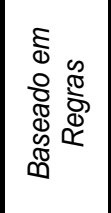 & 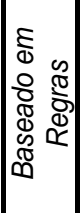 & 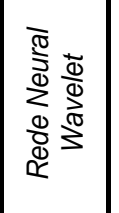 & 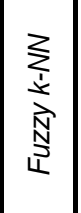 & $\sum_{\infty}$ & 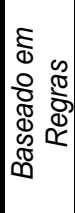 & 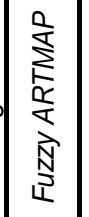 & 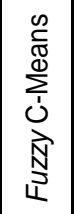 & 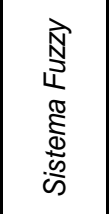 & 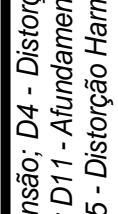 \\
\hline 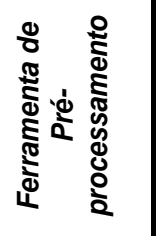 & 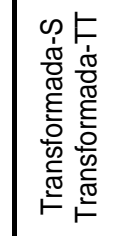 & 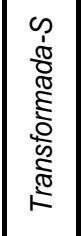 & 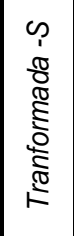 & 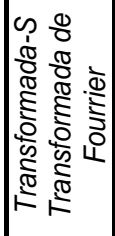 & 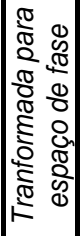 & 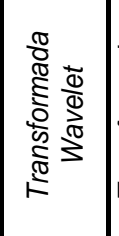 & 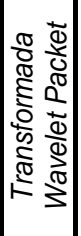 & 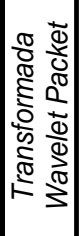 & 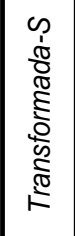 & 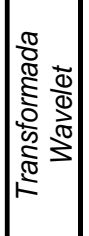 & 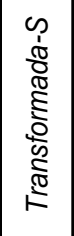 & 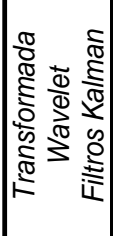 & 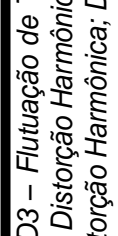 \\
\hline ळ্ & ஸे & 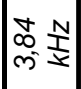 & $\stackrel{N}{\frac{N}{1}}$ & $\frac{\frac{N}{y}}{60}$ & , & 演 & $\begin{array}{l}\cdots \\
\cdots \\
m\end{array}$ & 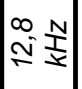 & $\stackrel{N}{N}$ & $\mid$\begin{tabular}{ll}
0 & \multicolumn{1}{c}{} \\
2 & $\frac{1}{2}$
\end{tabular} & 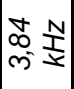 & $\underset{0}{*} \frac{N}{2}$ & \\
\hline ঙ্̀ & 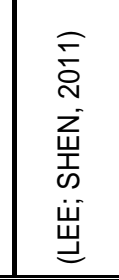 & 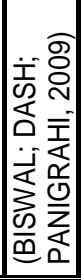 & 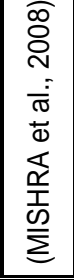 & 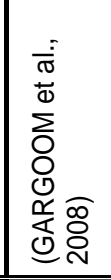 & 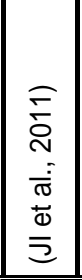 & 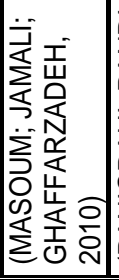 & 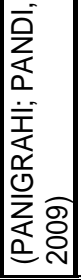 & 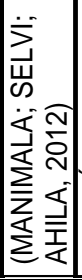 & 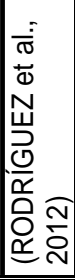 & 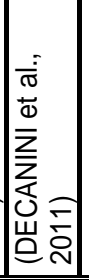 & 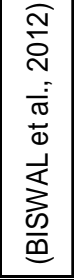 & 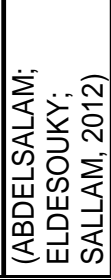 & $\frac{\mathbb{2}}{4}$ \\
\hline
\end{tabular}


Nesta linha, a motivação desta pesquisa visa desenvolver um método simples e eficaz que possa melhor classificar todos os distúrbios de QEE que foram encontrados na literatura revisada e apresentados na Tabela 1.1.

\subsection{Justificativas da Pesquisa}

As motivações e a metodologia proposta desta dissertação são justificadas com base nos relatos mais recentes publicados pela comunidade científica, os quais são provenientes de revistas renomadas da área. De forma a melhor apresentar este trabalhos, a Tabela 1.1 faz então um comparativo entre os sinais analisados, o método utilizado e os distúrbios que foram classificados em cada um desses trabalhos.

Assim, observa-se pela Tabela 1.1 que a identificação dos distúrbios relacionados à QEE pode ser realizada em duas etapas. A primeira consiste no préprocessamento de sinais, responsável por extrair as características das formas de onda de tensão e de corrente. A segunda etapa destina-se na utilização de sistemas de classificação de padrões, responsável por detectar e classificar os distúrbios de qualidade de energia elétrica, tendo-se como entrada as características obtidas na primeira etapa.

O pré-processamento ressalta as características importantes dos distúrbios de QEE, objetivando minimizar o esforço computacional utilizado no processo de detecção e classificação (SAINI; KAPOOR, 2012). A extração de características consiste na parte mais importante do método, pois além do conjunto de características extraídas ser capaz de reduzir o padrão de amostras do sinal, esta deve também ser capaz de preservar as informações significativas de cada distúrbio (SAINI; KAPOOR, 2012). 
Os artigos revisados extraem as características do sinais a partir de um vetor obtido da aplicação de ferramentas de pré-processamento, responsáveis por realizar transformações no sinal, resultando em um novo conjunto de dados que representa o sinal em outro espaço, as quais se destacam as seguintes: Transformada Wavelet (TW), Transformada de Fourier (TF) e a Transformada-S (TS).

A partir do vetor de dados resultante são então realizados cálculos para extração de características. A maioria dos artigos analisados extraem características por meio de medidas estatísticas simples (desvio padrão, média, variância), cálculos que estimam a desordem do sistema (entropia, entropia de Shannon) e cálculos que caracterizam a forma de onda (energia, root mean square (rms)).

Para realização da classificação e detecção desses distúrbios de QEE, diferentes tipos de algoritmos têm sido propostos de modo a relacionar as características extraídas com os distúrbios de qualidade de energia. Entres os métodos mais utilizados se destacam a Lógica Fuzzy, as Redes Neurais Artificiais, os Support Vector Machine (SVM) e as Árvores de Decisão.

De acordo com a Tabela 1.1 nota-se que os métodos até então propostos utilizam ferramentas de análise do sinal que aumenta a complexidade. Além disso, algumas ferramentas de pré-processamento que são utilizadas como TS e TW não satisfazem bem os requisitos para serem empregadas em tempo real (GRANADOSLIEBERMAN et al., 2011).

Outro fator observado é que os autores somente validam o método proposto para uma única taxa de frequência de amostragem, portanto, não se sabe se a metodologia apresentará bons resultados quando for utilizada com outros dados adquiridos em uma menor frequência de amostragem. Estes testes são importantes, pois não existe uma padronização que determina a taxa de amostragem utilizada 
pelos medidores. Segundo o PRODIST (ANEEL, 2012), a frequência mínima tem que ser de $960 \mathrm{~Hz}$.

\subsection{Objetivos}

Considerando as lacunas existentes na exploração do tema, esta dissertação de mestrado tem como objetivo investigar, desenvolver, projetar e validar uma metodologia compacta que possa ser empregada para detecção e classificação dos distúrbios de QEE. A metodologia desenvolvida realiza a extração das características do sinal utilizando tanto cálculos que não necessitam de transformações de domínio nos sinais também como técnicas de pré-processamento utilizando a Transformada Rápida de Fourier. Estas características extraídas serão utilizadas como entradas de um classificador baseado em Árvore de Decisão, sendo esta responsável por associar o padrão de entrada a um distúrbio.

Dessa forma, os objetivos específicos desta dissertação podem sem pontuados da seguinte maneira:

- Modelar um banco de dados dos distúrbios de qualidade da energia elétrica, o qual contenha o maior número de janelas com características distintas de cada distúrbio estudado sobre diferentes taxas de amostragem;

- Desenvolver uma etapa de extração de característica, baseada em cálculos simples, que possua um baixo custo computacional;

- Apresentar a aplicação de um método que seja capaz de detectar os eventos de QEE, de forma rápida e simples.

- Implementar Árvores de Decisões que sejam viáveis ao problema de classificação dos distúrbios de qualidade de energia elétrica; 
- Realizar vários testes a fim de avaliar a precisão da metodologia proposta no problema de classificação dos distúrbios de qualidade da energia, sobre diferentes frequências de amostragem.

\subsection{Principais Contribuições}

Esta dissertação de mestrado pretende fornecer as seguintes contribuições:

- Desenvolvimento de um banco de dados que armazene a maior quantidade possível de distúrbios com diferentes características. Este banco irá contribuir para fornecer diferentes tipos de eventos, que serão utilizados para testar a metodologia e também auxiliar posteriores estudos de QEE.

- Desenvolvimento de uma ferramenta compacta que possibilite uma melhor detecção e classificação dos distúrbios de QEE.

\subsection{Organização}

O trabalho está organizado em sete capítulos principais. Desta forma, o Capítulo 1 foi direcionado a introduzir o tema desta pesquisa, bem como apresentar as motivações e justificativas que levaram à realização da dissertação.

O Capítulo 2 destina-se ao estado da arte. Assim, são analisadas em detalhes as publicações relacionadas com a detecção e classificação dos distúrbios de qualidade da energia elétrica.

No Capítulo 3 são apresentadas as principais características dos distúrbios de QEE que são modelados nesta dissertação. llustra-se também todo o processo de modelagem e processamento da base de dados criada. 
No Capítulo 4 são exibidos todos os fundamentos e cálculos matemáticos responsáveis pela extração de característica dos sinais.

No Capítulo 5 realiza-se uma explanação detalhada sobre o método proposto para a detecção, sendo que os resultados são também apresentados.

No Capítulo 6 são exibidos os detalhes do método de identificação dos distúrbios de qualidade da energia elétrica. Adicionalmente, são apresentados os resultados que são obtidos com o método proposto.

Por fim, cabe ao Capítulo 7 fornece as discussões e conclusões obtidas até o momento. 


\section{Estado da Arte}

Este trabalho tem o objetivo de detectar e identificar os distúrbios de QEE em sistemas elétricos de potência no ponto de acoplamento comum (PAC).

Este capítulo apresenta as publicações envolvendo os métodos utilizados para identificar os distúrbios de qualidade de energia elétrica, fazendo-se um comparativo entre principais técnicas de pré-processamento, as quais são combinadas com diferentes tipos de classificadores.

Assim, inicialmente são apresentados os trabalhos que utilizam a Transformada Wavelet como ferramenta de pré-processamento (Seção 2.1); em seguida, são analisados os trabalhos que fazem uso da Transformada-S (Seção 2.2). Logo após, são explanadas as metodologias que analisam o sinal por meio de duas ou mais ferramentas de pré-processamento (Seção 2.3); por fim, são apresentados os trabalhos que utilizam técnicas não convencionais para a análise dos sinais.

\subsection{Métodos de Classificação de Distúrbios de QEE utilizando Transformada Wavelet}

A utilização da Transformada Wavelet (TW) como ferramenta de préprocessamento do sinal de sistemas elétricos de potência surgiu em meados de 1994, onde se destaca o trabalho de (SANTOSO; POWERS; GRADY, 1994). Neste trabalho os autores empregam a TW para detectar os distúrbios de qualidade de energia elétrica.

Desde então, a TW tem sido amplamente utilizada no sistema elétrico de potência, devido a sua capacidade de examinar um sinal simultaneamente no plano tempo-frequência (ADDISON, 2002). A TW permite a decomposição de um sinal 
discreto em vários níveis, onde cada nível possui duas partes, que são chamados de aproximação e detalhe. As aproximações armazenam informações sobre as componentes de baixa frequência, enquanto os detalhes armazenam as informações sobre as componentes de alta frequência (Figura 2.1).

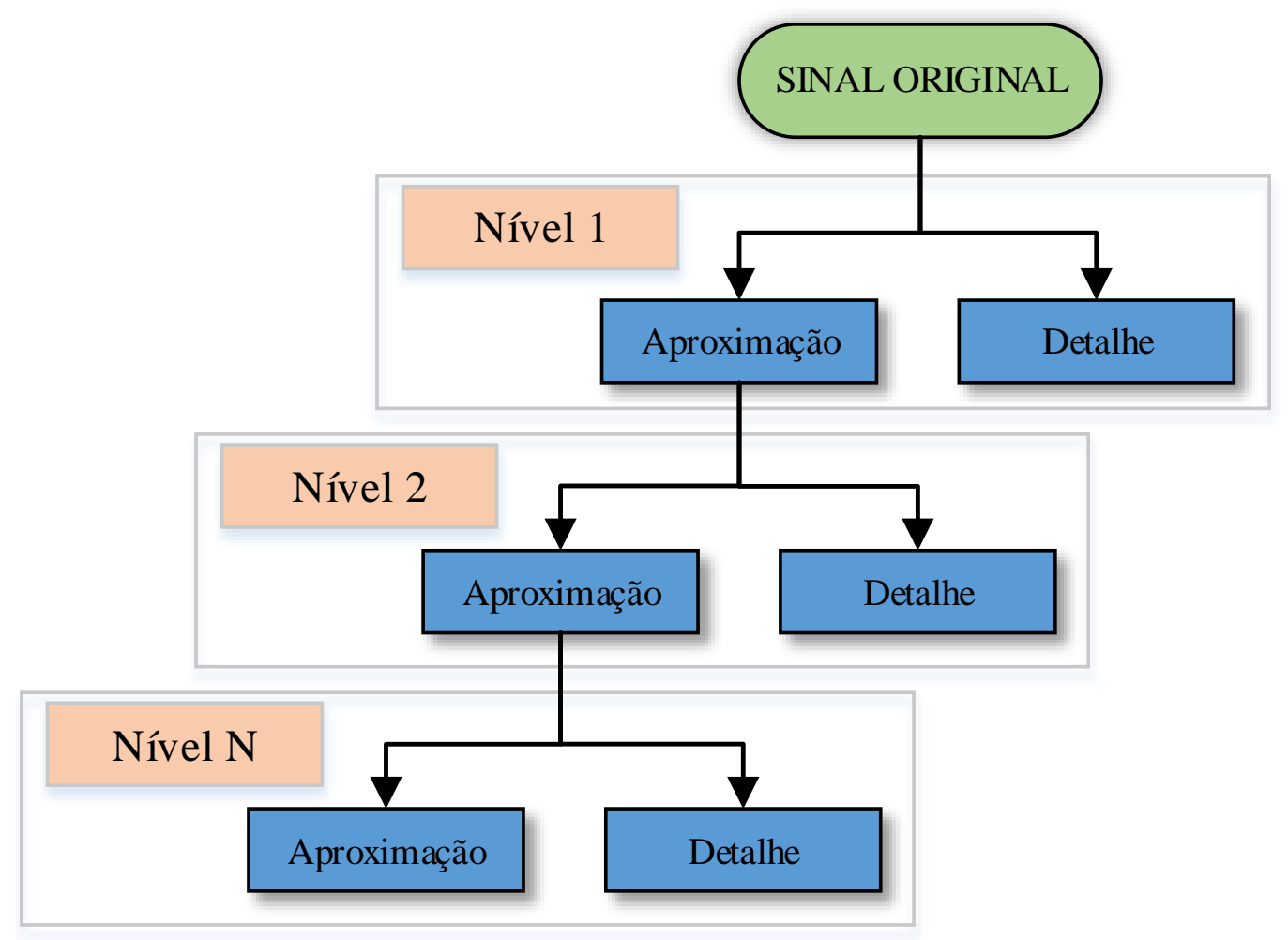

Figura 2.1 - Decomposição Realizada pela Transformada Wavelet.

$\mathrm{Na}$ sequência, são apresentados os trabalhos revisados que utilizam a Transformada Wavelet sobre diferentes formas, sendo as principais: a Transformada Wavelet Discreta (TWD), Transformada Wavelet Packet (TWP), que são combinadas com diferentes tipos de classificadores.

Em Masoum, Jamali e Ghaffarzadeh (2010) é proposto um método para detectar e classificar os distúrbios de QEE empregando a Transformada Wavelet Discreta e a Rede Wavelet. Na etapa de pré-processamento o sinal é decomposto em 12 níveis utilizando a TWD. Em seguida, faz-se necessário remover o ruído presente 
no sinal, por meio da TWD, eliminando os coeficientes, que estão abaixo de um limiar, obtido pelo método do estimador de risco imparcial de Stain e limiarização universal. A detecção do distúrbio é realizada utilizando um critério de identificação baseado na generalização da distorção harmônica total no domínio Wavelet. Quando este critério for maior que 1, ocorre a detecção; caso contrário, o sinal analisado é considerado como normal. Após o distúrbios ser detectado no sinal, ocorre então a extração de características, sendo que dos 12 níveis de decomposição são extraídas 64 características e técnica de Principal Component Analysis (PCA) é utilizada para selecionar as características que melhor distingue cada um dos disturbios. As características selecionadas são introduzidas na Rede Neural Wavelet. Este tipo de rede utiliza Wavelets como funções de ativação dos neurônios. É importante comentar que para a escolha da função Wavelet mãe, 40 diferentes tipos de funções são consideradas e testadas. O critério de escolha é feito de acordo com a porcentagem de acertos da classificação, sendo a symmlet-4 selecionada. Os resultados obtidos apresentam uma média de $98,18 \%$ de acertos.

Panigrahi e Pandi (2009) propõem uma classificação automática do distúrbio utilizando Transformada Wavelet Packet como ferramenta de pré-processamento e o algoritmo fuzzy k-nearest neighbour (FkNN) como ferramenta de classificação. A TWP consiste na decomposição completa do sinal tanto em níveis de detalhes como em níveis de aproximação. O método se inicia com a decomposição do sinal por meio da TWP até o $4^{\circ}$ nível de decomposição. Assim, foi obtido um sinal de 16 partes iguais de $100 \mathrm{~Hz}$. Num total de 6 características estatísticas como: energia, desvio padrão, média, kurtosis, skewness e entropia, são extraídas de cada um dos 16 nós da árvore de decomposição, gerando um vetor de características de tamanho 96. Devido ao tamanho deste vetor, um algoritmo genético (AG) é utilizado para selecionar um vetor 
com 16 características, uma para cada nó folha da árvore de decomposição Wavelet. O vetor resultante do AG é utilizado como entrada do classificador FKNN. Os dados utilizados para teste da metodologia são obtidos tanto com a utilização de funções paramétricas, como por dados práticos obtidos em laboratórios. Os resultados demonstram que a WPT, juntamente com o classificador FkNN e a implementação do AG, aumentaram a taxa de classificação, proporcionando uma média de acerto de $96,27 \%$.

O método utilizado em Manimala, Selvi e Ahila (2012) se diferencia de Panigrahi e Pandi (2009) por utilizar Support Vector Machine (SVM), ao invés do algoritmo FkNN, para classificar os distúrbios. Assim, em Manimala, Selvi e Ahila (2012), o sinal é decomposto por meio da TWD até o $4^{\circ}$ nível de decomposição, resultando num total de 16 nós diferentes. Em seguida, as características: energia, desvio padrão, média, kurtosis, skewness, entropia, mediana e variação entre o valor de máximo e mínimo, são calculadas para cada nó, produzindo assim, um vetor de características de comprimento 128. Algoritmos Genéticos ou Simulated Annealing (SA) são utilizados para encontrar o melhor conjunto de 16 características, uma para cada nó da árvore de decomposição e definir os parâmetros do kerneldo classificador SVM. A metodologia foi testada com dados obtidos a partir de equações paramétricas, dados obtidos a partir de circuitos de teste criados utilizando o software Simulink do Matlab e dados práticos. Pelos resultados pode-se notar que a seleção de características e a otimização dos parâmetros livres do classificador SVM utilizando GA e AS levam a uma melhor taxa de acertos, quando comparadas com outras técnicas de classificação encontradas na literatura.

O método utilizado por Erişti, Uçar e Demir (2010) faz uso da Transformada Wavelet e Análise Multi-resolução juntamente com o classificador SVM. A princípio, o 
sinal é decomposto em 10 níveis utilizando a Daubechie com suporte 4 como Wavelet mãe. Após a etapa de pré-processamento, 11 características são extraídas de cada um dos 10 coeficientes de detalhe e do coeficiente de aproximação, resultando num total de 121 características. Em seguida, as melhores características são selecionadas utilizando a técnica de seleção de características chamada de sequential forward selection. O vetor de características selecionado é introduzido no classificador SVM. Os resultados experimentais indicam que o método proposto é robusto para tarefa de classificação de distúrbios de qualidade de energia elétrica. No entanto, cabe comentar que para um sinal que possui diferentes tipos de ruído, torna-se necessário, selecionar outros tipos características.

Em Decanini et al. (2011) os autores propõem uma ferramenta automática de detecção e classificação dos distúrbios de QEE denominada de Rede Neuro-FuzzyWavelet. Para isto são estabelecidos três módulos: o módulo de detecção de distúrbios, o módulo de extração de características e o módulo de classificação. A detecção estima a amplitude máxima do sinal. Se a amplitude estimada for igual ao parâmetro de normalidade, não existe anormalidade no sinal; caso contrário, indica a presença do distúrbio. Uma vez detectado o distúrbio, o processo segue para o módulo de extração de características. Para isto, o sinal é então decomposto em 12 níveis utilizando Análise Multi-resolução Wavelet com função Wavelet mãe Daubechie com suporte 4. Em seguida, é calculada a norma entropia para cada um dos coeficientes Wavelet de detalhe e para o coeficiente Wavelet de aproximação, resultando em um vetor de tamanho 13. Segundo os autores, a norma entropia calcula o grau de irregularidade do sistema, sendo utilizada como uma ferramenta para quantificar a ordenação dos sinais não-estacionários. Com o objetivo de reduzir a complexidade computacional, somente as 5 características mais relevantes são 
utilizadas como entrada do classificador. Esta etapa de classificação consiste no terceiro módulo e utiliza o classificador neural ARTMAP-fuzzy, que se caracteriza como sendo uma Rede Neural ARTMAP que utiliza em seus cálculos a teoria de conjuntos fuzzy. Para demonstrar a viabilidade do método proposto, uma série de testes foram realizados considerando oito tipos de distúrbios, que foram obtidos por modelos paramétricos e dados de um sistema real simulado no ATP.

No trabalho de Meher e Pradhan (2010) a Transformada Wavelet é utilizada para decompor o sinal até o quarto nível. Após a etapa de pré-processamento, 5 características são extraídas de cada um dos coeficientes de aproximação e do último coeficiente de detalhe, resultando em um vetor com 25 características. Em seguida, 0 vetor de características é introduzido em 4 diferentes tipos de classificadores fuzzy que são: Sistema Fuzzy utilizando o operador de agregação produto, Sistema Fuzzy utilizando o operador de agregação mínimo, máxima verossimilhança fuzzy e Fuzzy kNN. Cada um dos 4 classificadores são testados utilizando sinais que não apresentam ruídos, como sinais que apresentam ruídos. É importante comentar também que 3 tipos de Wavelet mãe são analisadas. Pelos resultados observa-se que a TW com função Daubechie com suporte 8, combinada com o classificador Fuzzy que utiliza o operador de agregação produto, apresenta os melhores resultados.

Em Oleskovicz et al. (2009) os autores propõem uma metodologia que utiliza a Transformada Wavelet e a técnica de Análise de Multi-resolução para detectar os distúrbios. A classificação é feita por meio da aplicação de RNAs (Redes Neurais Artificiais) independentes. Assim, o método proposto se encarrega de detectar 0 distúrbio em uma janela de dados. Tal janela possui o tamanho de um ciclo e se desloca com passo de um quarto de ciclo. Para cada janela adquirida, o primeiro nível de detalhe, calculado pela técnica de Análise Multi-resolução Wavelet utilizando a 
Wavelet mãe Symmlet suporte 4, é comparado com um limiar pré-estabelecido. Caso o sistema detecte anomalia na janela, o distúrbio é detectado e ativa a fase de classificação. Após a janela com distúrbio ser detectada, a janela é decomposta até o $7^{\circ}$ nível utilizando a TW com Wavelet mãe Haar. Os 7 níveis de detalhe são divididos em 3 zonas que correspondem às zonas de alta, média e baixa frequência do sinal. A partir da média das energias calculadas, com base no teorema de Parseval, de cada nível de detalhe que compõe a zona, três características são obtidas e utilizadas como entrada de dois tipos de arquiteturas de RNA: a Rede Neural Perceptron Multicamada (PMC) e a Rede neural com função de base radial. É importante salientar que para cada arquitetura de RNA são implementadas cinco RNAS especialistas, cada uma responsável pela classificação de cada distúrbio. Para testar a metodologia, o sistema proposto foi treinado e testado com dados obtidos da simulação em software ATP e, em seguida, foram utilizados dados reais para validar o método. Os resultados mostram que, quando se utilizam dados de simulação, a Rede Neural PMC apresenta melhor taxa de acerto quando comparada com a rede neural RBF. No entanto, o mesmo não ocorre quando se utiliza dados reais; neste caso, a RBF apresentou melhor generalização.

\subsection{Métodos de Classificação de Distúrbios de QEE utilizando Transformada-S}

Vários estudos têm utilizados a Transformada-S para análise de sistemas de energia por que o método permite a localização dos espectros de tempo-frequência. Tal técnica pode ser considerada conceitualmente como um híbrido da Transformada de Fourier e Transformada Wavelet Contínua. A TS fornece informações de tempo e frequência, com resoluções diferentes, utilizando um comprimento de janela variável (GARGOOM et al., 2008). A saída da TS é uma matriz complexa cujas linhas e colunas 
representam a frequência e o tempo, respectivamente. $\mathrm{Na}$ sequência são apresentados os aspectos mais relevantes dos trabalhos que utilizam a Transformada-S.

Em Biswal, Dash e Panigrahi (2009) e B. Biswal et al. (2012) a TransformadaS é aplicada ao sinal utilizando uma janela gaussiana modificada. Esta janela foi aplicada para melhorar a resolução dos distúrbios de QEE no contorno de tempofrequência. Um vetor de características é extraído da matriz de saída da Transformada-S. Em seguida, o algoritmo fuzzy C-means é usado para agrupar as características em clusters distintos, de modo a classificar os distúrbios de QEE. Para refinar os centros dos clusters, o algoritmo fuzzy C-means é combinado com o método de otimização Adaptativo Particle Swarm Optimization (APSO). A diferença deste método de otimização para o método Particle Swarm Optimization (PSO) convencional é que a inércia das partículas varia de acordo com a aptidão da população, aumentando a capacidade de encontrar ótimos globais. O método proposto é então testado com dados simulados no Simulink e os resultados obtidos são comparados com outra metodologia que difere da utilizada, por empregar a Transformada Wavelet para extração de características. Assim, é mostrado que a TS atingiu melhores resultados do que a TW.

Mishra et al. (2008) apresentam uma proposta baseada em Transformada-S, onde somente quatro características são necessárias para classificar os distúrbios, reduzindo assim o esforço e o tempo computacional. As características extraídas servem de entrada para o classificador neural probabilístico (Probabilistic Neural Network, PNN) e seu desempenho é comparado com dois outros classificadores: rede PMC e rede neural LVQ. Por fim, testes na presença de ruídos são realizados utilizando a rede probabilística, a qual é treinada com sinais de ruído que consistem 
em 20, 30 e 40 dB (relação sinal ruído) e testados com 20, 25, 30, 35 e 40. Os resultados da classificação de PNN são satisfatórios, mesmo com níveis de ruído diferentes durante o treinamento e teste.

Em Rodríguez et al. (2012), os autores apresentam uma abordagem que utiliza a Transformada-S combinada com um classificador baseado em regras. $\mathrm{Na}$ técnica proposta o sinal é pré-processado por meio da Análise de Multiresolução da TS. Um vetor de 6 características é obtido a partir da observação do contorno de frequência da matriz-S. Com base na análise de cada característica foi possível criar um classificador baseado em regra, formado por 4 módulos independentes, onde cada um é responsável por identificar somente uma das 4 classes de perturbações (distúrbios de alta magnitude, distúrbios de baixa magnitude, transitórios e distorção de forma de onda) atribuída a ele. A detecção é feita comparando um atributo com uma constante linear que define a fronteira de decisão que separa a presença ou não do distúrbio. A fim de discriminar o afundamento da interrupção, pertencentes a classe de magnitude baixa, uma função quadrática é atribuída a este módulo. Por fim, a identificação do distúrbio se dá a partir da saída binária de cada módulo, que indica se a perturbação está presente ou não. Portanto, os módulos funcionam de modo que todo o sistema pode facilmente detectar distúrbios complexos. O método proposto é testado com um conjunto de dados sintéticos, conjunto de dados obtidos por simulação utilizando PSCAD/EMTDC e um conjunto de sinais medidos em instalações elétricas. Os resultados são comparados com outra metodologia que utiliza Transformada Wavelet e Rede Neural PMC. Pode-se observar que o sistema de classificação baseado em regras obtém melhores resultados do que a metodologia que utiliza RNA e TW. 
Em Uyar, Yildirim e Gencoglu (2009) a Transformada-S discreta é aplicada sobre os sinais que representam os distúrbios de QEE. Na sequência, um estudo visual é feito em 4 gráficos que são: frequência em função do tempo, amplitude máxima em função do tempo, amplitude máxima em função da frequência normalizada e desvio padrão em função da frequência normalizada. Após análise dos gráficos são obtidas 14 características úteis para representar o sinal. A partir destas características são criados gráficos de dispersões, objetivando encontrar fronteiras capaz de separar e distingue cada perturbação. As características que melhor identifiquem estas fronteiras são utilizadas como entrada das RNA. A fim de testar a sensibilidade do método, foram realizados vários testes utilizando sinais normais e ruidosos. Os resultados mostram que com apenas um conjunto de 4 características é possível obter uma boa classificação dos distúrbios de QEE.

Em Huang et al. (2012) é proposto um sistema de classificação utilizando a Transformada-S e Redes Neurais Probabilísticas. A partir da análise da matriz-S, resultante do pré-processamento utilizando a TS, são calculados 18 tipos de características para serem utilizadas na fase de classificação. No entanto, o uso de muitas entradas pelo classificador PNN aumenta o tempo e complexidade computacional do mesmo, por isto um estudo comparativo é feito entre a melhor combinação de duas características que melhor consiga distinguir os eventos. Este par de características escolhida é utilizada como entrada da PNN. O classificador foi testado para sinais de perturbação simulados com e sem a presença de ruídos, e foram também comparados com outros dois classificadores: o classificador PMC e o classificador RBF. A comparação entre os resultados mostra que o classificador baseado em PNN foi mais preciso do que as abordagens que utilizam PMC e RBF. 
Gargoom et al. (2008) apresentam uma técnica para monitoramento automático de eventos de qualidade de energia, baseado na Análise de Multiresolução da Transformada-S, e no teorema de Parseval. Este teorema afirma que a energia de um sinal permanece o mesmo, quer seja calculado em um domínio de sinal (tempo) ou em um domínio de transformação (frequência). Primeiramente, a abordagem proposta obtém vetores de frequências instantâneas a partir da TS. Com base no teorema de Parserval é calculada a energia de cada uma das frequências do vetor, resultando em um vetor de energia das frequências. O vetor é então utilizado para distinguir 3 diferentes regiões de frequências que pode ser utilizado para classificar os distúrbios de acordo com o cálculo do valor máximo do vetor de energia. Se o valor máximo estiver na região 1, então o evento pode ser classificado como elevação, afundamento ou interrupção. Similarmente, se o valor máximo estiver nas regiões 2 ou 3, o distúrbio é classificado como harmônica ou transitório, respectivamente. Foi demonstrado pelos resultados que a técnica consegue classificar adequadamente os distúrbios de qualidade de energia.

Em Panigrahi, Dash e Reddy (2009) é feito um estudo comparativo entre a Transformada-S e a Transformada Wavelet para deteç̧ão e classificação de distúrbios de QEE. O estudo é feito com diferentes tipos de sinais normais e ruidoso, obtidos por meio de simulação com Matlab ou dados obtidos a partir de laboratório. Com relação à detecção, os autores observaram que tanto a TS como TW são capazes de detectar o início e o fim do distúrbio em um sinal normal sem a presença de ruído. No entanto, para sinais ruidosos, a TW não apresenta bons resultados, enquanto que o desempenho da TS é satisfatório. Com relação à classificação, a comparação é feita de acordo com o desempenho do classificador SVM que utiliza como entrada as características obtidas a partir da TS e TW. Conclui-se que SVM 
baseado em TS tem o melhor desempenho em comparação com o SVM em conjunto com a TW, tanto em ambiente normal como em ambiente ruidoso. É importante frisar que os resultados da classificação SVM são satisfatórios, mesmo se o nível de ruído é diferente durante o treinamento e teste.

\subsection{Métodos de Classificação de Distúrbios de QEE utilizando Multiplas Ferramentas de Pré-Processamento}

Em alguns artigos foi observado que as características foram extraídas após a aplicação de duas ou mais ferramentas de pré-processamento. Portanto, em seguida, são apresentados alguns trabalhos que apresentam este tipo de metodologia.

Em Lee e Shen (2011) as ferramentas de pré-processamento utilizadas foram a Transformada-S e Transformada-TT. A Transformada-S é responsável por obter a representação do sinal dos distúrbios de QEE na resolução de tempo-frequência, já a Transformada-TT mapeia o sinal no domínio do tempo para o sinal no domínio de tempo-tempo, podendo assim obter as características transitórias do sinal. Após o préprocessamento, 62 características são extraídas a partir de 11 curvas de características obtidas por meio de cálculos simples como: máxima, mínima, media, desvio padrão e RMS de cada coluna e linha da matriz-S e elementos da diagonal principal da matriz-TT. Em seguida, uma Rede Neural Probabilística baseada em seleção de recursos é utilizada para escolher as características mais relevantes dentre as 62. Com a finalidade de validar a seleção de atributos, o conjunto de características selecionadas são testadas em três classificadores diferentes: Rede PMC, k-vizinhos mais próximos e rede PNN. Os melhores resultados são obtidos utilizando o classificador neural MLP. 
Em Salem, Mohamed e Samad (2010) os autores desenvolveram um sistema de hardware para classificação e detecção dos distúrbios em tempo real. As características dos sinais são extraídas a partir da análise da matriz-S resultante da Transformada-S e do vetor de frequência da Transformada de Fourier que é utilizado para extrair características das harmônicas. A partir da análise das características extraídas, torna-se possível formular um conjunto de regras simples que servem para classificar e detectar os distúrbios de QEE. Para avaliar o desempenho do método proposto baseado em regras, ele é comparado com dois outros métodos de redes neurais artificiais, que são: a rede probabilística (PNN) e a MLP. Os resultados mostraram que a classificação baseada em regras obteve melhor precisão quando comparada com os outros dois métodos.

O principal objetivo em Zhang, Li e Hu (2011) é implementar um classificador em tempo real que possua um baixo esforço computacional. Para isto, a extração de características no tempo e na frequência é feita por meio de cálculos estatísticos utilizando o valor RMS e a Transformada Discreta de Fourier. É importante comentar que para testar a confiabilidade do método em tempo real, o pré-processamento de sinal e extração de características é implementado em um Digital Signal Processor (DSP). Após a fase de extração de características, um conjunto de regras pode ser obtido e utilizado para criar uma árvore de decisão baseada em regras. A fim de avaliar o desempenho da metodologia, são realizados dois tipos de testes, o primeiro utiliza formas de ondas simuladas no simulink e o segundo assume formas de ondas adquiridas a partir de um instrumento Fluke 61000. Para o segundo caso, as formas de ondas são pré-processadas utilizando DSP e Field-Programmable Gate Array (FPGA) e introduzidas como entrada para o software responsável pela classificação. 
Os resultados dos testes mostraram que o método proposto obtém uma precisão de classificação aceitável e atende aos requisitos das aplicações reais.

No trabalho de Hooshmand e Enshaee (2010) é apresentado um sistema de detecção e classificação de distúrbios de qualidade de energia elétrica que utiliza Transformada Wavelet e Transformada de Fourier combinadas com o classificador baseado em logica fuzzy. A execução do método proposto ocorre em três etapas. $\mathrm{Na}$ primeira etapa, um conjunto de característica é extraído de cada janela adquirida do sinal, a partir dos parâmetros derivados da aplicação da Transformada de Fourier e da Transformada Wavelet. Este conjunto de características compõe o vetor de entrada de dois sistemas fuzzy responsáveis pela detecção e classificação dos distúrbios de QEE, cujas funções de pertinências são otimizadas pelo método PSO. Assim, para a segunda etapa é utilizado um sistema fuzzy que detecta ou não a presença do distúrbio na janela. Se a resposta do sistema de detecção for negativa o processo irá então obter uma nova janela e retornará para a primeira etapa. Caso contrário, significa que a perturbação na janela foi detectada e a terceira etapa será realizada. A terceira etapa consiste em identificar o tipo de distúrbio que foi detectado, sendo utilizado para isto um segundo sistema fuzzy responsável pela classificação. Os resultados demonstram que o método tem grande capacidade e precisão na detecção e classificação correta de diferentes tipos de distúrbios de QEE, mesmo sob condições de ruído.

\subsection{Considerações Finais}

Neste capítulo, foi apresentado uma diversidade de produções científicas que extraem as características a partir da transformada wavelet e transformada-S. 
De acordo com os trabalhos que utilizam a Transformada Wavelet como ferramenta de pré-processamento, foi observado que ela consegue uma boa resolução do sinal no plano tempo-frequência; no entanto, o processo de análise pode ser fortemente influenciado pela escolha de alguns parâmetros como: nível de decomposição do sinal e tipo de Wavelet mãe. Adicionalmente, notou-se que a TW não apresenta bons resultados quando existe um ruído sobreposto ao sinal.

Com relação aos trabalhos que utilizam a Transformada-S como ferramenta de pré-processamento, foi observado que a TS é utilizada para suprir os problemas obtidos com a utilização da Transformada Wavelet. Portanto, esta consegue uma boa localização dos espectros reais e imaginários no tempo e não sofre alterações com o ruído. No entanto, a Transformada-S baseia-se na forma de processamento em bloco e, portanto, sua utilização em tempo real não é recomendada (GRANADOSLIEBERMAN et al., 2011).

No capítulo também faz-se uma breve revisão dos trabalhos que utilizam múltiplas ferramentas de pré-processamento, as quais são utilizadas de modo que cada ferramenta supri as desvantagens de outras.

Durante o levantamento bibliográfico foi observada uma diversidade de produções cientificas que extraem características a partir de ferramentas não convencionais. Entre estas produções se destacam Cho et al. (2010) que utiliza a Transformada de Gabor que corresponde a uma expansão da Transformada Rápida de Fourier, a Transformada de Gabor possui como vantagem uma boa resolução no tempo-frequência e uma boa relação sinal-ruído, porem a sua complexidade computacional é diretamente proporcional a frequência de amostragem do sinal.

Em outros trabalhos são utilizados Filtros Linear de Kalman como em Abdelsalam, Eldesouky e Sallam (2012), o filtro de kalman possui boa estimativa de 
amplitude e conteúdo harmônico, no entanto não são muitos robustos aos ruídos e tem uma alta complexidade computacional. Outra metodologia que também foi encontrada e que se difere da convencional é a transformação do sinal para o espaço de fase ou um espaço 3-D, como em Ji et al. (2011) e Pires, Amaral e Martins (2011), respectivamente, esta abordagem tem a vantagem de ser rápida e simples, no entanto sofre muita influência do ruído. 


\section{Modelagem e Processamento dos Distúrbios Relacionados à Qualidade da Energia Elétrica}

Este capítulo objetiva explanar de forma geral os principais aspectos a respeito das características dos distúrbios de QEE que serão apresentados nesta dissertação, assim como a modelagem matemática que será utilizada para obtenção de uma forma de onda que representa os distúrbios de forma sintética.

A modelagem matemática é realizada com base na recomendação IEEE Recommended Practice for Monitoring Electric Power Quality (IEEE Std. 1159-2009) e no Procedimento de Distribuição de Energia Elétrica no Sistema Elétrico Nacional, PRODIST em seu oitavo módulo (ANEEL, 2012), os quais estabelecem uma padronização nas definições que envolvem a qualidade de energia elétrica. A partir desta modelagem, foi possível criar um banco de dados heterogêneo, com uma vasta gama de distúrbios que apresentam características semelhantes aos encontrados no sistema elétrico.

O IEEE Std. 1159-2009 define 7 categorias de distúrbios (Tabela 3.1), que são: transitórios, variações de tensão de curta duração (VTCD), variação de tensão de longa duração (VTLD), desequilíbrio de tensão, distorção da forma de onda, flutuações e variação da frequência do sistema. Já o PRODIST (ANEEL, 2012) define 5 classes que são: distorções harmônicas, variações de tensão de curta duração, desequilíbrio de tensão, flutuação de tensão e variação da frequência. 
Tabela 3.1 - Categorias típicas de fenômenos eletromagnéticos definidos pelo IEEE.

\begin{tabular}{|c|c|c|c|}
\hline Categorias & $\begin{array}{l}\text { Conteúdo } \\
\text { Espectral }\end{array}$ & Duração Típica & $\begin{array}{c}\text { Magnitude de } \\
\text { Tensão }\end{array}$ \\
\hline \multicolumn{4}{|l|}{ Transitórios } \\
\hline \multicolumn{4}{|l|}{ Impulsivos } \\
\hline Nanosegundo & 5 ns pico & $<50 n s$ & \\
\hline Microsegundo & $1 \mu \mathrm{s}$ pico & $50 n s-1 m s$ & \\
\hline Milisegundo & $0.1 \mathrm{~ms}$ pico & $>1 \mathrm{~ms}$ & \\
\hline \multicolumn{4}{|l|}{ Oscilatórios } \\
\hline Baixa Frequência & $<5 \mathrm{kHz}$ & $0.3-50 \mathrm{~ms}$ & $0-4 p . u$ \\
\hline Média Frequência & $5-500 \mathrm{kHz}$ & $20 \mu s$ & $0-8 p . u$ \\
\hline Alta Frequência & 0.5-5 MHz & $5 \mu s$ & $0-4 p u$ \\
\hline \multicolumn{4}{|l|}{$\begin{array}{l}\text { Variação de Tensão de Curta } \\
\text { Duração (VTCD) }\end{array}$} \\
\hline Instantâneo & & $0.5-30$ ciclos & $<0.1$ p.u \\
\hline Afundamento & & $0.5-30$ ciclos & $0.1-0.9$ p.u \\
\hline Elevação & & $0.5-30$ ciclos & $1.1-1.8$ p.u \\
\hline \multicolumn{4}{|l|}{ Momentâneo } \\
\hline Interrupção & & 30 ciclos $-3 s$ & $<0.1$ p.u \\
\hline Afundamento & & 30 ciclos $-3 s$ & $0.1-0.9$ p.u \\
\hline Elevação & & 30 ciclos $-3 s$ & $1.1-1.8$ p.u \\
\hline Temporário & & & \\
\hline Interrupção & & $>3 s-1 \mathrm{mim}$ & $<0.1$ p.u \\
\hline Afundamento & & $>3 s-1 \mathrm{mim}$ & $0.1-0.9$ p.u \\
\hline Elevação & & $>3 s-1 \mathrm{mim}$ & $1.1-1.8$ p.u \\
\hline \multicolumn{4}{|l|}{$\begin{array}{l}\text { Variação de Tensão de Longa } \\
\text { Duração }\end{array}$} \\
\hline Interrupção Sustentada & & $>1 \mathrm{mim}$ & 0.0 p.u \\
\hline Sobtensões & & $>1 \mathrm{mim}$ & $0.8-0.9$ p.u \\
\hline Sobretensões & & $>1 \mathrm{mim}$ & $1.1-1.8 p . u$ \\
\hline Desequiliorio & & Regime & \\
\hline Tensão & & Permanente & $0.5-2 \%$ \\
\hline Corrente & & $\begin{array}{c}\text { Regime } \\
\text { Permanente }\end{array}$ & $10-30 \%$ \\
\hline \multicolumn{4}{|l|}{ Distorções na Forma De Onda } \\
\hline Nível CC & & $\begin{array}{l}\text { Regime } \\
\text { Permanente }\end{array}$ & $0-0.1 \%$ \\
\hline Distorções Harmônicas & $0-9 \mathrm{kHz}$ & $\begin{array}{c}\text { Regime } \\
\text { Permanente }\end{array}$ & $0-20 \%$ \\
\hline Inter Harmônicos & $0-9 \mathrm{kHz}$ & $\begin{array}{c}\text { Regime } \\
\text { Permanente }\end{array}$ & $0-2 \%$ \\
\hline Notching & & $\begin{array}{c}\text { Regime } \\
\text { Permanente }\end{array}$ & \\
\hline Ruído & Toda Banda & $\begin{array}{c}\text { Regime } \\
\text { Permanente }\end{array}$ & $0-1 \%$ \\
\hline $\begin{array}{l}\text { Flutuação de Tensão } \\
\text { Variação da Frequência }\end{array}$ & $<25 \mathrm{~Hz}$ & $\begin{array}{c}\text { Intermitente } \\
>10 \mathrm{~s} \\
\end{array}$ & $\begin{array}{l}0.1-7 \% \\
\pm 0.10 \mathrm{~Hz} \\
\end{array}$ \\
\hline
\end{tabular}

Fonte: (IEEE Std. 1159-2009). 
Assim, este capítulo está dividido em 3 partes, na Seção 3.1 é realizada uma breve análise dos eventos de qualidade de energia estudados nesta dissertação; na Seção 3.2 são explicados os detalhes das equações paramétricas que modelam tais distúrbios de QEE; a Seção 3.3 se encarrega de detalhar a fase de processamento e criação do Banco de Dados.

\subsection{Distúrbios de QEE Modelados}

No presente trabalho foram modelados 15 distúrbios que foram encontrados frequentemente na literatura revisada. Tais distúrbios são apresentados na Tabela 3.2 e pertencem às seguintes categorias: transitórios, variações de tensão de curta duração (VTCD), distorções na forma de onda e flutuações de tensão, as quais são definidas pelo IEEE.

Tabela 3.2 - Distúrbios de qualidade de energia elétrica modelados

\begin{tabular}{|c|c|}
\hline Sigla & Distúrbios \\
\hline D1 & Afundamento \\
\hline D2 & Elevação \\
\hline D3 & Flutuação de Tensão \\
\hline D4 & Distorção Harmônica \\
\hline D5 & Impulso Transitório \\
\hline D6 & Interrupção Momentânea \\
\hline D7 & Sransitório Oscilatório \\
\hline D8 & Afundamento Com Distorção Harmônica \\
\hline D9 & Afundamento com Transitório Oscilatório \\
\hline D10 & Elevação Com Distorção Harmônica \\
\hline D11 & Elevação com Transitório Oscilatório \\
\hline D12 & Distorção Harmônica com Interrupção \\
\hline D13 & Flutuação de Tensão com Distorcão Harmônica \\
\hline D14 & I4 \\
\hline D15 &
\end{tabular}

As VTCD são conceituadas como desvios significativos no valor eficaz da tensão em curtos intervalos de tempo. Já a categoria transitório, é definida por ser 
uma manifestação no sinal com alta frequência e um curto intervalo de tempo, provenientes de alterações súbitas nas condições operacionais do sistema (DUGAN et al., 2002).

A flutuação de tensão é uma variação aleatória e repetitiva do valor eficaz da tensão. Por fim, a distorção da forma de onda é definida como desvios da forma senoidal de tensão na frequência fundamental do sistema.

Dessa forma, é apresentado em seguida as características importantes de cada distúrbio como: duração do evento, espectro da harmônica e as possíveis causas da ocorrência dos distúrbios. Esta explanação faz-se necessária para um melhor entendimento de como são definidas as equações paramétricas que modelam os distúrbios de qualidade de energia elétrica.

\subsubsection{Transitórios Impulsivos}

Os transitórios impulsivos é uma alteração não desejável e repentina nas condições de regime permanente da tensão, corrente ou ambas, com polaridade unidirecional positiva ou negativa, possuindo um nível de frequência bastante diferenciado da frequência da rede elétrica (DUGAN et al., 2002). A Figura 3.1 mostra um transitório impulsivo. Estes distúrbios são causados principalmente por descargas atmosféricas e tem como consequência a redução da vida útil de motores e geradores.

De acordo com o tempo de subida e de descida, o transitório impulsivo pode ser classificado em nanosegundos, microssegundos e milissegundos, sendo que suas características são apresentadas na Tabela 3.1. 


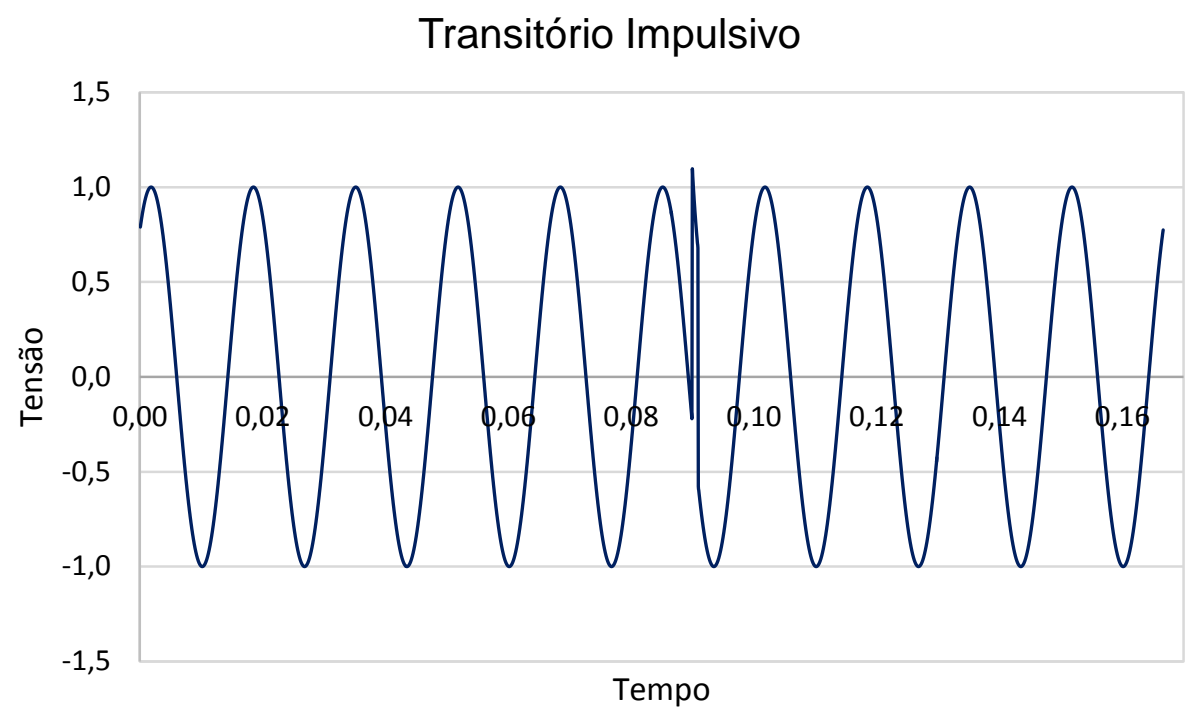

Figura 3.1-Exemplo de Transitório Impulsivo.

\subsubsection{Transitórios Oscilatórios}

Os transitórios oscilatórios se diferenciam do transitório impulsivo principalmente por incluir tanto valores de polaridade positiva como valores de polaridade negativa, tais transitórios podem ser descritos por sua amplitude, duração e conteúdo espectral (IEEE Std 1159-2009). A Figura 3.2 ilustra um evento de transitório oscilatório.

De acordo com o conteúdo espectral, eles são divididos em 3 classes: transitórios oscilatórios de baixa frequência (frequências abaixo de $5 \mathrm{kHz}$ ) causados por energização dos transformadores, transitórios oscilatórios de media frequências (frequência entre $5 \mathrm{kHz}$ e $500 \mathrm{kHz}$ ) originados principalmente por energização de bancos capacitores e transitórios oscilatórios de alta frequência (frequência acima de $500 \mathrm{kHz}$ ) que é uma resposta do sistema a um transitório impulsivo. 


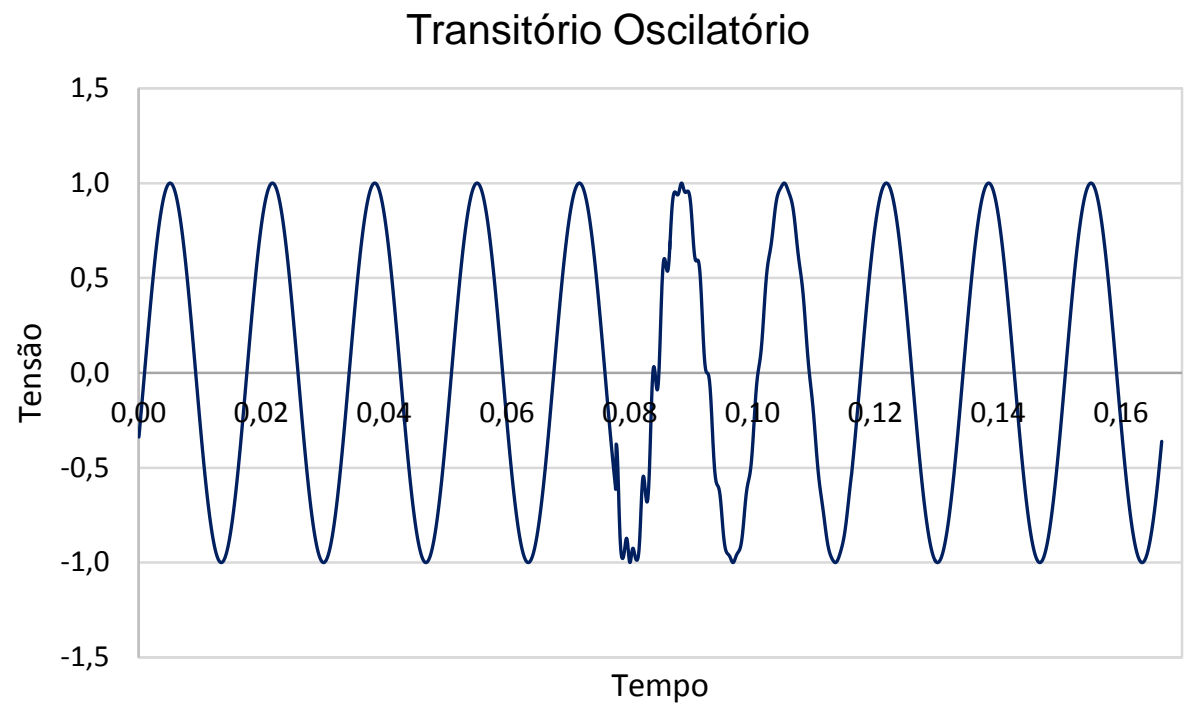

Figura 3.2-Exemplo de Transitório Oscilatório.

\subsubsection{Afundamento}

O afundamento corresponde a uma redução da variação de tensão, entre 0,9 e 0,1 p.u. do valor eficaz da tensão nominal (Figura 3.3). Estes distúrbios destacamse como sendo as mais significantes formas de alterações que se manifestam nas redes elétricas (MALANGE, 2010), sendo causados principalmente por curtoscircuitos ocorridos nas redes de distribuição de energia, energização de grandes cargas, partidas de grandes motores e magnetização de um transformador (IEEE Std 1159-2009).

As principais consequências do afundamento de tensão são: desligamento e danos de equipamentos, redução de vida útil ou deficiência nos equipamentos e falha de operação dos dispositivos (MALANGE, 2010). 


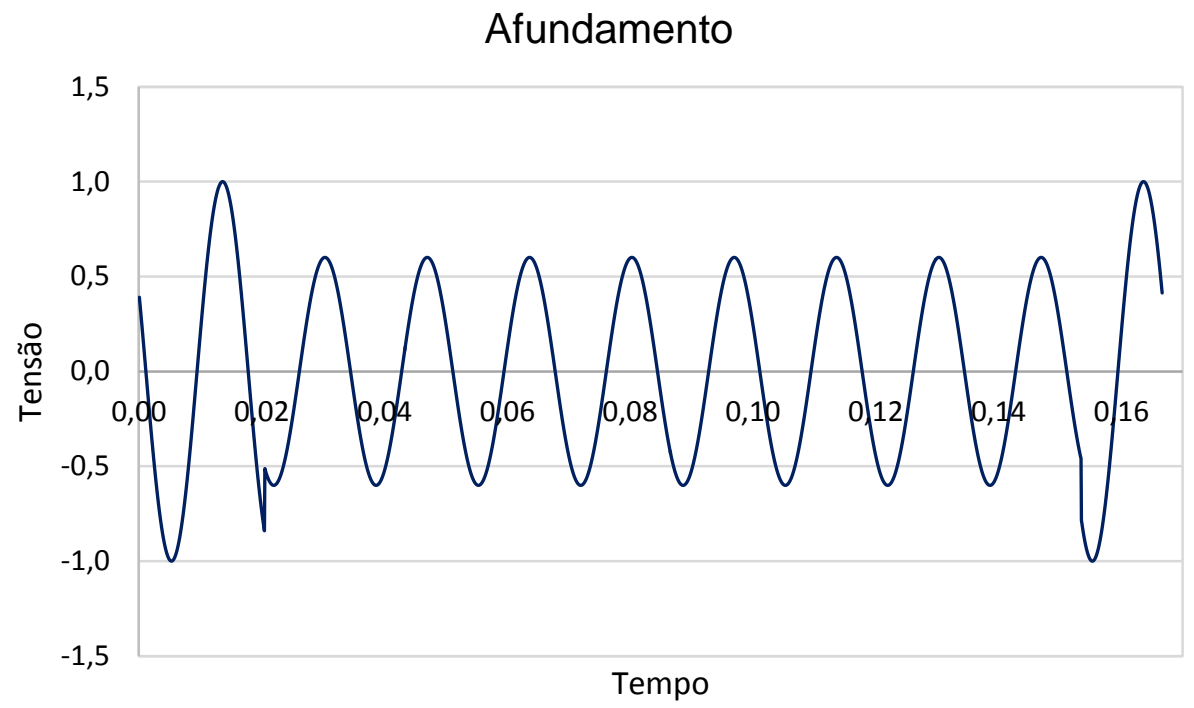

Figura 3.3-Exemplo de Afundamento de Tensão.

\subsubsection{Interrupção}

Eventos que possuem como características uma redução da variação de tensão abaixo de 0,1 p.u. são considerados como interrupção (Figura 3.4). As interrupções podem ser resultados de falhas no sistema de energia, descargas atmosféricas ou manutenção ne rede. As interrupções ocasionam queda do sistema, danificação de componentes e interrupção dos processos produtivos.

A duração de uma interrupção é determinada geralmente por dispositivos de proteção e evento que está causando a falha. Algumas interrupções são precedidas de afundamento de tensão. O afundamento ocorre no período de tempo entre o início de uma falta e a operação do dispositivo de proteção do sistema (IEEE Std 11592009). 


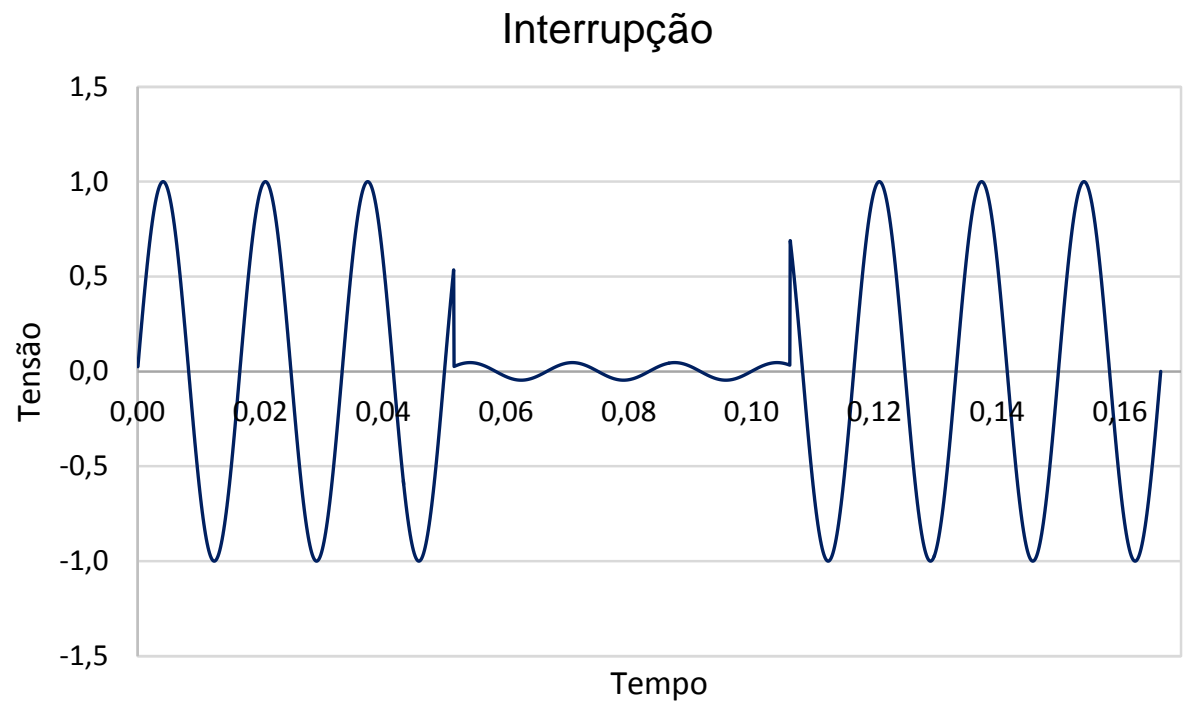

Figura 3.4-Exemplo de Interrupção.

\subsubsection{Elevação}

A elevação de tensão consiste em um aumento da tensão eficaz entre 1,1 e 1,8 p.u (Figura 3.5). Tal como ocorre com os afundamentos, as elevações são associadas à condição de falhas no sistema, mas elas são menos comum do que o afundamento de tensão.

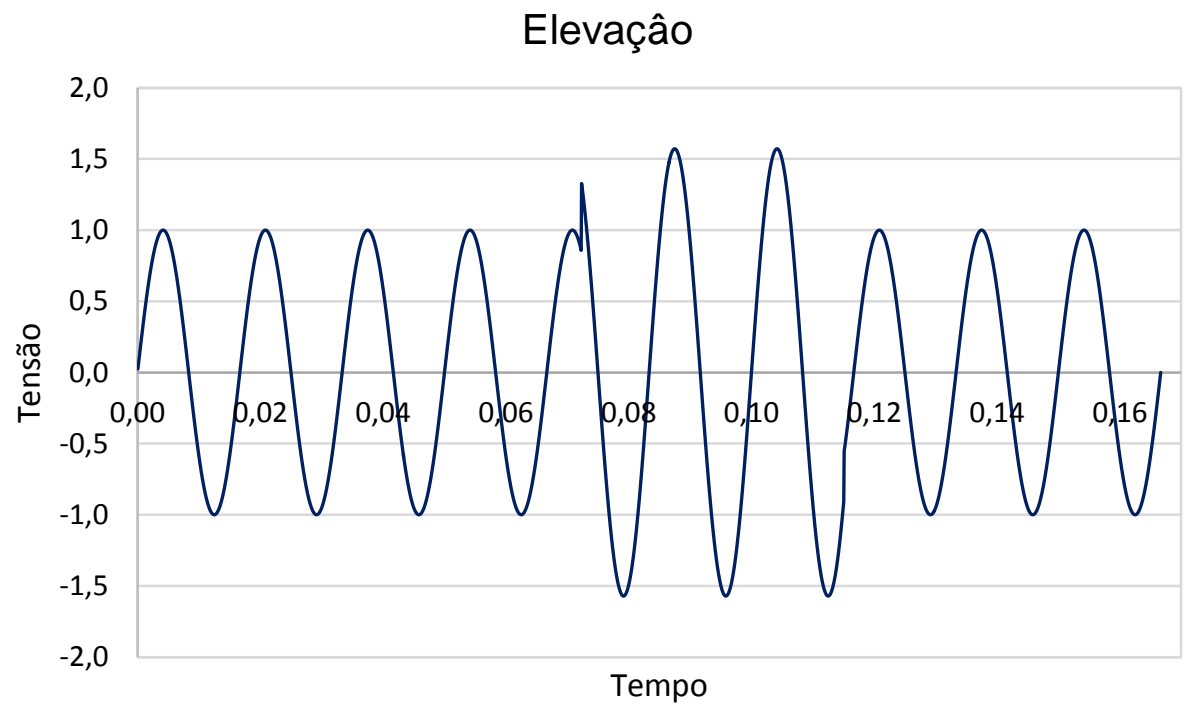

Figura 3.5-Exemplo de Elevação de Tensão. 
O principal problema causado por este distúrbio recai sobre os equipamentos eletrônicos, uma vez que podem danifica-los, resultando na má operação e/ou em sua inutilização. A gravidade de uma elevação se dá em função da localização do defeito, da impedância do sistema e do aterramento (IEEE Std 1159-2009).

\subsubsection{Distorções Harmônicas}

Distorções Harmônicas são tensões ou correntes senoidais com frequências múltiplas inteiras da frequência fundamental à qual o sistema é abastecido (Figura 3.6). Tais frequências são também denominadas de componentes harmônicas e são oriundas das características não lineares de cargas conectadas ao sistema de energia.

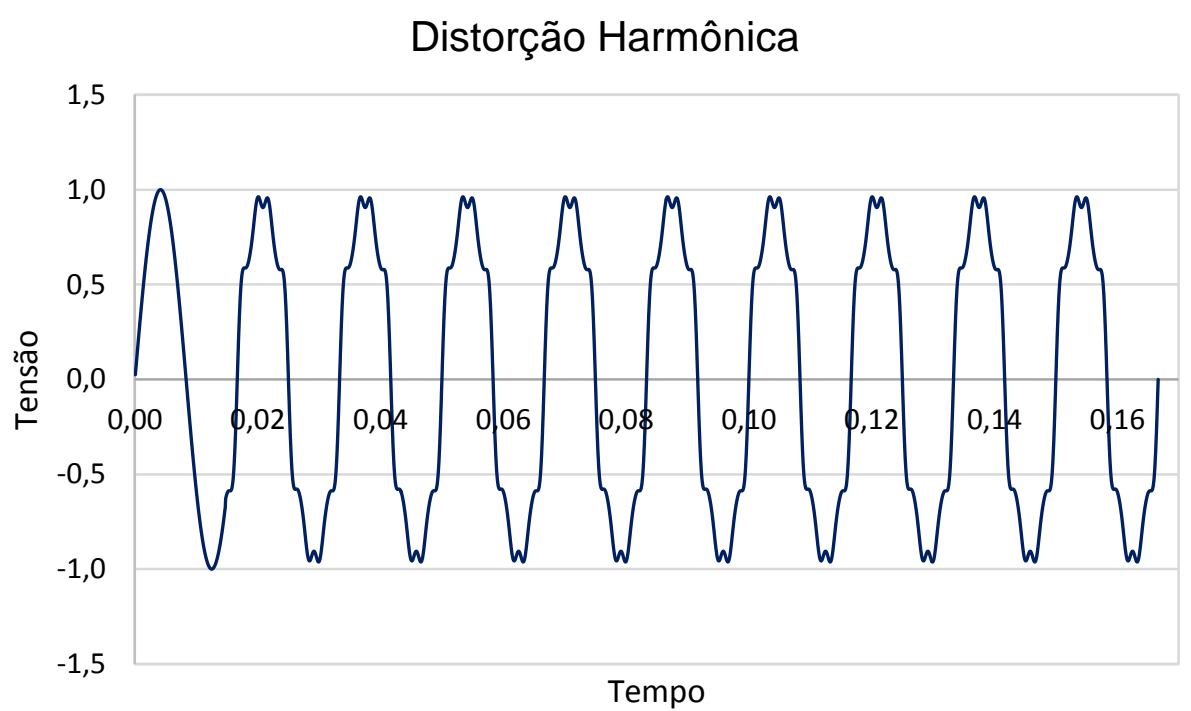

Figura 3.6-Exemplo de Distorção Harmônica.

As distorções harmônicas vêm se tornando uma preocupação crescente para o sistema de energia por causar grandes prejuízos aos usuários conectados à rede, aos equipamentos presentes nas indústrias e a banco de capacitores, por originar 
condições de ressonância que diminui a vida útil dos mesmos. Os efeitos das distorções harmônicas podem ser minimizados por utilização de filtros harmônicos, reatores de linha, melhoria na fiação e no aterramento.

\subsubsection{Notching}

Os notching são distúrbios periódicos de tensão causados pela operação de dispositivos elétricos quando a corrente é comutada de uma fase para outra (Figura 3.7). As componentes de frequência associadas a estes distúrbios são de alto valor e, desta forma, não podem ser medidas pelos equipamentos normalmente utilizados para análise harmônica (DUGAN et al., 2002).

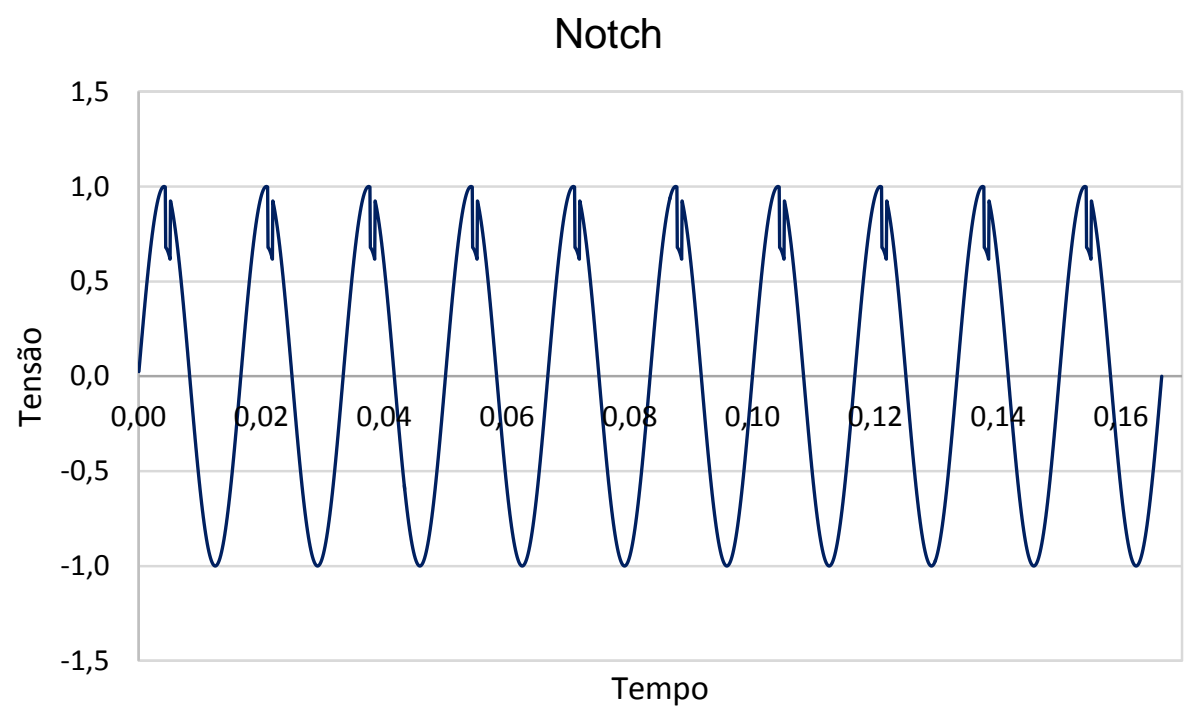

Figura 3.7- Exemplo de Notch.

\subsubsection{Spike}

Apesar do Spike não ser considerado nas normas estudadas (IEEE. STD. 1159-2009, ANEEL, 2010), este foi modelado por ter sido encontrado em alguns trabalhos revisados apresentados na Tabela 1.1 (BISWAL; DASH; PANIGRAHI, 2009; 
JAYASREE; DEVARAJ; SUKANESH, 2010; LEE; SHEN, 2011; MASOUM; JAMALI; GHAFFARZADEH, 2010; MEHER; PRADHAN, 2010; MISHRA et al., 2008; PANIGRAHI; DASH; REDDY, 2009; PANIGRAHI; PANDI, 2009; SALEM; MOHAMED; SAMAD, 2010). Os spikes são caracterizados por picos periódicos em regime permanente do sinal, como mostra a Figura 3.8.

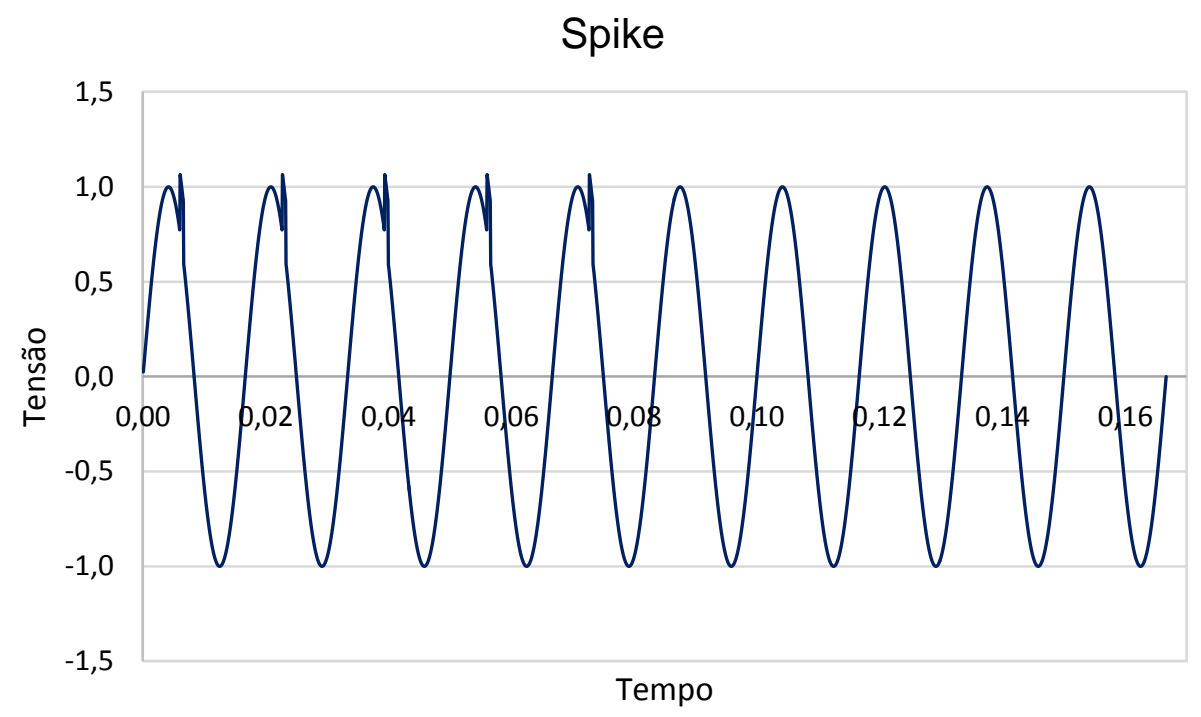

Figura 3.8- Exemplo de Spike.

\subsubsection{Flutuação de Tensão}

As flutuações de tensão correspondem à variação aleatória, repetitiva ou esporádica do valor eficaz da tensão (Figura 3.9). A magnitude de tal distúrbio se situa na faixa compreendida entre 0,9 p.u. e 1,1 p.u. As flutuações de tensão são causadas por cargas industriais e se manifestam de diferentes formas, como: flutuações aleatórias, flutuações repetitivas e flutuações esporádicas. As flutuações de tensão podem causar vários efeitos ao sistema elétrico, no entanto, o flicker é o efeito mais comum.

O flicker é resultado indesejável do impacto da flutuação de tensão sobre a intensidade da iluminação e pode ser percebido pelos seres humanos por mudanças 
repetitivas na intensidade de iluminação das lâmpadas residenciais. Os flickers são causados por elevadas cargas que solicitam altas correntes por breves, mas repetitivos, períodos de tempo (MALANGE, 2010).

Flutuação de Tensão

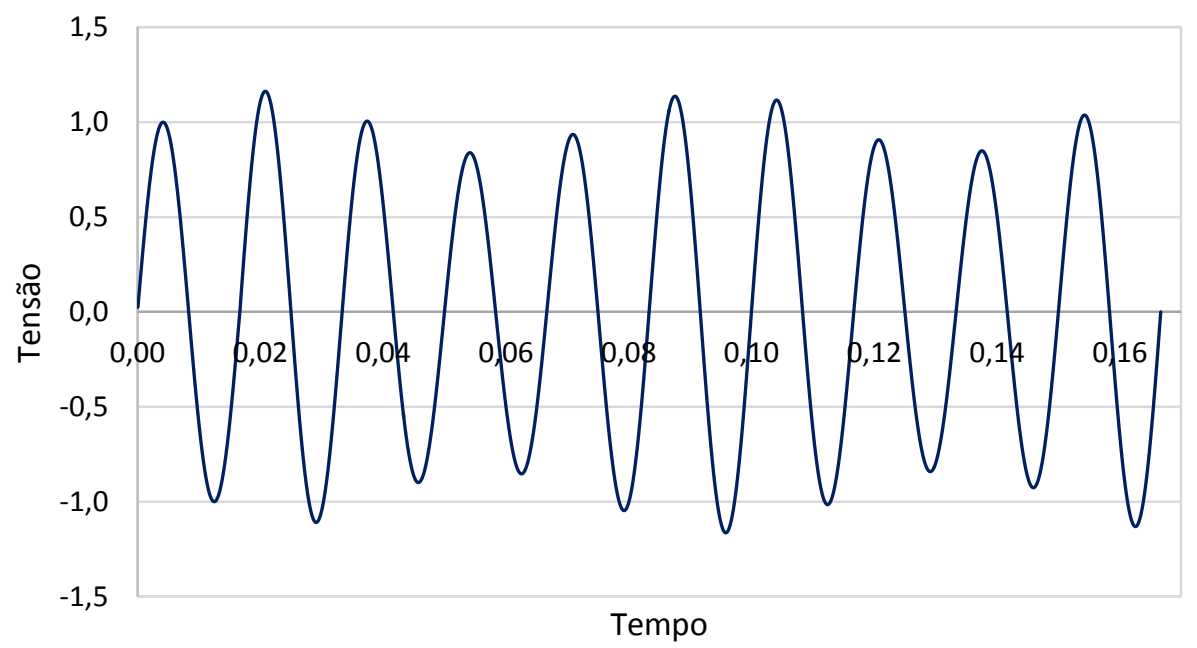

Figura 3.9- Exemplo de Flutuação de Tensão.

\subsubsection{Distúrbios Combinados}

Os distúrbios combinados são descritos pela aparição simultânea de um ou mais distúrbios simples no sinal de energia elétrica, caracterizados principalmente pelo afundamento com distorção harmônica, elevação com distorção harmônica, elevação com transitório oscilatório, distorção harmônica com interrupção. A Figura 3.10 apresenta uma distorção harmônica combinada com um afundamento de tensão.

As causas destes distúrbios estão ligadas a uma série de fenômenos que ocorrem de maneira simultâneas a rede, como, por exemplo: pode-se aparecer harmônica devido a cargas não lineares conectadas ao sistema juntamente com afundamento de tensão devido à energização de grande cargas. 


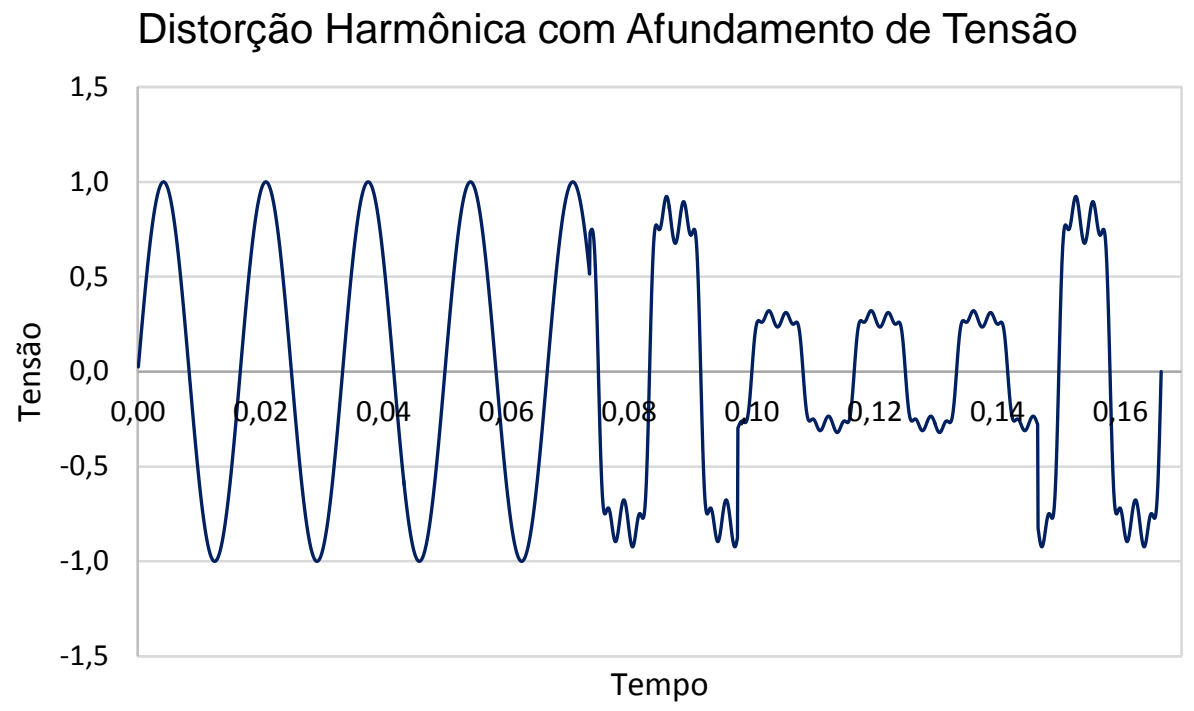

Figura 3.10- Exemplo de Distorção Harmônica com Afundamento de Tensão.

\subsection{Modelagem Matemática dos Distúrbios de Qualidade de Energia Elétrica}

As considerações iniciais, estudadas nas seções anteriores, são necessárias para entender como foi realizada a modelagem de cada distúrbio. Portanto, na sequência, é apresentada a modelagem matemática de cada distúrbio abordado.

A modelagem matemática tem como principal vantagem adquirir vários tipos de distúrbios diferentes e com características condizentes com os eventos de QEE reais. Portanto, é possível obter por meio de equações sintéticas uma ampla gama de sinais, podendo assim estimar a capacidade de generalização dos classificadores (MANIMALA; SELVI; AHILA, 2012; RODRÍGUEZ et al., 2012).

Uma representação matemática para modelar um sinal $v(t)$ pode ser descrita na Equação (3.1), ou seja:

$$
v(t)=s_{1}(t)+\left(s_{1}(t)+s_{2}(t)+s_{3}(t)+\ldots s_{m}(t)\right)
$$

onde $s(t)$ corresponde à função senoidal pura e as funções $s_{1} \ldots s_{m}(t)$ representam as componentes dos distúrbios do sinal e $m$ indica o índice da componente que será 
adicionada ao sinal. Estas parcelas podem estar presentes ou não no sinal elétrico, e contribuem para a formação do evento com maior ou menor intensidade.

Como já foi comentado anteriormente, os limites dos parâmetros impostos para cada distúrbio modelados foram definidos de forma a respeitar tanto a norma IEEE. STD. 1159-2009 como o PRODIST (ANEEL, 2012). Assim os 15 distúrbios são obtidos utilizando as equações paramétricas obtidas na literatura (HOOSHMAND; ENSHAEE, 2010; LEE; SHEN, 2011). De modo a melhor sintetizar tais equações, estas são apresentadas por meio da Tabela 3.3.

Tabela 3.3 - Equações sintéticas que representam os distúrbios

\begin{tabular}{|c|c|c|}
\hline Distúrbio & Equações & Parâmetros \\
\hline $\begin{array}{l}\text { Interrupção } \\
\text { Momentânea }\end{array}$ & $v(t)=\left[1-v_{n}\left(u\left(t-t_{1}\right)-u\left(t-t_{2}\right)\right)\right] \operatorname{sen}(2 \pi * f * t+\varphi)$ & $\begin{array}{l}0 \leq v_{n} \leq 0.1 \\
T \leq t_{2}-t_{1} \leq 9 T\end{array}$ \\
\hline Afundamento & $v(t)=\left[1-v_{n}\left(u\left(t-t_{1}\right)-u\left(t-t_{2}\right)\right)\right] \operatorname{sen}(2 \pi * f * t+\varphi)$ & $\begin{array}{l}0.1 \leq v_{n} \leq 0.9 \\
T \leq t_{2}-t_{1} \leq 9 T\end{array}$ \\
\hline Elevação & $v(t)=\left[1+v_{n}\left(u\left(t-t_{1}\right)-u\left(t-t_{2}\right)\right)\right] \operatorname{sen}(2 \pi * f * t+\varphi)$ & $\begin{array}{l}0.1 \leq v_{n} \leq 0.8 \\
T \leq t_{2}-t_{1} \leq 9 T\end{array}$ \\
\hline $\begin{array}{l}\text { Flutuação de } \\
\text { Tensão }\end{array}$ & $v(t)=\left[1+v_{n} \sin \left(2 \pi * f_{n} * t\right)\right] \operatorname{sen}(2 \pi * f * t+\varphi)$ & $\begin{array}{l}0.05 \leq v_{n} \leq 0.1 \\
8 \leq f_{n} \leq 25\end{array}$ \\
\hline $\begin{array}{l}\text { Transitório } \\
\text { Oscilatório }\end{array}$ & $\begin{array}{l}v(t)=\operatorname{sen}(2 \pi f t+\varphi)+ \\
\alpha * e^{\left(-\left(t-t_{1}\right) / \tau\right)} *\left(u\left(t-t_{1}\right)-u\left(t-t_{2}\right)\right) * \operatorname{sen}\left(2 \pi f_{n} t\right)\end{array}$ & $\begin{array}{l}0.1 \leq \alpha \leq 0.8 \\
0.5 T \leq t_{2}-t_{1} \leq 3 T \\
300 H z \leq f_{n} \leq 900 H z \\
8 m s \leq \tau \leq 40 \mathrm{~ms}\end{array}$ \\
\hline Notch & $\begin{array}{l}v(t)=\operatorname{sen}(2 \pi f t+\varphi)-\operatorname{sgn}(f t)+ \\
\sum_{i=0}^{k} A N *\left\{u\left[t-\left(t_{i}+0.02 i\right)\right]-u\left[t-\left(t_{2}+0.02 i\right)\right]\right\}\end{array}$ & $\begin{array}{l}0.1 \leq A N \leq 0.4 \\
2 \leq k \leq 8 \\
\text { sgn-funçaoSinal }\end{array}$ \\
\hline Spike & $\begin{array}{l}v(t)=\operatorname{sen}(2 \pi f t+\varphi)+\operatorname{sgn}(f t)+ \\
\sum_{i=0}^{k} A N *\left\{u\left[t-\left(t_{i}+0.02 i\right)\right]-u\left[t-\left(t_{2}+0.02 i\right)\right]\right\}\end{array}$ & $\begin{array}{l}0.1 \leq A N \leq 0.4 \\
2 \leq k \leq 8 \\
\text { sgn- funçaoSina }\end{array}$ \\
\hline $\begin{array}{l}\text { Impulso } \\
\text { Transitório }\end{array}$ & $\begin{array}{l}v(t)=1.1 * v_{p}\left(e^{-7.5 * 10^{2}\left(t-t_{1}\right)}-e^{-3.44 * 10^{2}\left(t-t_{2}\right)}\right) * \\
\left(u\left(t-t_{1}\right)-u\left(t-t_{2}\right)\right)\end{array}$ & $\begin{array}{l}0.2 \leq v_{p} \leq 1 \\
T \leq t_{1} \leq 7 T \\
t_{2}=t_{1}+1 m s\end{array}$ \\
\hline
\end{tabular}




\begin{tabular}{|c|c|c|}
\hline Distúrbio & Equações & Parâmetros \\
\hline $\begin{array}{l}\text { Elevação } \\
\text { Com } \\
\text { Distorção } \\
\text { Harmônica }\end{array}$ & $\begin{array}{l}v(t)=\left[1+\alpha\left(u\left(t-t_{1}\right)-u\left(t-t_{2}\right)\right)\right] *\{\operatorname{sen}(2 \pi f t+\varphi)+ \\
\propto_{2} * \operatorname{sen}\left(2 * 2 \pi f t+\varphi_{2}\right)+\propto_{3} * \operatorname{sen}\left(2 * 2 \pi f t+\varphi_{3}\right) \\
\left.+\ldots+\propto_{i} * \operatorname{sen}\left(i * 2 \pi f t+\varphi_{i}\right)\right\}\end{array}$ & $\begin{array}{l}0.1 \leq v_{n} \leq 0.8 \\
T \leq t_{2}-t_{1} \leq 9 T \\
0.015 \leq \alpha_{\text {par }} \leq 0.03 \\
0.035 \leq \alpha_{\text {impar }} \leq 0.06 \\
-\pi \leq \varphi_{i} \leq \pi\end{array}$ \\
\hline $\begin{array}{c}\text { Elevação com } \\
\text { Transitório } \\
\text { Oscilatório }\end{array}$ & $\begin{array}{l}v(t)=\operatorname{sen}(2 \pi f t+\varphi) \\
+\operatorname{sen}\left(2 \pi f_{n} t\right) * \alpha * e^{\left(-\left(t-t_{1}\right) / \tau\right)} *\left(u\left(t-t^{\prime}{ }_{1}\right)-u\left(t-t^{\prime}{ }_{2}\right)\right) \\
*\left[1+\alpha\left(u\left(t-t_{1}\right)-u\left(t-t_{2}\right)\right)\right]\end{array}$ & $\begin{array}{l}0.1 \leq v_{n} \leq 0.8 \\
T \leq t_{2}-t_{1} \leq 9 T \\
0.1 \leq \alpha \leq 0.8 \\
0.5 T \leq t_{2}-t^{\prime}{ }_{1} \leq 3 T \\
t_{1}<t_{2}{ }_{2}<t_{2} \\
t_{2}<t^{\prime}{ }_{1}<t_{1} \\
300 H z \leq f_{n} \leq 900 H \\
8 \mathrm{~ms} \leq \tau \leq 40 \mathrm{~ms}\end{array}$ \\
\hline $\begin{array}{l}\text { Flutuação de } \\
\text { Tensão com } \\
\text { Distorção } \\
\text { Harmônica }\end{array}$ & $\begin{array}{l}v(t)=\left[1+v_{n} \sin \left(2 \pi * f_{n} * t\right)\right] *\{\operatorname{sen}(2 \pi f t+\varphi)+ \\
\propto_{2} * \operatorname{sen}\left(2 * 2 \pi f t+\varphi_{2}\right)+\propto_{3} * \operatorname{sen}\left(2 * 2 \pi f t+\varphi_{3}\right) \\
\left.+\ldots+\propto_{i} * \operatorname{sen}\left(i * 2 \pi f t+\varphi_{i}\right)\right\}\end{array}$ & $\begin{array}{l}0.05 \leq v_{n} \leq 0.1 \\
8 \leq f_{n} \leq 25 \\
0.015 \leq \alpha_{\text {par }} \leq 0.03 \\
0.035 \leq \alpha_{\text {impar }} \leq 0.06 \\
-\pi \leq \varphi_{i} \leq \pi\end{array}$ \\
\hline $\begin{array}{l}\text { Flutuação de } \\
\text { Tensão com } \\
\text { Distorção } \\
\text { Harmônica }\end{array}$ & $\begin{array}{l}v(t)=\left[1+v_{n} \sin \left(2 \pi * f_{n} * t\right)\right] *\{\operatorname{sen}(2 \pi f t+\varphi)+ \\
\propto_{2} * \operatorname{sen}\left(2 * 2 \pi f t+\varphi_{2}\right)+\propto_{3} * \operatorname{sen}\left(2 * 2 \pi f t+\varphi_{3}\right) \\
\left.+\ldots+\propto_{i} * \operatorname{sen}\left(i * 2 \pi f t+\varphi_{i}\right)\right\}\end{array}$ & $\begin{array}{l}0.05 \leq v_{n} \leq 0.1 \\
8 \leq f_{n} \leq 25 \\
0.015 \leq \alpha_{\text {par }} \leq 0.03 \\
0.035 \leq \alpha_{\text {impar }} \leq 0.06 \\
-\pi \leq \varphi_{i} \leq \pi\end{array}$ \\
\hline $\begin{array}{l}\text { Distorção } \\
\text { Harmônica } \\
\quad \text { com } \\
\text { Interrupção }\end{array}$ & $\begin{array}{l}v(t)=\left[1-\alpha\left(u\left(t-t_{1}\right)-u\left(t-t_{2}\right)\right)\right] *\{\operatorname{sen}(2 \pi f t+\varphi)+ \\
\propto_{2} * \operatorname{sen}\left(2 * 2 \pi f t+\varphi_{2}\right)+\propto_{3} * \operatorname{sen}\left(2 * 2 \pi f t+\varphi_{3}\right) \\
\left.+\ldots+\propto_{i} * \operatorname{sen}\left(i * 2 \pi f t+\varphi_{i}\right)\right\}\end{array}$ & $\begin{array}{l}0.9 \leq v_{n} \leq 0.1 \\
T \leq t_{2}-t_{1} \leq 9 T \\
0.015 \leq \alpha_{\text {par }} \leq 0.03 \\
0.035 \leq \alpha_{\text {impar }} \leq 0.06 \\
-\pi \leq \varphi_{i} \leq \pi\end{array}$ \\
\hline $\begin{array}{l}\text { Distorção } \\
\text { Harmônica }\end{array}$ & $\begin{array}{l}v(t)=\operatorname{sen}(2 \pi f t+\varphi)+\propto_{2} * \operatorname{sen}\left(2 * 2 \pi f t+\varphi_{2}\right) \\
+\propto_{3} * \operatorname{sen}\left(2 * 2 \pi f t+\varphi_{3}\right)+\ldots+\propto_{i} * \operatorname{sen}\left(i * 2 \pi f t+\varphi_{i}\right)\end{array}$ & $\begin{array}{l}0.015 \leq \alpha_{\text {par }} \leq 0.03 \\
0.035 \leq \alpha_{\text {impar }} \leq 0.06 \\
-\pi \leq \varphi_{i} \leq \pi\end{array}$ \\
\hline $\begin{array}{l}\text { Afundamento } \\
\text { Com } \\
\text { Distorção } \\
\text { Harmônica }\end{array}$ & $\begin{array}{l}v(t)=\left[1-\alpha\left(u\left(t-t_{1}\right)-u\left(t-t_{2}\right)\right)\right] *\{\operatorname{sen}(2 \pi f t+\varphi)+ \\
\propto_{2} * \operatorname{sen}\left(2 * 2 \pi f t+\varphi_{2}\right)+\propto_{3} * \operatorname{sen}\left(2 * 2 \pi f t+\varphi_{3}\right) \\
\left.+\ldots+\propto_{i} * \operatorname{sen}\left(i * 2 \pi f t+\varphi_{i}\right)\right\}\end{array}$ & $\begin{array}{l}0.1 \leq v_{n} \leq 0.9 \\
T \leq t_{2}-t_{1} \leq 9 T \\
0.015 \leq \alpha_{\text {par }} \leq 0.03 \\
0.035 \leq \alpha_{\text {impar }} \leq 0.06 \\
-\pi \leq \varphi_{i} \leq \pi\end{array}$ \\
\hline $\begin{array}{l}\text { Afundamento } \\
\text { com } \\
\text { Transitório } \\
\text { Oscilatório }\end{array}$ & $\begin{array}{l}v(t)=\operatorname{sen}(2 \pi f t+\varphi) \\
+\operatorname{sen}\left(2 \pi f_{n} t\right) * \alpha * e^{\left(-\left(t-t_{1}\right) / \tau\right)} *\left(u\left(t-t_{1}^{\prime}\right)-u\left(t-t_{2}^{\prime}\right)\right) \\
*\left[1-\alpha\left(u\left(t-t_{1}\right)-u\left(t-t_{2}\right)\right)\right]\end{array}$ & \begin{tabular}{|l|}
$0.1 \leq v_{n} \leq 0.9$ \\
$T \leq t_{2}-t_{1} \leq 9 T$ \\
$0.1 \leq \alpha \leq 0.8$ \\
$0.5 T \leq t_{2}-t_{1} \leq 3 T$ \\
$t_{1}<t_{2}{ }_{2}<t_{2}$ \\
$t_{2}<t_{1}{ }_{1}<t_{1}$ \\
$300 H z \leq f_{n} \leq 900 H Z$ \\
$8 m s \leq \tau \leq 40 m s$
\end{tabular} \\
\hline
\end{tabular}


De acordo com as equações apresentadas na Tabela 3.3, para modelagem de um evento de variação de tensão de curta duração (Afundamento, Elevação e Interrupção), é necessário adicionar ao sinal senoidal puro, Figura 3.11 (a), uma componente que altere a amplitude da onda no intervalo de tempo que o sinal é caracterizado. Para isto, utiliza-se uma função degrau $(u)$ que retorna o valor 1 durante período $(T f-T i)$ que o distúrbio ocorre, ou valor 0, caso contrário, Figura 3.11 (b). A saída da função degrau será multiplicada pelo parâmetro $v_{n}$ que corresponde à amplitude do distúrbio a ser inserido, Figura 3.11 (c).

Já a flutuação de tensão é modelada pela adição de uma onda senoidal com frequência $f_{n}$ responsável por inserir as variações aleatórias, repetitiva ou esporádica do valor eficaz da tensão que caracterizam o distúrbio e o parâmetro e $V_{n}$ que fornece a amplitude do fenômeno.

As distorções harmônicas são formadas pela adição simultânea de várias funções seno que representam cada componente harmônica a ser inserida no sinal, no instante que ocorre o evento. Cada componente harmônica (I) possuem três parâmetros que definem a amplitude $\left(\alpha_{i}\right)$, ângulo de fase $\left(\varphi_{i}\right)$ e frequência $\left(f_{i}\right)$. As amplitudes e ângulos de fase das harmônicas de cada sinal gerado são definidos aleatoriamente, já a frequência é obtida multiplicando a ordem da harmônica pela frequência fundamental.

O distúrbio notch e spike são modelados com base em um somatório que representam a periodicidade do evento de comutação entre as fases. A equação do notch e spike se diferem somente pela primeira utilizar uma operação de subtração que garante a variação de tensão em direção ao eixo $x$, enquanto a equação da 
operação do segundo utiliza uma adição para garantir que a variação seja em direção oposta.

(a)

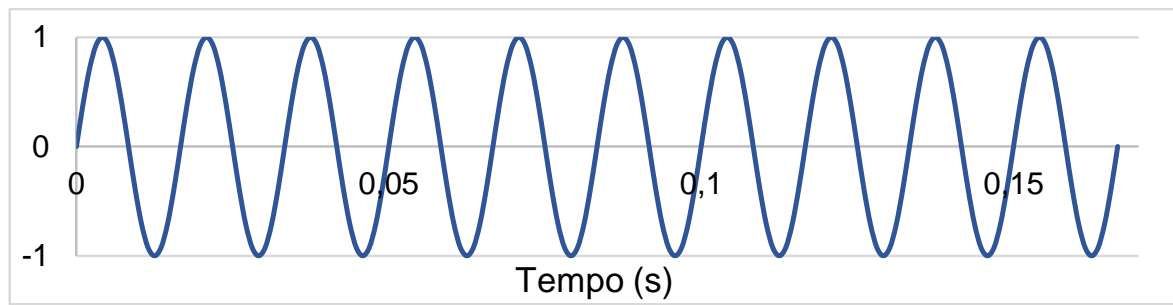

(b)

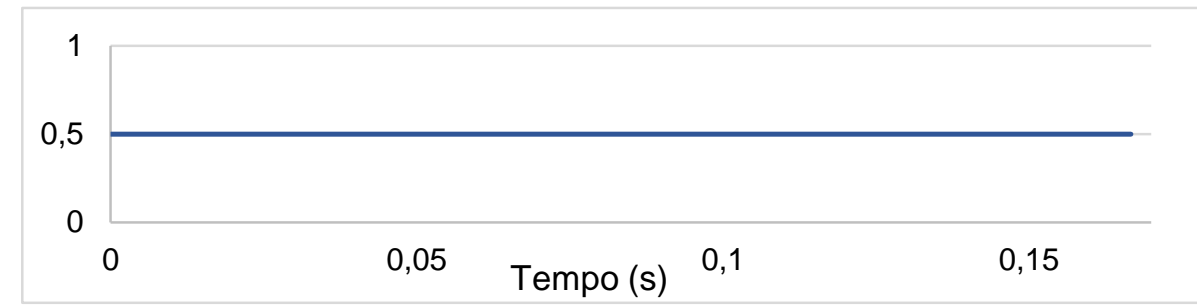

(c)

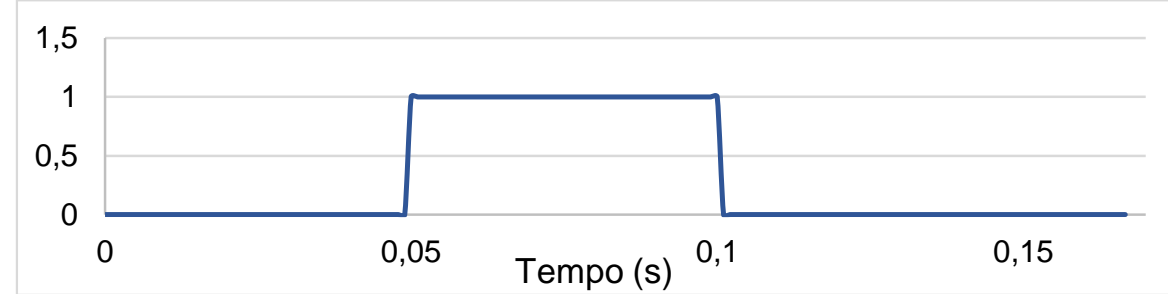

(d)

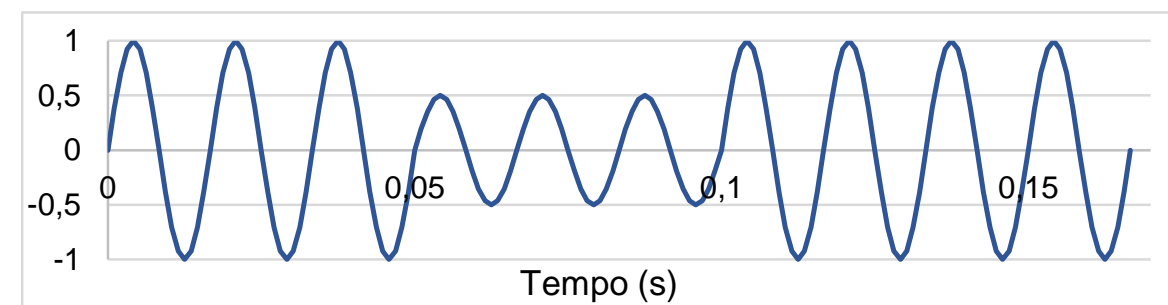

Figura 3.11- Processo para formulação de um sinal com distúrbio Afundamento (a - Sinal senoidal puro, $b$ - função degrau u(t), $c$ - amplitude do distúrbio $d$ - distúrbio gerado).

O transitório oscilatório é modelado por uma senóide de frequência $f_{n}$, que corresponde à frequência do distúrbio, um parâmetro $\propto$ que define a amplitude do distúrbio e uma função degrau que define a duração do transitório oscilatório. O parâmetro $\tau$ modela a atenuação do distúrbio, sendo que este parâmetro é importante 
porque em um evento real a atenuação ocorre de maneira diferente de acordo com tipo de sistema. Assim, quando $\tau$ assume valor máximo, o fenômeno transitório é atenuado de modo menos brusco durante todo o intervalo de tempo, enquanto para $\tau$ assumindo valor mínimo o distúrbio é atenuado num intervalo mais curto. Caso não exista este parâmetro, o distúrbio não será atenuado, permanecendo-se então constante.

Assim como a equação que caracteriza o transitório oscilatório, a modelagem do transitório impulsivo é caracterizada pela subtração de duas funções exponenciais que caracteriza a unipolaridade deste distúrbio e um parâmetro $\alpha$ que representa sua amplitude.

Por fim, os distúrbios combinados são gerados pela soma das funções que representam os distúrbios simples caracterizados nos distúrbios combinados.

\subsection{Processamento e Montagem do Banco de Dados de QEE}

Tendo em mãos as equações matemáticas que modelam cada distúrbio de QEE, tornou-se possível montar 5 bancos de dados, os quais se diferenciam somente pela taxa de amostragem das janelas de dados que os compõem. Portanto, cada um dos 5 bancos possui respectivamente janelas de dados adquiridas sobre a taxa de 16 amostras/ciclo, 32 amostras/ciclo, 64 amostras/ciclo, 128 amostras/ciclo, 256 amostras/ciclo.

Estes bancos foram utilizados com objetivo de testar o poder de classificação do método proposto, mesmo com dados obtidos sobre uma baixa taxa de amostragem, já que quanto menor a taxa, menor será a caracterização do distúrbio na janela. Pela Figura 3.12 pode-se observar a caracterização de um transitório oscilatório que se inicia a $0,077 \mathrm{~s}$ e termina a $0,11 \mathrm{~s}$, possuindo uma amplitude de 0,3 
com uma frequência de 593 hZ, sendo adquirido sobre 5 diferentes taxas de amostragem.
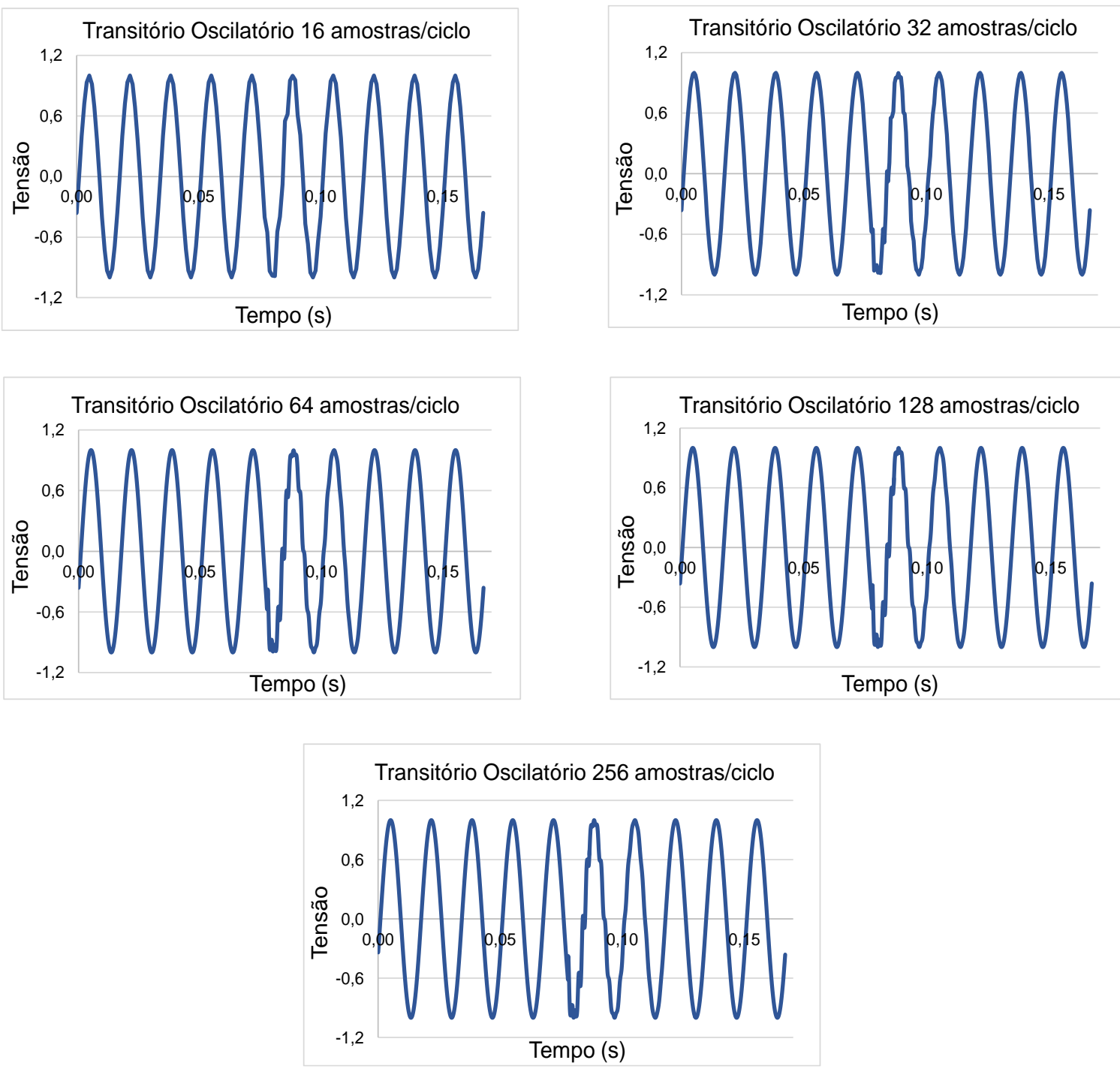

Figura 3.12 - Caracterização do disturbio transitório oscilatório sobre diferentes taxas de amostragem.

A menor taxa de amostragem foi fixada como 16 amostras/ciclo devido ao PRODIST regulamentar que os equipamentos de medição devem atender no mínimo aos seguintes requisitos:

- Taxa de amostragem: 16 amostras/ciclo;

- Conversor A/D (analógico/digital) de sinal e tensão: 12 bits;

- Precisão: até $1 \%$ da leitura. 
Para obtenção das janelas que compõem os bancos de dados, inicialmente, 100 estudos de casos de cada distúrbio são gerados aleatoriamente, possuindo tamanho de 10 ciclos, uma frequência de $60 \mathrm{~Hz}$ e sobre a taxa amostragem mais alta (15360 Hz ou 256 amostras/ciclo), onde os parâmetros referente a cada distúrbio são alterados de forma aleatória (dentro de sua gama específica). A frequência é igual a $60 \mathrm{~Hz}$, pois esta é estabelecida pelo PRODIST (ANEEL, 2012) e o tamanho do sinal é 10 ciclos. Este tamanho foi estabelecido por ser usualmente encontrado na literatura.

Novamente com o objetivo de testar a metodologia proposta sobre diferentes tipos de janelas de dados, para cada um dos sinais gerados é inserido um ruído brando gaussiano com relação sinal/ruído de $20 \mathrm{~dB}, 25 \mathrm{~dB}, 35 \mathrm{~dB}, 40 \mathrm{~dB} 45 \mathrm{~dB}$. A Figura 3.13 mostra como é inserido um ruído com relação sinal ruído de 20 dB, em um sinal seno. Este ruído é inserido no sinal somando a ele, uma janela de dados aleatória, com tamanho igual ao sinal e desvio padrão igual a 1 (Figura 3.13 b), multiplicada por uma constante (Figura 3.13 c) obtida pela Equação (3.2).

$$
\alpha=\frac{1}{\sqrt{2 * 10^{\left(\frac{S N R}{10}\right)}}}
$$

onde SNR corresponde a relação sinal ruído.

Após a inserção do ruído em cada um dos 100 distúrbios é realizado um janelamento de forma a obter um vetor que será inserido no banco. Tal janelamento ocorre deslocando-se uma janela de dados com tamanho de um ciclo do sinal e com passo de 1 ponto até atingir toda dimensão do mesmo (Figura 3.14). Como mostra a Figura 3.14, cada janela adquirida é rotulada de acordo com a presença ou não do distúrbio na janela. Assim, as janelas que não apresentam distúrbios recebem são 
classificadas como normais, já as janelas que apresentam pelo menos um ponto do distúrbio, são classificadas pelo distúrbio caracterizado.

(a)

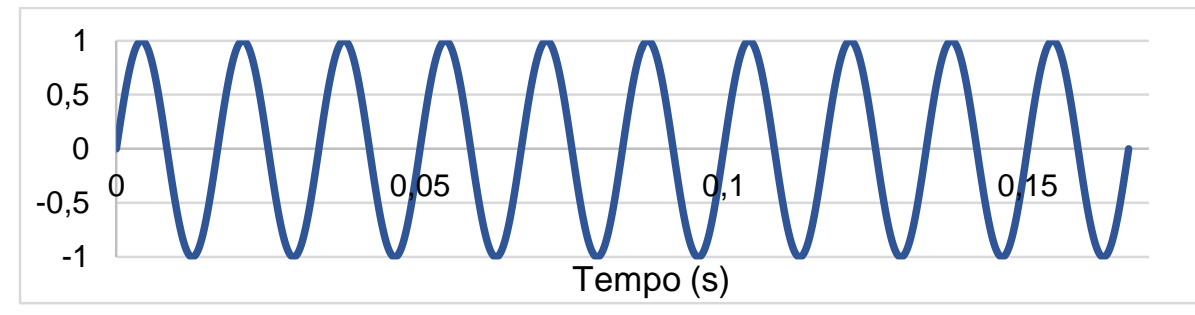

(b)

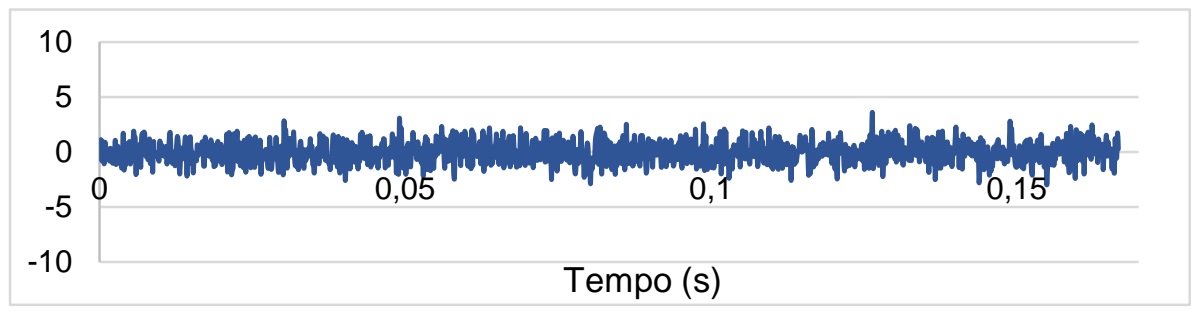

(c)

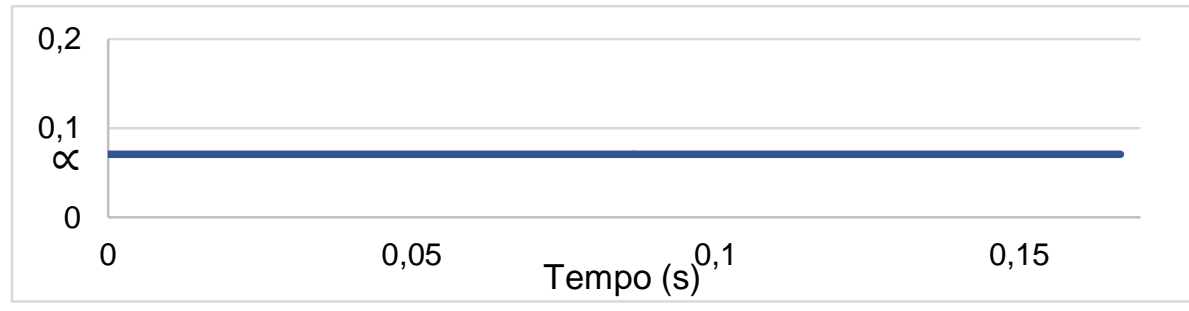

(d)

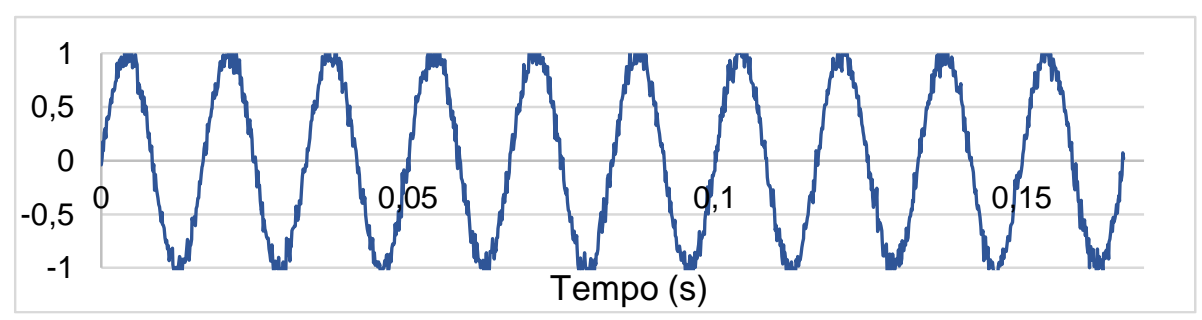

Figura 3.13 - Processo para formulação de um sinal com o ruído (a - Sinal senoidal puro, $b$ - Janela de dados com distribuição normal, $c$ - constante $\alpha d$ - sinal gerado com ruído de 20DB)

É importante comentar que o janelamento é realizado 5 vezes para cada sinal, no qual o primeiro é responsável por adquirir janelas de dados de 16 amostras/ciclo que serão inseridas no $1^{\circ}$ banco. Já o segundo é responsável por adquirir sobre o mesmo sinal um conjunto de janelas que possuem 32 amostras/ciclo, as quais serão adicionadas no $2^{\circ}$ banco. Portanto, este processo ocorre sucessivamente até que as 
janelas de dados de cada distúrbio seja adicionada em cada um dos 5 bancos de dados, de acordo com a taxa de amostragem.

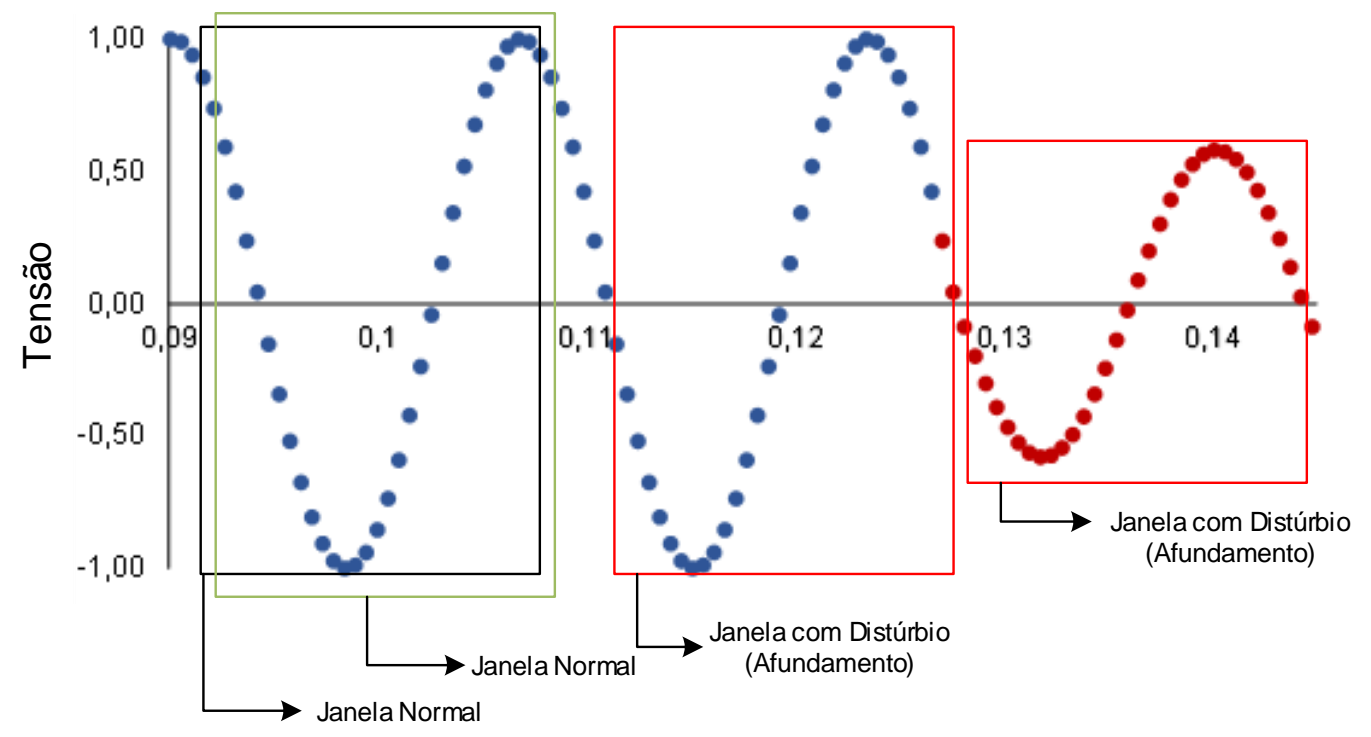

Figura 3.14 - Processo de movimentação da janela

\subsection{Considerações Finais}

Este capítulo apresentou os tipos de distúrbios de qualidade de energia elétrica, assim como os detalhes da modelagem matemática e criação do banco de dados. É importante comentar que como resultado final de todo o processo, foram construídas 5 tabelas de dados diferentes, cada uma representado, respectivamente, as taxas de amostragem de 16 amostras/ciclo, 32 amostras/ciclo, 64 amostras/ciclo, 128 amostras/ciclo, 256 amostras/ciclo. Estas tabelas são compostas por janelas, que apresentam ou não ruído, e caracterizam cada um dos 15 distúrbios implementados, mais a janela que representa o sinal normal, todas com faixas de ruído de $45 \mathrm{~dB}, 40$ $\mathrm{dB}, 35 \mathrm{~dB}, 30 \mathrm{~dB}, 25 \mathrm{~dB}, 20 \mathrm{~dB}$.

A partir destes bancos de dados será possível então testar e validar o sistema de detecção e classificação, utilizando uma grande quantidade de distúrbios, os quais 
possuem características diferentes e condizentes com os encontrados em um sistema real. 


\section{Extração de Características}

Este capítulo tem como objetivo apresentar em detalhes os cálculos empregados para extração de característica das janelas que compõem o banco de dados. Assim, na sequência, são explanados os objetivos e vantagens do método escolhido para extração de características (Seção 4.1). Depois de fornecidos os detalhes, os cálculos matemáticos são apresentados (Seção 4.2 e Seção 4.3).

\subsection{Aspectos da Extração de Características}

Em problemas que visam a classificação de padrões, a redução da dimensionalidade dos dados faz-se extremamente importante, principalmente, quando o vetor de entrada do classificador é relativamente grande. Esta redução deve ser feita de maneira a eliminar as características redundantes do vetor original, resultando em um novo vetor com características similares ao dado original, mas com tamanho reduzido. Assim, o processo que transforma os dados de entrada em um novo padrão adequado para posterior classificação é chamado extração de características (SALEM; MOHAMED; SAMAD, 2010).

A extração de características é, portanto, a chave para o reconhecimento de padrões, de modo que o melhor classificador apresentará uma baixa taxa de acertos se os recursos não forem bem escolhidos. Assim, um extrator de característica deve reduzir o vetor padrão (ou seja, a forma de onda original) para uma menor dimensão, preservando todas as informações úteis a partir do vetor original (UYAR; YILDIRIM; GENCOGLU, 2009). Adicionalmente, a extração de recursos minimiza esforço computacional utilizado no classificador. 
Desta forma, esta etapa tem o objetivo de extrair as características distintivas das janelas adquiridas e, por consequência, reduzir a dimensionalidade do vetor de entrada do classificador

Neste contexto, analisando-se o objetivo da metodologia proposta de implementar um sistema compacto, a fase da extração de características neste trabalho se difere das observadas na literatura, por obter algumas características sem a necessidade de utilizar ferramentas de transformação de domínio, sendo estas obtidas a partir de cálculos simples no domínio do tempo e, as demais características são adquiridas utilizando a Transformada Rápida de Fourier (TRF), a qual foi escolhida por se tratar de uma ferramenta compacto e rápida quando comparada com outros métodos encontrados na prática como Transformada Wavelet e TransformadaS (GRANADOS-LIEBERMAN et al., 2011)

\subsection{Características Extraídas no Domínio do Tempo}

O desvio padrão, entropia, entropia de Shannon, entropia de Renyi, fator de crista, Kurtosis, desvio padrão, desvio médio, média harmônica, skewnes, Root Mean Square (RMS), fator de forma, a diferença entre o maior e o menor valor da janela (Dif) e valor de pico são características obtidas no domínio do tempo de cada janela $d_{i j}$, onde i representa o índice da janela e j representa a posição de cada ponto obtido, variando de 1 até $N$, o qual corresponde à quantidade de amostras na janela. $\mathrm{Na}$ sequência, são mostrados em detalhes como todas as características citadas são calculadas.

O desvio padrão, desvio médio, média harmônica, skweness, kurtosis são chamadas de medidas estatísticas ou medidas descritivas. Tais medidas resumem as informações das amostras em uma visão global dos dados (MADRI, 2011) 
A média harmônica de uma janela $i$ é calculada pela quantidade de pontos amostrados $N$ dividido pelo somatório do inverso de cada ponto. É então definida como sendo o número de membros dividido pela soma do inverso dos membros $d_{i j}$, como mostra a Equação (4.1):

$$
\text { médiaHarmonica }=\frac{N}{\sum_{j=1}^{N} \frac{1}{d_{i j}}}
$$

O desvio médio calcula a dispersão dos pontos $d_{i j}$ em torno da média da janela $i$, obtido pela Equação (4.2):

$$
\text { desvio_médio }_{i}=\frac{\sum_{j=1}^{N} \mid d_{i j}-\text { média }_{i} \mid}{N}
$$

Já o desvio padrão de uma janela $i$, é obtido de acordo com a Equação (4.3):

$$
\sigma_{i}=\sqrt{\sigma_{i}^{2}}
$$

onde $\sigma_{i}^{2}$ corresponde variância da janela $i$. A variância é obtida pela diferença de cada ponto $d_{i j}$ entre a média, elevada ao quadrado (MADRI, 2011), calculada de acordo com a Equação (4.4).

$$
\sigma_{i}^{2}=\frac{\sum_{j=1}^{N}\left(d_{i j}-\text { média }_{i}\right)^{2}}{N-1}
$$

O tamanho da amostra é subtraído de 1 devido ao fator de correção de Bessel, que visa uma estimativa mais precisa.

A skewness é uma medida que verifica o comportamento dos dados da amostra. Se a assimetria é negativa, os dados estão espalhados mais para a esquerda; se a assimetria é positiva, os dados estão espalhados mais para direita; quando a assimetria é zero, a distribuição é considerada normal. Para o cálculo da 
assimetria de cada janela $i$ foi utilizada a função skewness presente no software Matlab e definida pela Equação (4.5).

$$
\text { Skewness }_{i}=\sum_{j=1}^{N} \frac{\left(d_{i j}-\text { média }_{i}\right)^{3}}{N \sigma^{3}}
$$

A kurtosis corresponde ao grau de achatamento de uma distribuição. Assim como a assimetria, a curtose também é calculada por meio da função matemática curtose definida no software Matlab e dada pela Equação (4.6).

$$
\text { Kurtosis }_{i}=\frac{\frac{1}{N} \sum_{j=1}^{N}\left(d_{i j}-\text { média }_{i}\right)^{4}}{\left[\frac{1}{N} \sum_{j=1}^{N}\left(d_{i j}-\text { média }_{i}\right)^{2}\right]^{2}}
$$

As medidas de entropia: entropia de Shannon e entropia de Rennyi sugiram a partir da teoria da informação, introduzidas nos estudos de Shannon (SHANNON, 1948), que define os conceitos de medida de informação, de capacidade de transferência de informação sobre um canal e de codificação. Shannon definiu a informação como sendo uma quantidade matemática precisa e plenamente caracterizada em Teoria da Informação.

Nos trabalhos de Shannon, é definido uma grandeza matemática que mede a quantidade de informação e incerteza acerca de uma variável aleatória $x$. Intuitivamente, um dado tem tanto mais informação quanto maior for o seu grau de aleatoriedade. Na Tecnologia da Informação acredita-se que os estudos devem se concentrar em métodos para estimar diretamente a entropia de um conjunto de dados; portanto, os cálculos que envolvem a entropia nesta dissertação são realizados com o objetivo de definir a quantidade de informação dos dados que compõem a janela $i$ analisada. 
A entropia é definida como o somatório do log dos pontos $d_{i j}$ da janela $i$ analisada, ou seja:

$$
\text { entropia } a_{i}=\sum_{j=1}^{N} \log \left(d_{i j}^{2}\right)
$$

A entropia de Shannon e Entropia de Renyi são definidas pelas Equações (4.8) e (4.9)

$$
\begin{gathered}
\text { entropia_shannon }_{i}=-\sum_{j=1}^{N} d_{i j}^{2 *} \log \left(d_{i j}^{2}\right) \\
\text { entropia_renyi }=\frac{1}{1-\alpha}{ }^{*} \log \sum_{j=1}^{N} d_{i j}^{\alpha}
\end{gathered}
$$

onde o parâmetro $\propto$ da Entropia de Renyi é um parâmetro livre que foi ajustado por meio de diversos testes em 0,6.

As outras características como energia, RMS, fator de crista, fator de forma, valor de diferença entre o ponto máximo e mínimo do sinal (Dif) e valor de pico correspondem a cálculos simples que caracterizam a forma de onda de um sinal senoidal.

As características Dif e valor de pico são calculadas por meio das Equações (4.10) e (4.11).

$$
\begin{gathered}
D i f_{i}=\max \left(d_{i j}\right)-\min \left(d_{i j}\right) \\
\operatorname{pico}_{i}=\max \left(d_{i j}\right)
\end{gathered}
$$

onde a função $\max (x)$ é a operação para encontrar o maior valor em um vetor e a operação $\min (x)$ é a operação para encontrar o menor valor em um vetor.

O RMS é calculado pela Equação (4.12).

$$
R M S_{i}=\sqrt{\frac{1}{N} * \sum_{j=1}^{N}\left|d_{i j}\right|}
$$


Fator de crista corresponde à razão entre o valor de pico pelo valor RMS da janela $i$ como mostra a Equação (4.13).

$$
\text { Fator_Crista }{ }_{i}=\frac{\text { pico }}{R M S_{i}}
$$

O fator de forma, também conhecido como fator de ondulação, corresponde à razão entre a média e o valor RMS de cada janela $i$, definido pela Equação (4.14)

$$
\text { Fator_Forma }{ }_{i}=\frac{\text { média }_{i}}{R M S_{i}}
$$

\subsection{Características Extraídas no Domínio da Frequência}

As características extraídas no domínio da frequência como: amplitude da componente fundamental, Total Harmonic Distortion (THD), amplitude e ângulo de fase das 25 primeiras componentes harmônicas são calculadas a partir da análise das componentes de frequência da Transformada de Fourier. Antes de apresentar a formulação matemática para obtenção destas características citadas, faz-se necessário uma breve explanação a respeito da Transformada de Fourier.

A teoria de Fourier afirma que qualquer sinal contínuo pode ser representado como a soma de ondas senoidais de frequências e amplitudes devidamente escolhidas (SMITH, S, 1999). Portanto, a Transformada de Fourier, proposta por JeanBaptiste Joseph Fourier, de uma função contínua $x(t)$ pode ser expressa por integrais de funções senoidais de frequências diferentes, desde que a área sob a curva dessa função seja um intervalo entre $[-\infty,+\infty]$, conforme mostra a Equação (4.15).

$$
X(\omega)=\int_{-\infty}^{\infty} x(t) e^{-j \omega t} d t
$$

onde $X(\omega)$ representa a função $x(t)$, com todas as características, no domínio da frequência. 
No entanto, em casos práticos, onde o sinal é representado no domínio de tempo discreto, utiliza-se a Discrete Fourier Transform (DFT), representada pela expressão:

$$
X(m)=\sum_{n=0}^{N_{a}} x(n) e^{-j\left(2 \pi / N_{a}\right) m n}
$$

onde $n$ é um número inteiro, entre $[0 \ldots N]$, que representa o índice do vetor discreto $x[n]$ analisado no domínio do tempo, mé também um número inteiro, entre $[0 . . . N]$, correspondente ao índice do vetor discreto $X[M]$ no domínio da frequência e $N$ é o número de amostras do vetor analisado. De acordo com a Equação (4.16) são necessárias $N^{2}$ multiplicações complexas e $N(N-1)$ somas complexas para obter os Mvalores do vetor X[M] (OPPENHEIM; SCHAFER; BUCK, 1999).

A saída DFT corresponde a um conjunto de números que representam as amplitudes de ondas seno e cosseno (no domínio da frequência), rotulada a uma amostra do vetor ou a uma componente de frequência utilizada de acordo com a aplicação e decomposta conforme a frequência de amostragem. Então, como o presente trabalho analisa o sinal que possui uma frequência igual a $60 \mathrm{~Hz}$, cada ponto da saída DFT corresponde a uma amplitude de um sinal seno com frequência múltipla da fundamental e espaçada de acordo com a frequência de amostragem do sinal.

Existem vários métodos que se propõem a calcular a transformada discreta de Fourier, no entanto, a Transformada Rápida de Fourier (TRF) é o mais utilizado por diminuir o esforço computacional da DFT e produzir os mesmo resultados.

Existem vários algoritmos para o cálculo da TRF, cuja ideia principal destes consiste de dividir recursivamente a transformada discreta em partes menores a fim de diminuir o número de somas e multiplicações aritméticas. É importante comentar 
que um dos requisitos da TRF consiste no fato de que a quantidade de amostras $N$ da janela de dados deve ser em função da potência de 2.

Depois do cálculo da TRF e obtenção do vetor $X[M]$, são obtidas as seguintes características: amplitude da componente fundamental, distorção harmônica total, amplitude absoluta e amplitude relativa das harmônicas múltiplas da frequência fundamental.

A Total Harmonic Distortion (THD) é a relação entre a raiz quadrada do somatório do quadrado de todas as harmônicas observadas e a amplitude da componente fundamental, sendo definida por:

$$
T H D_{i}=\frac{\sqrt{\sum_{k=2}^{N} X_{i}[k]^{2}}}{X_{i}[1]}
$$

As características amplitude absoluta e amplitude relativa das harmônicas múltiplas da fundamental são calculadas por meio da Equações (4.18) e (4.19)

$$
\begin{gathered}
\text { amplitude_absoluta }[\mathrm{M}]=\operatorname{abs}\left(\mathrm{X}_{i}[\mathrm{M}]\right) \\
\text { amplitude_relativa }_{i}[\mathrm{M}]=\frac{\text { amplitude_absoluta }_{i}[M]}{\text { amplitude_absoluta }_{i}[1]}
\end{gathered}
$$

As características amplitude absoluta e amplitude relativa foram extraídas das 25 primeiras posições do vetor $X_{i}[M]$, pois o PRODIST considera para fins de cálculos, uma faixa de frequência que deve compreender desde a componente fundamental até, no mínimo, a 25ํㅗำ ordem harmônica.

No entanto, para as janelas obtidas com taxas de amostragem de 16 amostras/ciclo e 32 amostras/ciclos, a resolução máxima de frequência que a TRF consegue obter é de $480 \mathrm{~Hz}$ e $960 \mathrm{~Hz}$, respectivamente. Assim para as características amplitude absoluta e relativa são calculadas até a $8^{\mathrm{a}}$ harmônica, para janelas obtidas com 16 amostras/ciclo e $16^{\text {a }}$ harmônicas para janelas obtidas com 32 amostras/ciclo. 


\subsection{Considerações Finais}

Neste capítulo foram apresentadas as característica extraídas das janelas que compõem o banco de dados. Tais características foram escolhidas visando tornar o processo de detecção e classificação mais compacto. Por isto, uma parte delas são obtidas sem a necessidade de utilizar ferramentas de transformação de domínio, diminuindo o esforço computacional do método, adicionalmente as outras características são calculadas a partir da Transformada Rápida de Fourier. Os próximos capítulos são responsáveis por apresentar detalhes do método de detecção e classificação, os quais utilizam como entrada as características demonstradas no neste capítulo. 


\section{Detecção dos Distúrbios da Qualidade de Energia Elétrica}

Este capítulo tem como objetivo apresentar, em detalhes, os aspectos do método desenvolvido para detectar o padrão das janelas que apresentam distúrbios. Portanto, na sequência, são explanados como funciona o sistema de detecção e localização (Seção 4.1), em seguida são apresentados os resultados obtidos com a utilização da técnica (Seção 4.2).

\subsection{Detecção do Distúrbio}

O sistema de detecção dos distúrbios de QEE foi desenvolvido com o intuito de obter uma metodologia compacta e rápida, tendo como base dois blocos que funcionam de forma concomitante. Cada bloco recebe como entrada, respectivamente, a característica RMS e THD de janela analisada. A saída destes blocos são utilizada como entrada em uma porta lógica “OU”, e sua saída determinará a presença ou não do distúrbio na janela analisada como mostra a Figura 5.1.

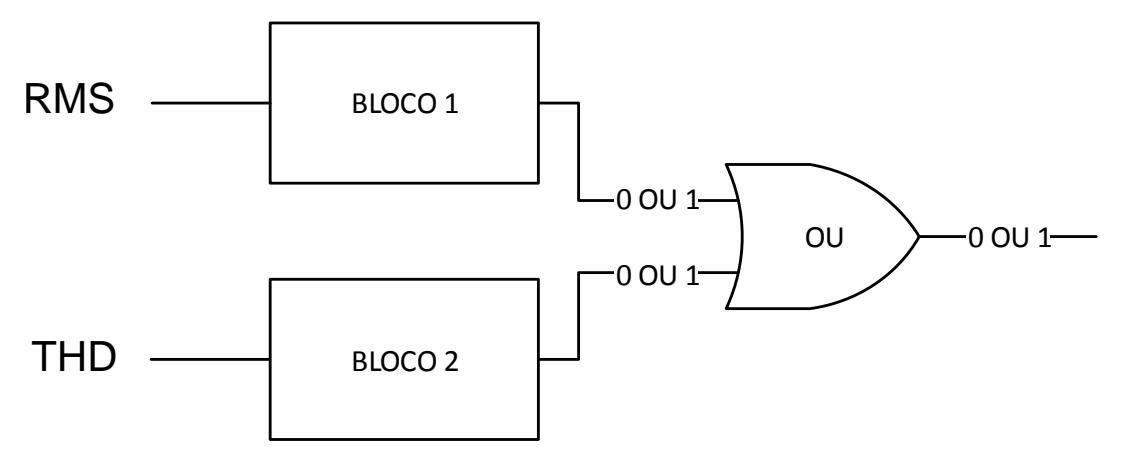

Figura 5.1 - Representação do método de detecção do distúrbio

Os dois blocos foram implementados, de forma que o bloco 2 é responsável por detectar as janelas que não são detectáveis pelo bloco 1, e vice versa. Dessa forma a operação de disjunção lógica resultará 1 (distúrbio detectado) se pelo menos 
uma dos blocos conseguir detectar o distúrbio. O resultado da porta "ou", só será 0 (janela normal) se os dois blocos considerarem a janela sem distúrbio.

A implementação de cada bloco parte do princípio que as janelas adquiridas, que não possuem distúrbios terão o valor da característica de entrada (THD ou RMS) muito próxima; no entanto, quando esta janela possuir um distúrbio, o valor da característica calculada, será diferente do encontrado para a janela normal.

Dessa forma pode-se evidenciar um método, onde cada bloco empregará uma regra de decisão baseado no valor da distância euclidiana, entre janelas sucessivas obtida de acordo com a Equação (5.1)

$$
\text { Dist }_{i}=\sqrt{\left(\text { Caracteristica }_{\text {referência }}-\text { Caracteristica }_{i}\right)^{2}}
$$

onde Dist $_{i}$ é calculada em cada um dos bloco e corresponde à distância euclidiana entre a característica, THD ou RMS (de acordo com o bloco), da janela i que está sendo analisada e um valor de referência. O valor de referência para o primeiro bloco é obtido de acordo com a análise da característica RMS das janelas normais, já para um segundo bloco é feito uma análise da característica THD das janelas normais.

Assim, quanto mais próximo for o valor da característica THD ou RMS ao parâmetro de referência, maior será o grau de afinidade da janela adquirida com uma janela normal; caso contrário, a janela terá maiores chances de apresentar um distúrbio. Desta forma, torna-se possível induzir em uma regra de detecção para cada bloco, do tipo "Se <condição> então <conclusão>", em que <condição> é uma inferência que detecta o distúrbio de acordo com a Dist $_{i}$ calculada e um limiar que define o limite máximo ou a fronteira de decisão, e <conclusão> é responsável por inferir na detecção do distúrbio, ou seja:

Regra: Se Dist $_{i} \geq$ limiar Então distúrbio detectado 
Por meio da regra acima sempre que Dist $_{i}$ possuir um valor acima do limiar, a janela sob análise possui um distúrbio. É importante comentar que os valores obtidos de cada bloco para o limiar e para o valor Caracteriticareferência são ajustados de acordo com a taxa de amostragem do sinal adquirido.

\subsection{Resultados obtidos pelo sistema de detecção dos distúrbios de QEE}

No que se segue serão discutidos os resultados que foram obtidos utilizando o método para detecção dos distúrbios. Desse modo, as Tabelas 5.1 à 5.5 ilustram, os resultados obtidos utilizando como entrada as janelas que constituem o banco de dados de 16 amostras/ciclo, 32 amostras/ciclo, 64 amostras/ciclo, 128 amostras/ciclo e 256 amostras/ciclo. Estes resultados são apresentados por meio de uma matriz de confusão, esta matriz tem como objetivo mostrar o número de previsões corretas em relação às esperadas. Para cada resultado é especificado no rodapé da tabela os valores da Caracteriticareferência e limiar que foram utilizados nos testes.

Tabela 5.1 - Resultado da Detecção para janelas adquiridas com taxa de amostragem de 16 amostras/ciclo

\begin{tabular}{|c|c|c|c|c|}
\hline & Janela com Distúrbio & Janela Normal & Total & $\%$ \\
\hline Janela com Distúrbio & 554746 & 84305 & 639051 & $87 \%$ \\
\hline Janela Normal & 32703 & 759046 & 791749 & $96 \%$ \\
\hline
\end{tabular}

Limiar Bloco 1: 0.035 -- Característicaneferência Bloco 1: 0.7078

Limiar Bloco 2: 0.07 -- Característica Referência Bloco 2: 0.0256

Tabela 5.2 - Resultado da Detecção para janelas adquiridas com taxa de amostragem de 32 amostras/ciclo

\begin{tabular}{||c|c|c|c|c||}
\hline & Janela com Distúrbio & Janela Normal & Total & $\%$ \\
\hline Janela com Distúrbio & 1142646 & 220716 & 1363362 & $84 \%$ \\
\hline Janela Normal & 131044 & 1347594 & 1478638 & $91 \%$ \\
\hline
\end{tabular}


Tabela 5.3 - Resultado da Detecção para janelas adquiridas com taxa de amostragem de 64 amostras/ciclo

\begin{tabular}{|c|c|c|c|c|}
\hline & Janela com Distúrbio & Janela Normal & Total & $\%$ \\
\hline Janela com Distúrbio & 2264209 & 549049 & 2813258 & $80 \%$ \\
\hline Janela Normal & 264559 & 2586583 & 2851142 & $91 \%$ \\
\hline
\end{tabular}

Limiar Bloco 1: 0.04 -- Característicaneferenncia Bloco 1:0.7082

Limiar Bloco 2: 0.063 -- Característicaneferencia Bloco 2: 0.0288

Tabela 5.4 - Resultado da Detecção para janelas adquiridas com taxa de amostragem de 128 amostras/ciclo

\begin{tabular}{|c|c|c|c|c||}
\hline & Janela com Distúrbio & Janela Normal & Total & $\%$ \\
\hline Janela com Distúrbio & 4663401 & 994447 & 5657848 & $82 \%$ \\
\hline Janela Normal & 760150 & 4891202 & 5651352 & $87 \%$ \\
\hline
\end{tabular}

Limiar Bloco 1: 0.0323 -- Característicaneferência Bloco 1:0.7083

Limiar Bloco 2: 0.0530 -- Característicaneferência Bloco 2: 0.0294

Tabela 5.5 - Resultado da Detecção para janelas adquiridas com taxa de amostragem de 256 amostras/ciclo

\begin{tabular}{|c|c|c|c|c|}
\hline & Janela com Distúrbio & Janela Normal & Total & $\%$ \\
\hline Janela com Distúrbio & 9280678 & 2034179 & 11314857 & $82 \%$ \\
\hline Janela Normal & 1502579 & 9781364 & 11283943 & $87 \%$ \\
\hline
\end{tabular}

Limiar Bloco 1:0.022 -- Característicaneferencia Bloco 1:0.7085

Limiar Bloco 2: 0.06 -- Característicaneferência Bloco 2: 0.0297

Pelos resultados apresentados nas Tabelas 5.1 à 5.5, observar-se que apesar da taxa de acerto ficar acima de $80 \%$, para as cinco taxa de amostragem, o erro do sistema aumenta à medida que aumenta o número de amostras por ciclos. Nota-se também que o método consegue melhor classificação para as janelas normais, ou seja, os erros são mais relevantes na situação que a janela possui distúrbio, no entanto é classificada como janela normal (falso negativo).

Com o intuito de melhor compreender o porquê dessa classificação errônea, foram realizados alguns testes utilizando somente as janelas de transição, que se caracterizam por apresentarem transição entre um sinal normal um sinal com 
distúrbio, estas janelas apresentam tanto pontos que apresentam um sinal normal quanto pontos que apresentam o distúrbio.

Nesse contexto, para as janelas que possuem taxa de amostragem de 16 amostras/ciclo, foram analisadas as janelas de transição que possuem até 15 pontos que caracterizam o distúrbio, já para as taxas de amostragem de 32 amostras/ciclo, 64 amostras/ciclo, 128 amostras/ciclo e 256 amostras/ciclo, foram analisadas, respectivamente, as janelas que possuem até $31,63,127$ e 255 pontos que caracterizam os distúrbios. Desse modo pretende-se analisar a taxa de acerto do método, para as primeiras janelas do distúrbio.

Estas janelas foram consideradas, porque pretende-se avaliar o desempenho do método em relação as janelas que apresentam distúrbios e possuem características mais próximas, os distúrbios presentes nestas janelas são mais difíceis de serem detectados. As Figuras 5.2 à 5.6 apresentam os resultados utilizando respectivamente, as janelas obtidas com uma taxa de amostragem de 16 amostras/ciclo, 32 amostras/ciclo, 64 amostras/ciclo, 128 amostras/ciclo e 256 amostras/ciclo. Estes resultados são apresentados em forma de um gráfico de barras onde cada barra caracteriza a taxa de acertos de acordo com o número de pontos que caracteriza o sinal que está presente na janela. 
Desempenho do método de detecção para 16 smostras/ciclo

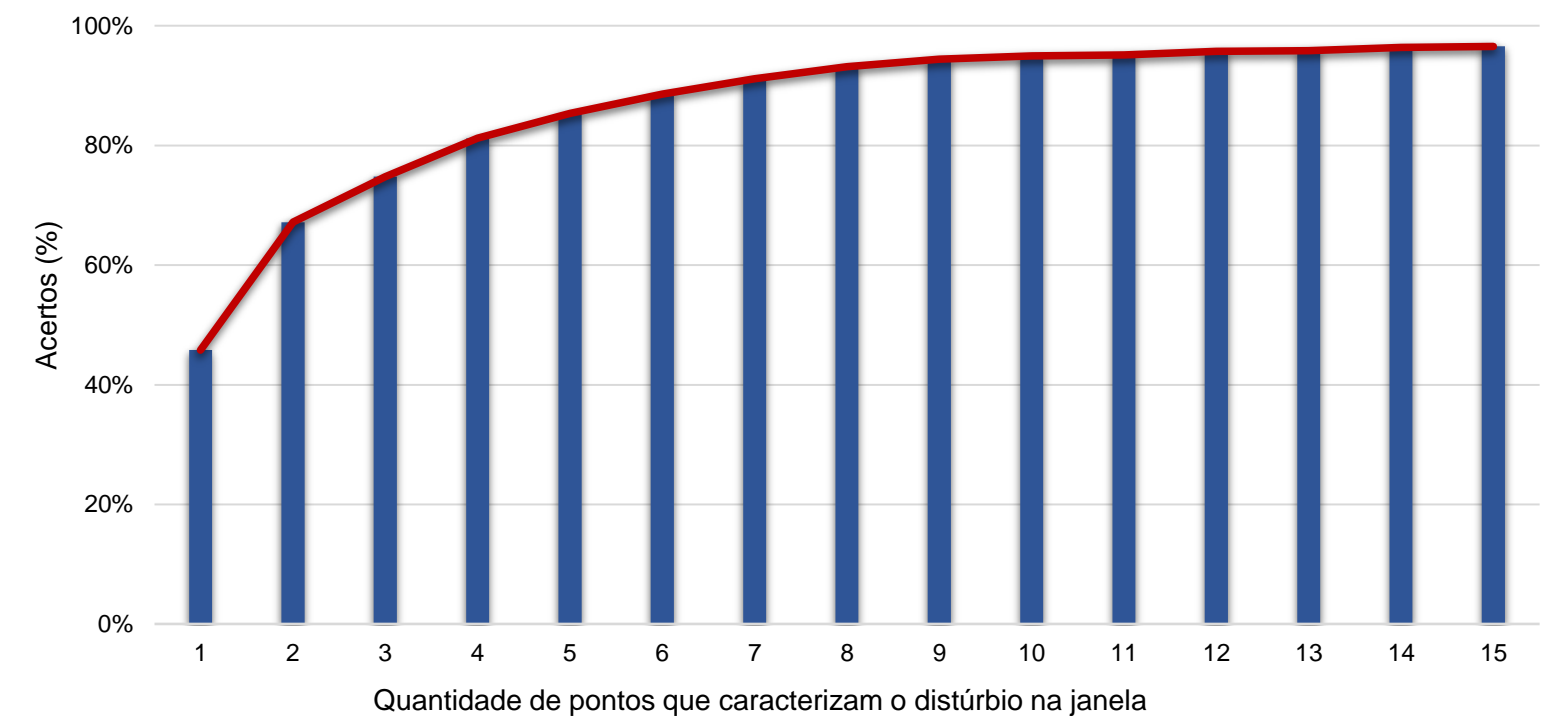

Figura 5.2 - Desempenho do método de detecção para as janelas de transição adquiridas sobre uma taxa de amostragem de 16 amostras/ciclo

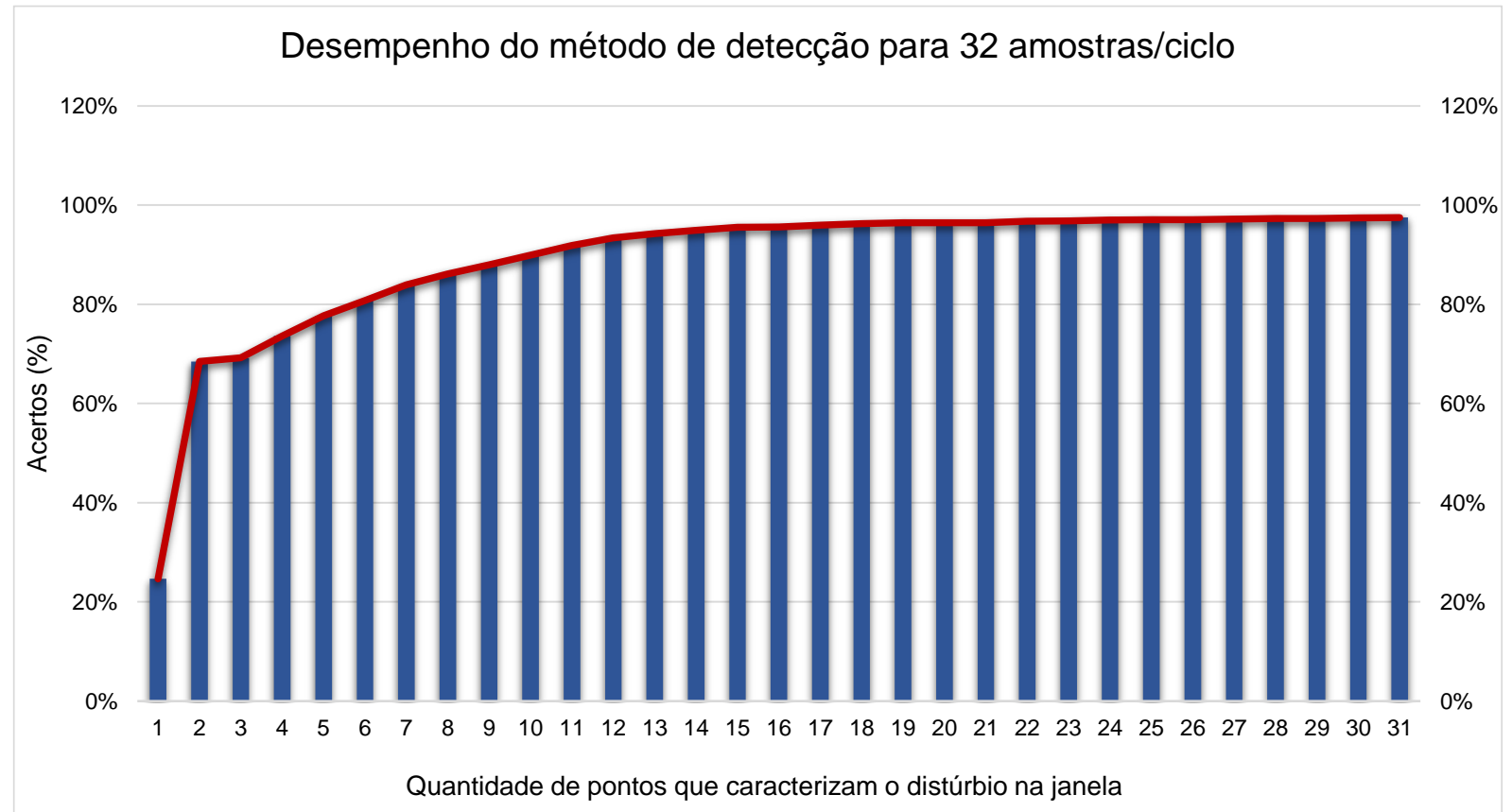

Figura 5.3 - Desempenho do método de detecção para as janelas de transição adquiridas sobre uma taxa de amostragem de 32 amostras/ciclo 


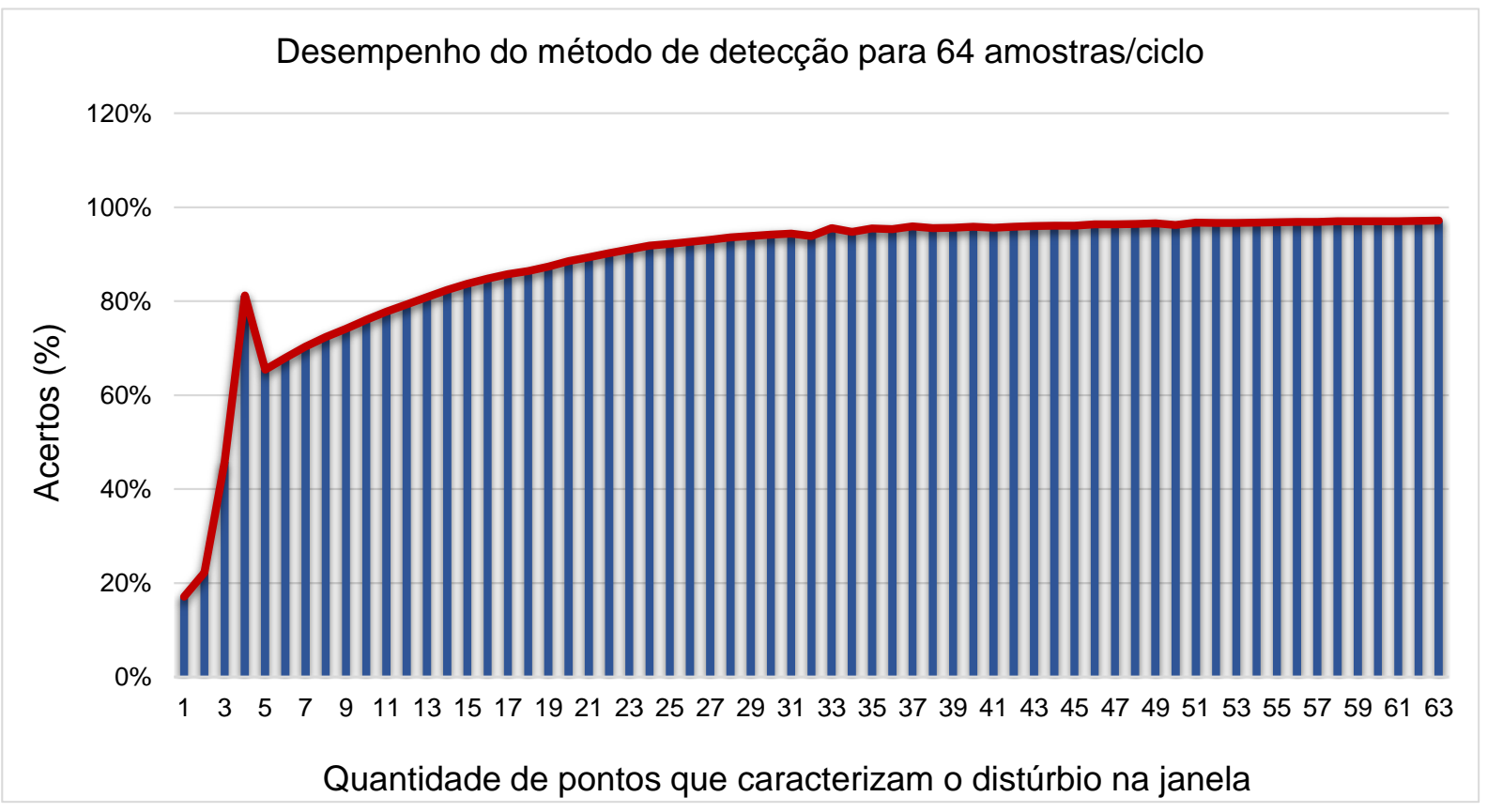

Figura 5.4 - Desempenho do método de detecção para as janelas de transição adquiridas sobre uma taxa de amostragem de 64 amostras/ciclo

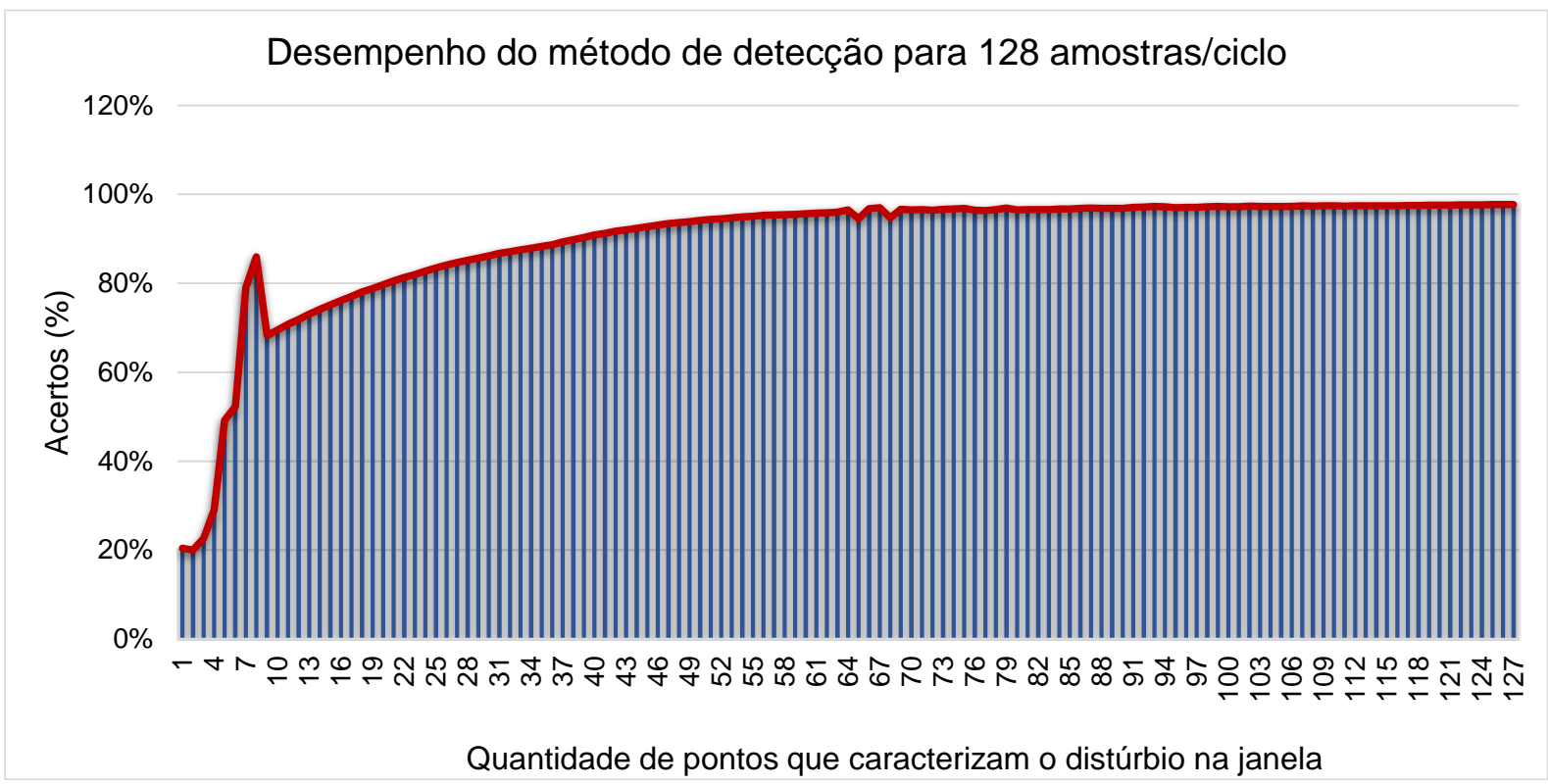

Figura 5.5 - Desempenho do método de detecção para as janelas de transição adquiridas sobre uma taxa de amostragem de 128 amostras/ciclo 


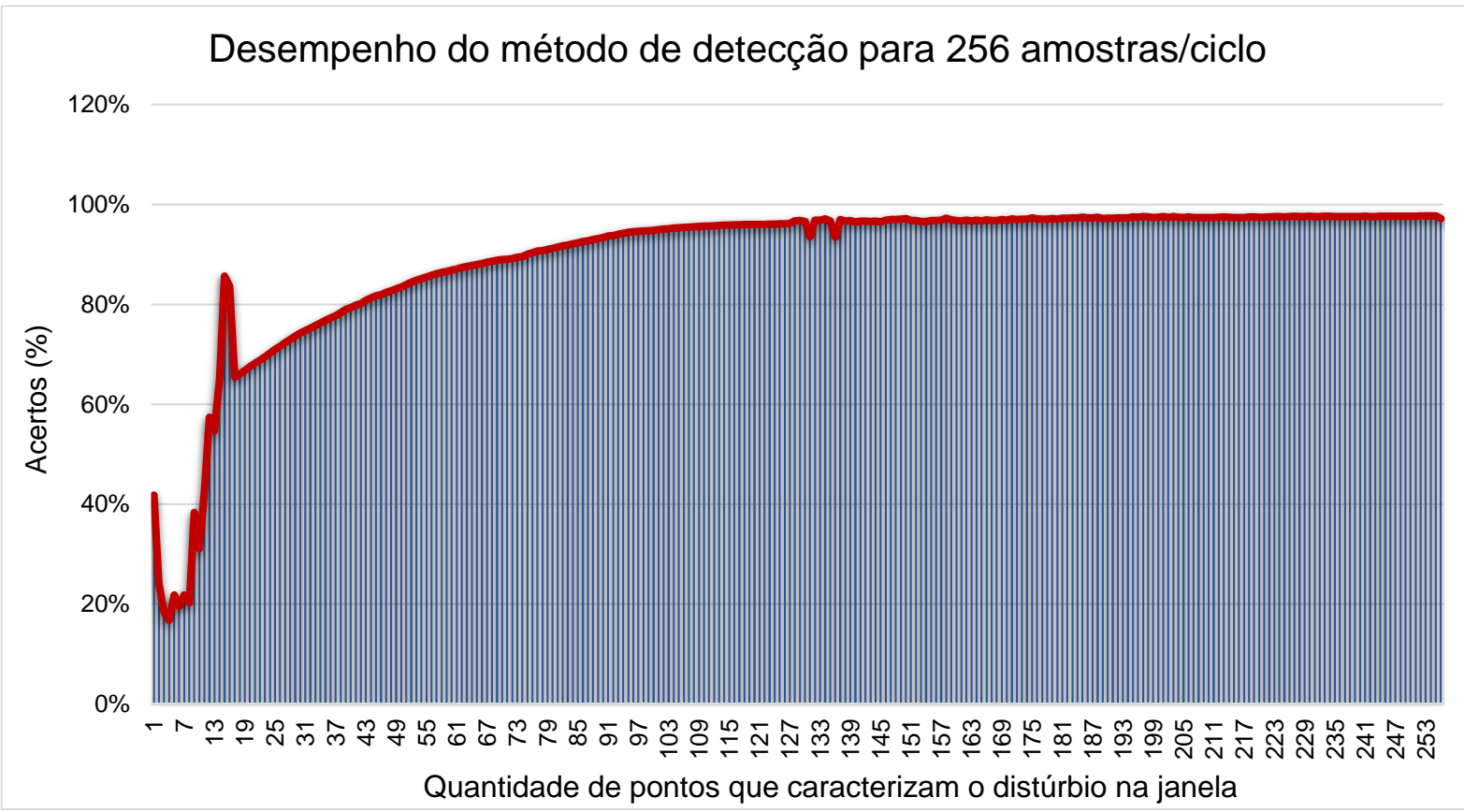

Figura 5.6 - Desempenho do método de detecção para as janelas de transição adquiridas sobre uma taxa de amostragem de 256 amostras/ciclo

De acordo com os gráficos que foram apresentados nas Figuras 5.2 à 5.6, observa-se que o método de detecção tem uma baixa taxa de acerto para as primeiras janelas que caracterizam o distúrbio, sendo que nas janelas adquiridas sobre as taxas de amostragem de 128 e 256 amostras/ciclo, e taxa de acerto para as primeiras janelas ficou abaixo de $40 \%$. Este fato ocorre, porque tais janelas apresentam características mais próximas das janelas normais, e então o método não consegue detectar o distúrbio.

Verifica-se também que para janelas adquiridas a uma taxa de amostragem de 16 amostras/ciclo o método se torna estável, em relação a taxa de acertos, para janelas que possuem mais de 5 pontos que caracterizam o distúrbio. No entanto para as janelas adquiridas sobre uma taxa de amostragem de 256 amostras/ciclo o método só consegue alcançar uma estabilidade, a partir das janelas que possuem mais de 100 pontos que caracterizam o distúrbio. Portanto, quanto menor for a taxa de amostragem, menos pontos serão necessários para detectar o distúrbio. 


\subsection{Considerações Finais}

Neste capítulo foram apresentados os aspectos da metodologia empregada para detecção dos distúrbios de qualidade de energia elétrica. O método possui a capacidade de diagnosticar a presença ou não do distúrbio em uma janela, possuindo como vantagem ser rápido e compacto, pois ele utiliza dois blocos, responsáveis por calcular a distância euclidiana da característica THD e RMS a um valor de referência. A saída de cada bloco é utilizada como entrada em uma porta logica "ou", que determina a presença ou não do distúrbio.

De acordo com os resultados apresentados no decorrer do capítulo, pode-se observar que a metodologia conseguiu detectar com uma precisão acima de $80 \%$ as janelas que apresentam distúrbios. Pelos gráficos apresentados nas Figuras 5.2 à 5.6 nota-se que o método conseguiu uma taxa de acerto acima de 95\% para as janelas de transição que possuem apenas $1 / 4$ de pontos que caracterizam o distúrbio inserido na janela.

Assim, obtidos os resultados para cada um dos bancos de dados definidos no capítulo 3, o próximo capítulo explana o sistema utilizado para a classificação dos distúrbios de qualidade de energia elétrica, bem como os resultados obtidos nesta etapa. 


\section{Classificação dos Distúrbios Relacionados à Qualidade da Energia Elétrica}

O sistema de análise dos distúrbios de QEE desenvolvido neste trabalho utiliza Árvore de Decisão, responsáveis por detectar padrões das características utilizadas como entrada e que foram apresentadas no Capítulo 4, com base no conhecimento adquirido na fase de treinamento, podendo assim inferir na classificação dos distúrbios de QEE. Os resultados experimentais serão devidamente reportados e justificados buscando validar a proposta apresentada.

Assim, este capítulo foi dividido em duas partes. A Secção 6.1 é responsável por apresentar as principais características a respeito de um classificador baseado em Árvore de Decisão, ao passo que a segunda parte é responsável por apresentar os resultados obtidos pelo sistema proposto.

\section{1 Árvore de Decisão}

Árvores de decisão são ferramentas que utilizam estratégias "dividir para conquistar" para aprendizagem de padrões de um conjunto de dados (WITTEN; FRANK, 2005), apresentando como principal vantagem a compilação de estruturas compactas e de grande legibilidade, de modo que seus resultados são facilmente entendíveis (HALMENSCHLAGER, 2002).

Assim, esta ferramenta utiliza uma representação em árvore, que ajuda na classificação e predição das amostras desconhecidas, sendo estruturada hierarquicamente em um conjunto de nós interconectados, cujos nós internos testam um atributo de entrada com uma constante de decisão e determina qual será o próximo nó descendente. Já os nós folhas classificam as instancias que os atingem 
de acordo com o rótulo associado a ele. Portanto, o conhecimento em uma árvore de decisão é representado por cada nó, que ao ser testado conduz a busca para um nó filho, até chegar em um nó folha. A Figura 6.1 representa a estrutura de uma árvore de decisão.

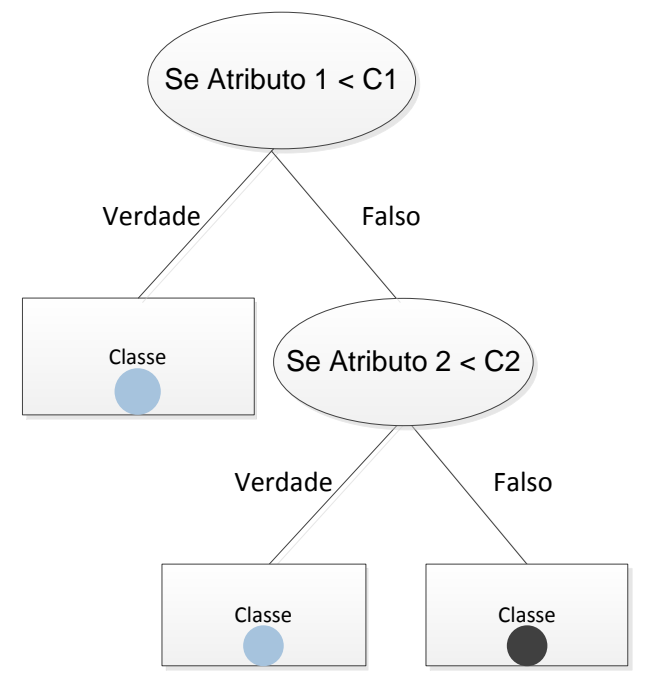

Figura 6.1 - Estrutura de uma árvore de decisão.

As árvores de decisão possuem características relevantes que viabilizam o método tais como os seguintes:

- Precisão: habilidade do modelo para avaliar ou prever corretamente classes, agrupamentos, regras;

- Velocidade: Uma vez construída uma árvore de decisão, seu uso é imediato e sua execução é computacionalmente muito rápida.

- Robustez: habilidade do modelo para avaliar ou prever corretamente, utilizando dados ruidosos ou com valores ausentes;

- Escalabilidade: capacidade de construir modelos eficientemente a partir de grandes volumes de dados;

- Interpretabilidade: alto nível de compreensão fornecido pelo modelo;

- Flexibilidade: o espaço das instancias é particionado em subespaços e cada subespaço é adaptado a diferentes modelos. 
Apesar da árvore de decisão ter como principal característica a velocidade, a construção de uma árvore, chamada de processo de indução, demanda um alto custo computacional, pois envolve uma análise detalhada dos dados, que dependendo da dimensão e do tamanho destes torna-se a indução trabalhosa (WITTEN; FRANK, 2005).

O processo de indução de uma árvore baseia-se na estratégia "dividir para conquistar", a qual consiste em dividir o espaço definido pelos atributos em subespaços menores e cada subespaço pode ser subdividido em novos subespaços ou associá-las a uma classe. A Figura 6.2 representa os passos de como ocorre o processo de "dividir para conquistar" para classificação de duas classes. Primeiramente, o valor de um atributo é comparado com a constante $\mathrm{C} 1$, dividindo-se o espaço em duas partes que melhor represente as duas classes, conforme a Figura 6.2. (a). Nota-se que a fronteira não conseguiu dividir completamente as duas classes, podendo então novamente estabelecer a fronteira que melhor separe os espaço onde as classes estão espalhadas Figura 6.2 (b).

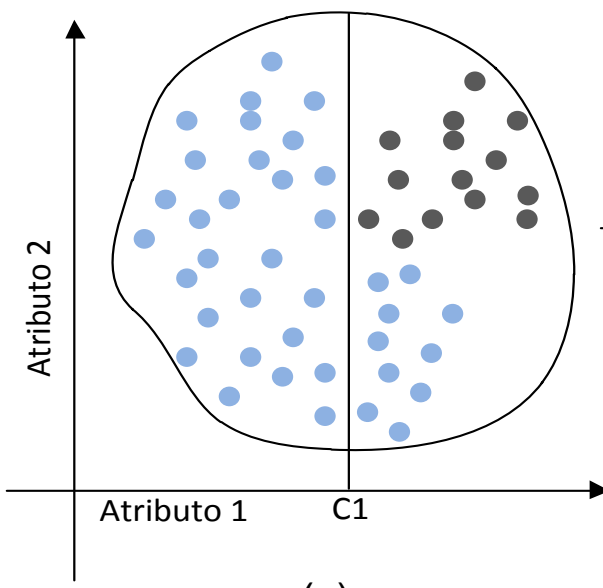

(a)

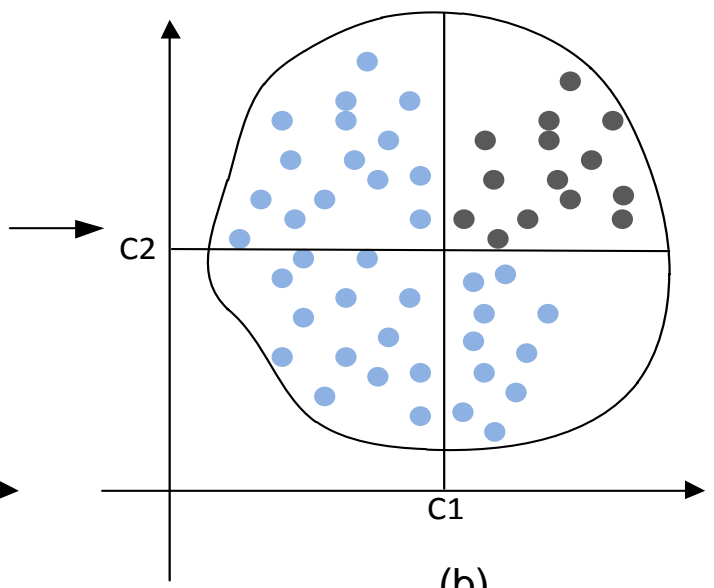

(b)

Figura 6.2 - Processo de classificação de duas classes utilizando árvore de decisão: obtenção da primeira fronteira de decisão (a) e segunda fronteira de decisão (b).

A partir desta explanação, pode-se observar que o processo de indução de uma árvore pode ser realizado de forma manual; no entanto, como já foi previamente 
mencionado, quando existe uma grande quantidade de dados este processo de criação torna-se complicado para ser realizado de forma manual. Assim sendo, recorre-se para uma abordagem automática de indução, baseada em aprendizado supervisionado, ou seja, o algoritmo constrói a árvore a partir de um conjunto de dados de treinamento com seus respectivos valores desejados.

O Top-Down Induction of Decision Tree (TDIDT) é um algoritmo bem conhecido e é utilizado como base para muitos algoritmos de indução de árvores de decisão. Tais algoritmos constroem árvores de decisão a partir do processo conhecido como particionamento, adicionando em cada nó um teste baseado em um atributo, responsável por dividir o conjunto de treinamento, adicionando-se ainda ligações para cada um dos possíveis valores resultantes. Em seguida, cada novo nó criado é novamente selecionado e um novo atributo de particionamento para o subconjunto de treinamento atribuído ao novo nó (HALMENSCHLAGER, 2002). Existem diversos tipos de algoritmos para indução de uma árvore de decisão, os quais são desenvolvidos utilizando algumas heurísticas que são apresentadas a seguir.

\subsubsection{Escolha do atributo para cada nó}

Na construção de uma árvore de decisão, faz-se necessário, para cada nó (não folha), a escolha de um atributo que melhor divide o conjunto de treinamento. Assim, os algoritmos de indução visam obter o melhor atributo a ser utilizado em um nó, por meio da utilização de métodos, responsáveis por verificar cada atributo candidato e selecionando aquele que melhor discrimine uma classe. Existem diferentes tipos de métodos para escolher o melhor atributo para cada nó, dentre eles destacam-se os seguintes: 
- Ganho de Informação: mede a redução da entropia causada pela partição do conjunto; assim, para medir esta redução, compara-se o grau de entropia do nó pai (antes da divisão) com o grau de entropia do nó filho (após a divisão), e o atributo que gera uma maior diferença é escolhido como condição teste. O ganho de entropia é definido por:

$$
\text { ganho }=\text { entropia }(\text { pai })-\sum_{j=1}^{n} \frac{N\left(v_{j}\right)}{N}{ }^{*} \operatorname{entropia}\left(v_{j}\right)
$$

onde $n$ é o número de atributos, $N$ é o número total de objetos do nópai e $N\left(v_{j}\right)$ é o número de exemplos associados ao nó-filho $v_{j}$

- Critério de Gini: mede a impuridade de um nó, a qual é máxima quando todas as classes possuem igual distribuição, e mínima quando existe apenas uma classe (HALMENSCHLAGER, 2002). O índice de Gini é definido por meio da Expresão (6.2)

$$
\text { índice_gini(nó) }=1-\sum_{i=1}^{k} p\left(C_{i} \mid \text { nó }\right)^{2}
$$

onde $p$ corresponde à probabilidade relativa da Classe $i$ em relação ao nó pai, e $k$ corresponde ao número de classes

\subsubsection{Critérios de parada}

Este critério é importante, pois as árvores estão propensas a overfitting, que ocorre quando Árvore de Decisão tem um crescimento exagerado, onde novos nós dividem uma partição pequena dos dados em partições menores, tornando a árvore mais específica, tal que consegue memorizar os dados de treinamento, porém, não é capaz de generalizar suas soluções para novas situações. 
Para evitar o overfitting duas metodologia são utilizadas, definidas como prépoda e pós-poda. O pré-poda é responsável por estabelecer um critério de parada do algoritmo de criação da árvore, podendo ser estabelecido para transformar um nó corrente em um nó folha, utilizando o ganho de informações, quando todas as divisões possíveis usando um atributo A gerem ganhos menores que um valor préestabelecido.

As técnicas de pós-poda são realizadas após a construção da árvore de decisão, substituindo uma sub-árvore, por um nó folha que representa a classe com mais frequência no ramo. A técnica de pós-poda calcula a taxa de erro caso a subárvore seja retirada. Se essa taxa de erro for menor que um valor pré-estabelecido, a árvore então é podada; caso contrário, não ocorrerá a poda.

\subsubsection{Algoritmo C4.5}

O algoritmo C 4.5 foi proposto por Ross Quinlan (QUINLAN, 1993), e visa a construção de uma árvore por meio de um conjunto de treinamento, utilizando o critério ganho de informação para escolher o melhor atributo a ser usando em cada nó e adotando a estratégia de pós-poda, a fim de reduzir o tamanho da árvore e evitar overfitting.

Um modelo de pseudocódigo da função recursiva do algoritmo C4.5 é apresentado abaixo.

1 Função C4.5 (R: conjuntos de atributos, S: conjunto de treinamento)

$2 \quad$ Se S está vazio

3 Falha

$4 \quad$ Fim se

$5 \quad$ Se S contém exemplos de mesma classe

$6 \quad$ Retorna um nó folha com valor da classe

$7 \quad$ Fim se

$8 \quad$ Se R está vazio

9 Retorna uma folha com o valor da classe mais frequente.

10 Se não 
Calcula o atributo D com maior ganho de informação, entre os atributos restantes de $\mathrm{R}$

Acrescenta um nó possuindo $o$ atributo $D$

Divide $\mathrm{S}$ em subconjuntos de acordo com os valores de $\mathrm{D}$

Chama função C4.5 para cada um desses subconjuntos Fim se

A função C4.5 recebe como entradas dois valores, o primeiro corresponde ao conjunto de atributos $R$, e o segundo corresponde aos dados de treinamento. A função escolhe um atributo $D$, entre todos os atributos, que possui um maior ganho de informação, e então divide o conjunto de treinamento $S$ em vários subconjuntos, de acordo com os valores do atributo $D$. A função $\mathrm{C} 4.5$ é então chamada novamente, passando como parâmetro cada subconjunto.

\subsection{Resultados Observados}

Na sequência serão mostrados os resultados obtidos utilizando as Árvores de Decisão como ferramenta de classificação. A árvore de decisão foi implementada usando a ferramenta computacional WEKA (Waikato Environment Knowledge for Analisys) fornecida pela Universidade de Waikato (WITTEN; FRANK, 2005).

São realizados dois tipos de testes, o primeiro se encarrega em testar a árvore de decisão para classificação de uma janela de dados de tamanho de um ciclo do sinal, já o segundo emprega a árvore de decisão para classificação de um sinal de tamanho igual a dez ciclos.

\subsubsection{Resultados para as janela do sinal com tamanho de um ciclo}

Para cada uma das cinco taxas de amostragem é criada uma árvore de decisão, responsável por classificar os distúrbios gerados sobre a taxa de amostragem relacionada a ela. Cada uma das árvores possuem como entradas todas 
as características que foram exemplificadas no Capítulo 3, totalizando 36 características para a árvore responsável por classificar as janelas com 16 amostras/ciclo, 48 características para a árvore responsável por classificar as janelas que possuem 32 amostras/ciclo e 66 características para as árvores responsáveis por classificar as janelas com taxa de amostragem de 64,128 e 256 amostras/ciclo. O número de características se difere por conta que a resolução máxima de frequência que a TRF consegue obter, para taxa de amostragem de 16 amostras/ciclo e 32 amostras/ciclo, são, respectivamente, $480 \mathrm{~Hz}$ e $960 \mathrm{~Hz}$. Assim, para as características amplitude absoluta e relativa são calculadas até a $8^{a}$ harmônica, para janelas obtidas com 16 amostras/ciclo e $16^{\text {a }}$ harmônicas para janelas obtidas com 32 amostras/ciclo.

Como foi supracitado, para construção de cada árvore é necessário definir um conjunto de treinamento. Dessa forma, para cada uma das 5 árvores (uma para cada taxa de amostragem), é definido um conjunto de treinamento composto pelos sinais que apresentam um sinal normal e sinais com nível de relação sinal/ruído (SNR) de $45 \mathrm{~dB}, 35 \mathrm{~dB}$ e $25 \mathrm{~dB}$.

Para testar a metodologia o conjunto de teste foi dividido em três subconjuntos: o primeiro corresponde aos sinais com SNR de 40dB, o segundo apresenta as janelas que possuem SNR de $30 \mathrm{~dB}$ e o último é compostos das janelas que possuem nível de ruído de $20 \mathrm{~dB}$. Este último conjunto de teste foi utilizado para testar o classificador em condições fora do intervalo utilizado para treinamento.

Em primeira instância são apresentados o desempenho da Árvore de Decisão treinadas utilizando as janelas adquiridas com uma taxa de amostragem de 16 amostras/ciclo. De forma a melhor entender os resultados, eles são apresentados por meio de uma matriz de confusão, a qual tem o objetivo de mostrar o número de previsões corretas em relação às esperadas para cada uma das janelas que possuem 
distúrbios. A diagonal principal representa a quantidade de janelas que foram classificadas corretamente. Assim as Tabelas 6.1 a 6.3 descrevem os resultados em termos de uma matriz de confusão utilizando respectivamente o conjunto de testes com $40 \mathrm{~dB}, 30 \mathrm{~dB}$ e $20 \mathrm{~dB}$.

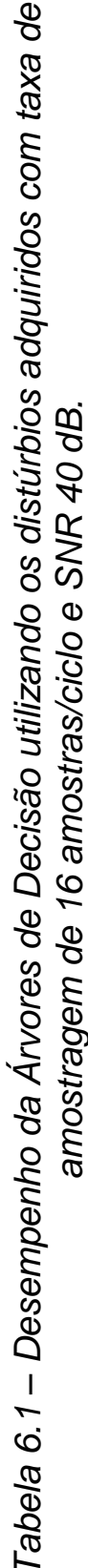

\begin{tabular}{|c|c|c|c|c|c|c|c|c|c|c|c|c|c|c|c|c|}
\hline ๕ & ஃ̊ & ஃ̊ & ஃ̊ & ळ̊ & ठ̊ํ & œ & ஃे & ஓे & ஓ̊ & ஓें & ळ & ஓ̊ & ஓి̊ & ○े & ॐ̊ ஹ & ¿ᄋ \\
\hline 嵒 & $\frac{\sim}{\infty}$ & 잉 & 흥 & 总 & $\stackrel{\infty}{f}$ & 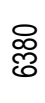 & 吕 & స్ర్ల & 肎 & ్ㅠㅁ & 哭 & 卓 & 怘 & $\underset{\mathscr{\Psi}}{\mathscr{\Psi}}$ & 웡 & \\
\hline
\end{tabular}

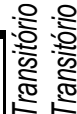

ठิ

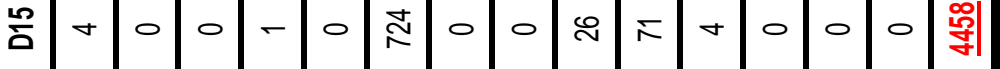

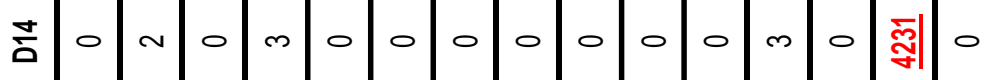

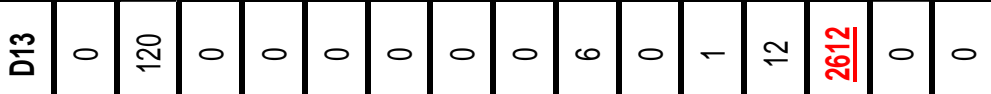

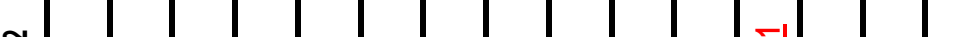

䒘

F்

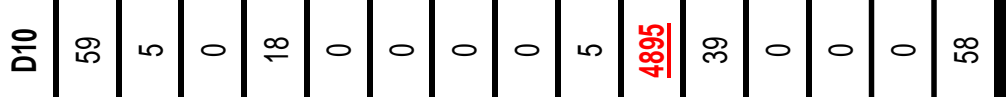

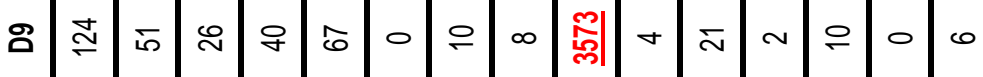

ロ

ลิ

๕

늠 m =

ப

ロ

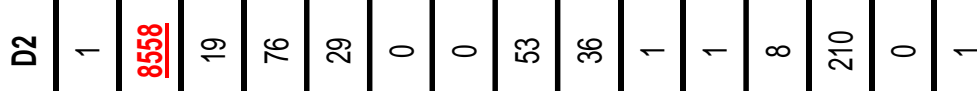

\begin{tabular}{|c|c|c|c|c|c|c|c|c|c|c|c|c|c|}
\hline 잉| & ๓ & $\approx$ & 이 & 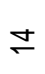 & న & 0 & - & $\stackrel{\infty}{\oplus}$ & ळ & $\underset{\sim}{\Delta}$ & 0 & 0 & 0 \\
\hline $\bar{\square}$ & ธิ & ஜூ & 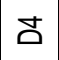 & $\stackrel{2}{2}$ & 8 & ธิ & $\stackrel{\circ}{\circ}$ & ه̊ & 음 & $\bar{\sigma}$ & $\stackrel{\simeq}{\square}$ & $\frac{m}{\square}$ & 考 \\
\hline
\end{tabular}




\begin{tabular}{|c|c|c|c|c|c|c|c|c|c|c|c|c|c|c|c|c|c|}
\hline$\widehat{\circ}$ & ๕̊ & ஓ̊ & ชั & ஓ̊ & ○̊ & $\frac{80}{0}$ & $\stackrel{\circ}{\stackrel{0}{人}}$ & ஓ & 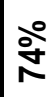 & $\mid \begin{array}{l}\stackrel{0}{0} \\
\stackrel{0}{\alpha}\end{array}$ & ১ે & & "ి & ஓे & ঃ̊ㅇㅇ & $\stackrel{0}{\circ}$ & ஓें \\
\hline 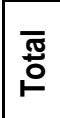 & $\frac{\sim}{\infty}$ & $\frac{の}{\infty}$ & 훙 & 㕣 & $\begin{array}{l}\infty \\
\stackrel{9}{+}\end{array}$ & 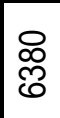 & 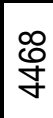 & $\overline{\widetilde{ఠ}}$ & ஜ্ঠি & $\begin{array}{l}0 \\
\text { ¿े } \\
\text { is }\end{array}$ & ळ & & 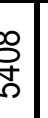 & 怘 & $\stackrel{\mathscr{\sim}}{\underset{\sim}{\sim}}$ & ปิ & 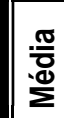 \\
\hline$\frac{10}{6}$ & $\stackrel{\leftrightarrow}{\checkmark}$ & 0 & - & m & - & 욤 & 0 & 0 & $\approx$ & $\frac{\sigma}{7}$ & S & & - & 0 & 0 & 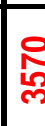 & \\
\hline 范 & 0 & $m$ & m & m & 10 & 0 & 0 & 0 & - & | & $c$ & & D & 0 & ঙิ & $c$ & \\
\hline$\frac{m}{\square}$ & 0 & ஜి & - & - & $\simeq$ & 0 & 0 & ナ & 이 & c & 0 & & $\widehat{n}$ & Ð్ల్| & 0 & $c$ & \\
\hline 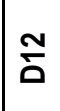 & 0 & ని & - & ๆ & $\stackrel{\infty}{\infty}$ & 0 & $\sim$ & $\nabla$ & ما & c & $c$ & & 市| & ఖ్ల & 0 & 0 & \\
\hline $\bar{\sigma}$ & $\bar{q}$ & - & 6 & 0 & 0 & $\neq$ & $m$ & 0 & $\hat{m}$ & ఠ & ֻั & & 0 & 0 & 0 & ㄱ & \\
\hline 음 & $\widehat{\aleph}$ & - & $\sim$ & $\cong$ & - & $\widetilde{్}$ & $m$ & $\sim$ & $\infty$ & ป్ & ఠ & & 0 & 0 & 0 & مي & \\
\hline 욤 & $\stackrel{N}{\sim}$ & 듬 & $\cong$ & O & $\stackrel{0}{\square}$ & ه & జ & $\bar{\infty}$ & ஜ্లি & $\propto$ & ๙ & & - & $\cong$ & 0 & $\infty$ & \\
\hline$\stackrel{\infty}{a}$ & 으 & in & $\stackrel{2}{\simeq}$ & $\stackrel{\infty}{m}$ & $\bar{\sim}$ & - & $\sim$ & 夌 & L & m & $c$ & & \& & - & 0 & $c$ & \\
\hline$\hat{a}$ & $\mathscr{~}$ & $m$ & 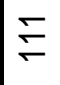 & $\stackrel{\infty}{=}$ & 0 & চ & 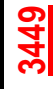 & $\simeq$ & 응 & 15 & c & & $\sim$ & - & 0 & - & \\
\hline $\mathscr{8}$ & $\mathscr{8}$ & 0 & m & $\sim$ & 0 & 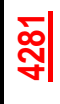 & $\varnothing$ & 0 & 0 & $\%$ & ล & & 0 & 0 & 0 & $\frac{0}{y}$ & \\
\hline 늠 & 0 & $\stackrel{2}{\sim}$ & $m$ & $\Lambda$ & $\mid$\begin{tabular}{l}
$\mathscr{0}$ \\
\hdashline
\end{tabular} & - & 으 & 이 & R & ר & r & & - & $\sim$ & 0 & - & \\
\hline 号 & 잉 & @ & $\frac{\infty}{\sim}$ & 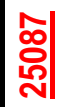 & 으 & $\Lambda$ & న్ & $\overline{\widetilde{m}}$ & $\underset{\infty}{\infty}$ & 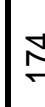 & ○ & & $\stackrel{0}{\epsilon}$ & $\bullet$ & $\sim$ & $\bar{c}$ & \\
\hline ח̊ & $\stackrel{\infty}{\sim}$ & $\infty$ & \&్ర & $\overline{\widetilde{N}}$ & $\approx$ & $\sigma$ & ह & $\bar{\sim}$ & ঙ্ & $r$ & 움 & & $\sim$ & $m$ & 0 & 0 & \\
\hline ฉิ & $\nabla$ & 윗 & 六 & 흥 & $\bar{\sigma}$ & 0 & $\bar{\sim}$ & $\stackrel{\infty}{+}$ & ని & $c$ & $c$ & & ষ্লি & $\stackrel{L}{\frac{L}{\gamma}}$ & 0 & 0 & \\
\hline$\overline{0}$ & 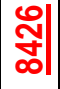 & $\infty$ & $\stackrel{\text { If }}{+}$ & $\stackrel{\sim}{\sim}$ & $\stackrel{d}{\sim}$ & ০ & $\stackrel{\infty}{\rightleftharpoons}$ & $\approx$ & ำ & $\stackrel{\infty}{a}$ & $\stackrel{\alpha}{\alpha}$ & & - & 0 & 0 & g & \\
\hline & $\overline{0}$ & ธี & ח & 吉 & مُ & 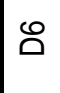 & 今 & $\stackrel{\infty}{\circ}$ & ฉ̊ & 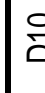 & i & & $\frac{\sim}{5}$ & $\stackrel{m}{\square}$ & $\frac{\dot{\theta}}{\square}$ & مان & \\
\hline
\end{tabular}


8

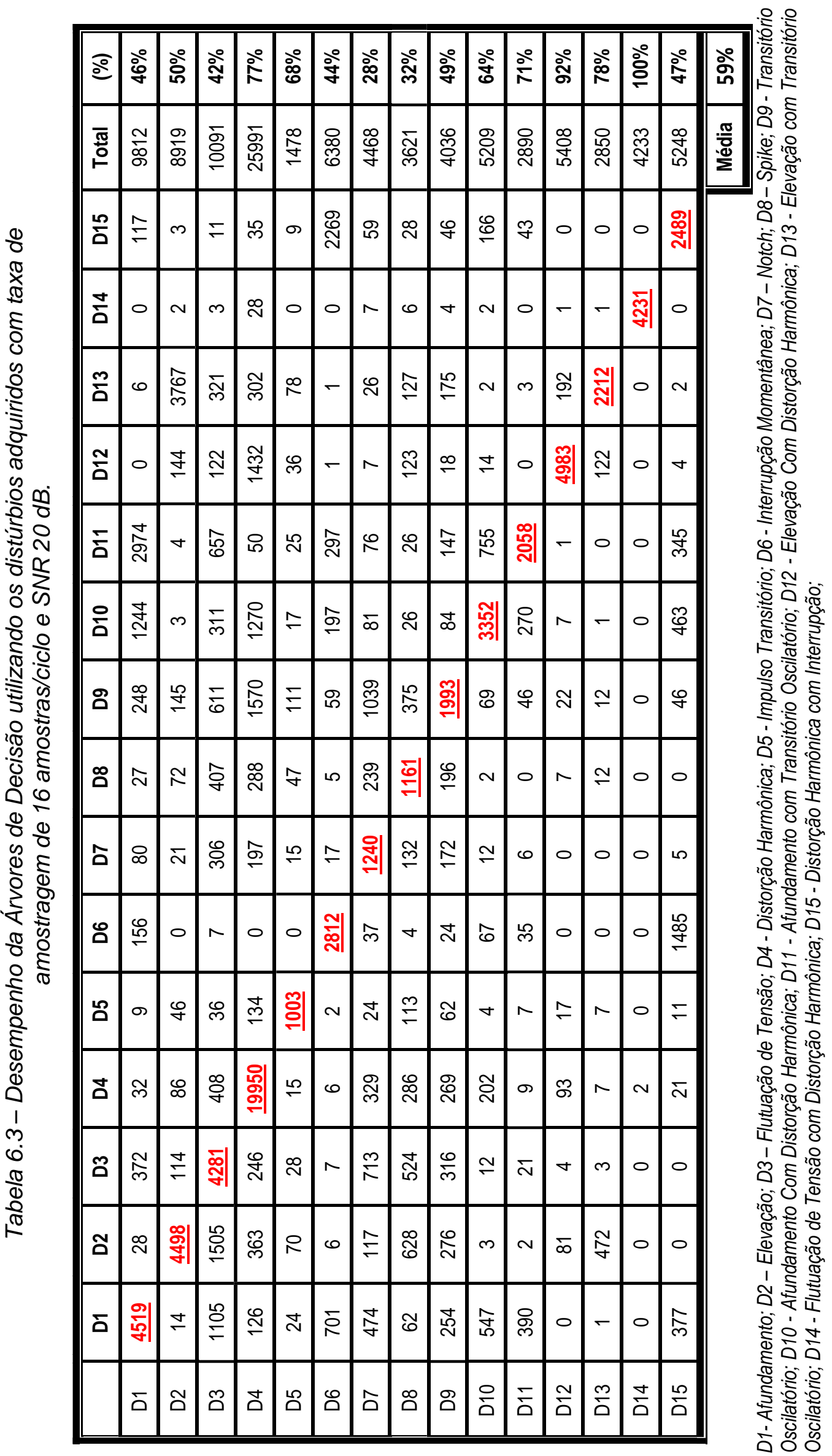


Pelos resultados apresentados nas Tabelas 6.1 à 6.3, pode-se observar que a árvore de decisão conseguiu uma boa classificação para o conjunto teste composto pelas janelas que possuem nível de ruído de $40 \mathrm{~dB}$. Nota-se que o erro do sistema aumenta, à medida que diminui a relação sinal ruído.

Pode-se observar que os erros são mais relevantes no conjunto de teste que possui um ruído de $20 \mathrm{~dB}$. Este erro se deve ao fato de que o ruído presente na janela altera o valor das característica extraídas desta janela, de modo que o classificador se equivoque e relacione esse padrão de entrada com uma outra classe, que não é aquela correta. Por exemplo, o ruído inserido nas janelas que apresentam o distúrbio afundamento faz com que elas tenham características bem semelhantes às janelas que apresentam os distúrbios afundamento com distorção harmônica e afundamento com transitório oscilatório, fazendo-se assim com que a árvore de decisão classifique algumas janelas de afundamento como afundamento e distorção harmônica ou afundamento e transitório oscilatório.

Assim, o ruído presente no sinal descaracteriza bastante o distúrbio, fazendose com que a árvore tenha uma taxa de acerto bastante baixa, para alguns distúrbios, como o notch e spike. Esta descaracterização pode ser evidenciada pela Figura 6.3, que mostra o gráfico do distúrbio notch, sobre diferentes níveis de ruído. Pelos gráficos nota-se que quando não existe ruído presente no sinal (Figura 6.3a) o distúrbio fica bem definido; no entanto, à medida que diminui a relação sinal ruído, ocorre uma descaracterização do distúrbio notch no sinal (Figura 6.3g). 

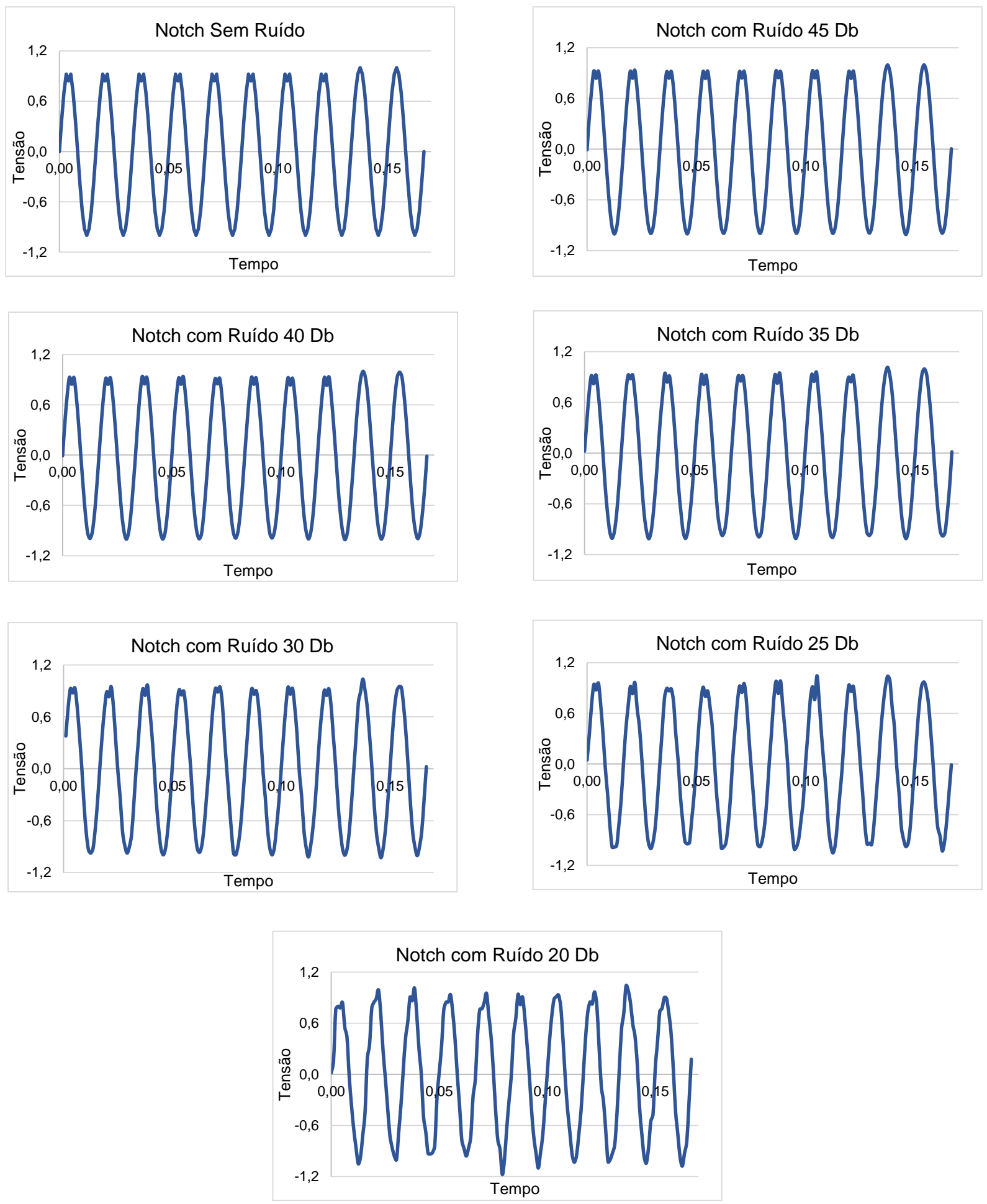

Figura 6.3 - Caracterização do disturbio transitório oscilatório sobre diferentes niveis de ruído: (a) - sinal sem ruído; (b) - SNR 45 dB; (c) - SNR $40 d B$; (d) - SNR 35 dB; (e) - SNR $30 d B$; (f) - SNR $25 d B ;(g)$ - SNR $20 d B .$.

Outro fator que foi observado por meio de uma análise detalhada nos dados é que os erros de identificação acontecem com mais frequências naquelas janelas 
onde o distúrbio não está perfeitamente caracterizado, ou seja, nas janelas que apresentam poucos pontos que caracterizam o distúrbio. Este fato pode ser visualizado pela Tabela 6.4, que apresenta a taxa de acerto de cada distúrbio em relação à quantidade de pontos que caracterizam o distúrbio. Como a taxa de amostragem é de 16 amostras/ciclo os distúrbios Impulso, notch e spike, só são caracterizados em 1 ponto, pois são distúrbios que acontecem em um curto intervalo de tempo. Portanto, pode-se notar que a medida que aumenta o número de pontos que caracteriza o distúrbio, a taxa de acerto do classificador também aumenta.

Tabela 6.4 - Resultados detalhado das janelas de Transição adquiridas a 16 amostras/ciclo.

\begin{tabular}{|l|l|l|l|l|l|l|l|l|l|l|l|l|l|l|l|}
\hline $\begin{array}{c}\text { Quantidade } \\
\text { de Pontos } \\
\text { com } \\
\text { Distúrbios }\end{array}$ & D1 & D2 & D3 & D4 & D5 & D6 & D7 & D8 & D9 & D10 & D11 & D12 & D13 & D14 & D15 \\
\hline 1 Ponto & $69,5 \%$ & $60,4 \%$ & $38,4 \%$ & $65,2 \%$ & $90,4 \%$ & $75,0 \%$ & $95,8 \%$ & $94,0 \%$ & $66,5 \%$ & $61,1 \%$ & $55,9 \%$ & $66,2 \%$ & $59,4 \%$ & $97,9 \%$ & $79,2 \%$ \\
\hline 2 Pontos & $81,1 \%$ & $80,8 \%$ & $65,1 \%$ & $72,8 \%$ & & $93,5 \%$ & & & $72,0 \%$ & $77,8 \%$ & $68,7 \%$ & $87,3 \%$ & $80,1 \%$ & $100 \%$ & $89,2 \%$ \\
\hline 3 Pontos & $83,0 \%$ & $89,6 \%$ & $75,0 \%$ & $81,4 \%$ & & $98,8 \%$ & & & $78,4 \%$ & $83,5 \%$ & $76,7 \%$ & $90,6 \%$ & $84,8 \%$ & $100 \%$ & $93,9 \%$ \\
\hline 4 Pontos & $93,1 \%$ & $96,6 \%$ & $80,9 \%$ & $87,8 \%$ & & $96,6 \%$ & & & $78,5 \%$ & $87,6 \%$ & $81,3 \%$ & $96,4 \%$ & $88,3 \%$ & $100 \%$ & $86,7 \%$ \\
\hline 5 Pontos & $94,1 \%$ & $96,9 \%$ & $84,3 \%$ & $94,6 \%$ & & $94,9 \%$ & & & $89,3 \%$ & $85,5 \%$ & $87,4 \%$ & $97,0 \%$ & $89,6 \%$ & $100 \%$ & $91,9 \%$ \\
\hline 6 Pontos & $96,8 \%$ & $96,8 \%$ & $91,0 \%$ & $97,1 \%$ & & $96,6 \%$ & & & $86,8 \%$ & $94,9 \%$ & $90,2 \%$ & $98,2 \%$ & $94,0 \%$ & $100 \%$ & $90,9 \%$ \\
\hline 7 Pontos & $93,6 \%$ & $97,1 \%$ & $92,2 \%$ & $98,8 \%$ & & $97,3 \%$ & & & $89,4 \%$ & $92,1 \%$ & $91,9 \%$ & $100 \%$ & $95,2 \%$ & $100 \%$ & $91,7 \%$ \\
\hline 8 Pontos & $94,9 \%$ & $96,2 \%$ & $95,7 \%$ & $98,5 \%$ & & $98,9 \%$ & & & $91,3 \%$ & $93,9 \%$ & $93,0 \%$ & $99,4 \%$ & $96,6 \%$ & $100 \%$ & $95,6 \%$ \\
\hline 9 Pontos & $94,8 \%$ & $98,9 \%$ & $94,6 \%$ & $99,5 \%$ & & $98,4 \%$ & & & $93,2 \%$ & $95,6 \%$ & $92,5 \%$ & $99,5 \%$ & $97,4 \%$ & $100 \%$ & $93,0 \%$ \\
\hline 10 pontos & $95,4 \%$ & $97,7 \%$ & $96,8 \%$ & $99,5 \%$ & & $97,3 \%$ & & & $91,9 \%$ & $96,7 \%$ & $92,1 \%$ & $100 \%$ & $96,5 \%$ & $100 \%$ & $94,7 \%$ \\
\hline 11 Pontos & $96,5 \%$ & $97,7 \%$ & $98,0 \%$ & $98,4 \%$ & & $96,8 \%$ & & & $94,0 \%$ & $93,1 \%$ & $94,6 \%$ & $100 \%$ & $93,7 \%$ & $100 \%$ & $95,3 \%$ \\
\hline 12 Pontos & $96,6 \%$ & $97,6 \%$ & $99,0 \%$ & $98,1 \%$ & & $96,4 \%$ & & & $94,3 \%$ & $92,6 \%$ & $94,1 \%$ & $100 \%$ & $98,2 \%$ & $100 \%$ & $96,3 \%$ \\
\hline 13 Pontos & $96,2 \%$ & $98,0 \%$ & $100 \%$ & $98,4 \%$ & & $98,4 \%$ & & & $93,3 \%$ & $95,4 \%$ & $97,8 \%$ & $99,0 \%$ & $96,0 \%$ & $100 \%$ & $95,9 \%$ \\
\hline 14 Pontos & $92,1 \%$ & $96,9 \%$ & $99,0 \%$ & $98,1 \%$ & & $95,9 \%$ & & & $93,0 \%$ & $94,4 \%$ & $93,9 \%$ & $100 \%$ & $96,7 \%$ & $100 \%$ & $90,4 \%$ \\
\hline 15 Pontos & $92,6 \%$ & $96,2 \%$ & $100 \%$ & $98,6 \%$ & & $86,5 \%$ & & & $96,1 \%$ & $93,0 \%$ & $93,0 \%$ & $99,0 \%$ & $97,5 \%$ & $100 \%$ & $85,0 \%$ \\
\hline
\end{tabular}

D1- Afundamento; D2 - Elevação; D3 - Flutuação de Tensão; D4 - Distorção Harmônica; D5 - Impulso Transitório; D6 - Interrupção Momentânea; D7 - Notch; D8 - Spike; D9 - Transitório Oscilatório; D10 - Afundamento Com Distorção Harmônica; D11 - Afundamento com Transitório Oscilatório; D12 - Elevação Com Distorção Harmônica; D13 - Elevação com Transitório Oscilatório; D14 - Flutuação de Tensão com Distorção Harmônica; D15 - Distorção Harmônica com Interrupção;

A seguir são explanados, de forma simplificado, por meio da Tabela 6.5 à 6.8 , os resultados das outras 4 árvores de decisão, as quais foram testadas utilizando os 
conjuntos formados pelas janelas adquiridas sobre uma taxa de amostragem de 32 amostras/ciclo, 64 amostras/ciclo, 128 amostras/ciclo e 256 amostras/ciclo e com relação sinal ruído de $40 \mathrm{~dB}, 30 \mathrm{~dB}$ e $20 \mathrm{~dB}$.

Tabela 6.5 - Desempenho da Árvores de Decisão utilizando os distúrbios adquiridos com taxa de amostragem de 32 amostras/ciclo

\begin{tabular}{||l|c|c|c|}
\hline \multirow{2}{*}{ Distúrbio } & \multicolumn{3}{|c|}{ 32 Amostras/Ciclo } \\
\cline { 2 - 4 } & SNR 40 dB & SNR 30 dB & SNR 20 dB \\
\hline Afundamento & $97 \%$ & $84 \%$ & $50 \%$ \\
\hline Afundamento Com Transitório Oscilatório & $93 \%$ & $87 \%$ & $84 \%$ \\
\hline Elevação & $96 \%$ & $90 \%$ & $57 \%$ \\
\hline Elevação com Transitório Oscilatório & $94 \%$ & $88 \%$ & $84 \%$ \\
\hline Flutuação de Tensão & $97 \%$ & $90 \%$ & $43 \%$ \\
\hline Distorção Harmônica & $98 \%$ & $97 \%$ & $72 \%$ \\
\hline Distorção Harmônica com Afundamento & $96 \%$ & $90 \%$ & $70 \%$ \\
\hline Distorção Harmônica com Elevação & $98 \%$ & $97 \%$ & $96 \%$ \\
\hline Distorção Harmônica com Flutuação de & $100 \%$ & $100 \%$ & $100 \%$ \\
\hline Tensão & $87 \%$ & $67 \%$ & $55 \%$ \\
\hline Distorção Harmônica com Interrupção & $89 \%$ & $77 \%$ & $72 \%$ \\
\hline Impulso Transitório & $93 \%$ & $78 \%$ & $53 \%$ \\
\hline Interrupção & $96 \%$ & $78 \%$ & $27 \%$ \\
\hline Notch & $92 \%$ & $74 \%$ & $33 \%$ \\
\hline Spike & $93 \%$ & $76 \%$ & $54 \%$ \\
\hline Transitório Oscilatório & $\mathbf{9 5 \%}$ & $\mathbf{8 5 \%}$ & $\mathbf{6 3 \%}$ \\
\hline Média & & & \\
\hline
\end{tabular}


Tabela 6.6 - Desempenho da Árvores de Decisão utilizando os distúrbios adquiridos com taxa de amostragem de 64 amostras/ciclo.

\begin{tabular}{|l|c|c|c|}
\hline \multirow{2}{*}{ Distúrbio } & \multicolumn{3}{|c|}{$\mathbf{6 4}$ Amostras/Ciclo } \\
\cline { 2 - 4 } & SNR 40 dB & SNR 30 dB & SNR 20 dB \\
\hline Afundamento & $95 \%$ & $79 \%$ & $53 \%$ \\
\hline Afundamento Com Transitório Oscilatório & $94 \%$ & $89 \%$ & $86 \%$ \\
\hline Elevação & $97 \%$ & $85 \%$ & $67 \%$ \\
\hline Elevação com Transitório Oscilatório & $95 \%$ & $90 \%$ & $86 \%$ \\
\hline Flutuação de Tensão & $96 \%$ & $90 \%$ & $52 \%$ \\
\hline Distorção Harmônica & $98 \%$ & $96 \%$ & $68 \%$ \\
\hline Distorção Harmônica com Afundamento & $97 \%$ & $93 \%$ & $73 \%$ \\
\hline Distorção Harmônica com Elevação & $99 \%$ & $98 \%$ & $97 \%$ \\
\hline Distorção Harmônica com Flutuação de & $100 \%$ & $100 \%$ & $100 \%$ \\
\hline Tensão & $89 \%$ & $76 \%$ & $56 \%$ \\
\hline Distorção Harmônica com Interrupção & $85 \%$ & $77 \%$ & $72 \%$ \\
\hline Impulso Transitório & $92 \%$ & $76 \%$ & $54 \%$ \\
\hline Interrupção & $91 \%$ & $72 \%$ & $26 \%$ \\
\hline Notch & $90 \%$ & $73 \%$ & $36 \%$ \\
\hline Spike & $91 \%$ & $79 \%$ & $42 \%$ \\
\hline Transitório Oscilatório & $\mathbf{9 4 \%}$ & $\mathbf{8 5 \%}$ & $\mathbf{6 4 \%}$ \\
\hline Média & & \\
\hline
\end{tabular}

Tabela 6.7 - Desempenho da Árvores de Decisão utilizando os distúrbios adquiridos com taxa de amostragem de 128 amostras/ciclo.

\begin{tabular}{|l|c|c|c|}
\hline \multirow{2}{*}{ Distúrbio } & \multicolumn{3}{|c|}{$\mathbf{1 2 8}$ Amostras/Ciclo } \\
\cline { 2 - 4 } & SNR 40 dB & SNR 30 dB & SNR 20 dB \\
\hline Afundamento & $90 \%$ & $83 \%$ & $61 \%$ \\
\hline Afundamento Com Transitório Oscilatório & $95 \%$ & $92 \%$ & $87 \%$ \\
\hline Elevação & $96 \%$ & $79 \%$ & $73 \%$ \\
\hline Elevação com Transitório Oscilatório & $95 \%$ & $93 \%$ & $87 \%$ \\
\hline Flutuação de Tensão & $96 \%$ & $91 \%$ & $55 \%$ \\
\hline Distorção Harmônica & $98 \%$ & $97 \%$ & $66 \%$ \\
\hline Distorção Harmônica com Afundamento & $97 \%$ & $94 \%$ & $80 \%$ \\
\hline Distorção Harmônica com Elevação & $99 \%$ & $98 \%$ & $96 \%$ \\
\hline Distorção Harmônica com Flutuação de & $99 \%$ & $99 \%$ & $99 \%$ \\
\hline Tensão & $94 \%$ & $78 \%$ & $57 \%$ \\
\hline Distorção Harmônica com Interrupção & $91 \%$ & $82 \%$ & $73 \%$ \\
\hline Impulso Transitório & $95 \%$ & $85 \%$ & $58 \%$ \\
\hline Interrupção & $91 \%$ & $75 \%$ & $24 \%$ \\
\hline Notch & $90 \%$ & $80 \%$ & $40 \%$ \\
\hline Spike & $92 \%$ & $83 \%$ & $53 \%$ \\
\hline Transitório Oscilatório & $\mathbf{9 4 \%}$ & $\mathbf{8 7 \%}$ & $\mathbf{6 7 \%}$ \\
\hline Média & & & \\
\hline
\end{tabular}


Tabela 6.8 - Desempenho da Árvores de Decisão utilizando os distúrbios adquiridos com taxa de amostragem de 256 amostras/ciclo.

\begin{tabular}{||l|c|c|c||}
\hline \multirow{2}{*}{ Distúrbio } & \multicolumn{3}{|c|}{256 Amostras/Ciclo } \\
\cline { 2 - 4 } & SNR 40 dB & SNR 30 dB & SNR 20 dB \\
\hline Afundamento & $96 \%$ & $91 \%$ & $62 \%$ \\
\hline Afundamento Com Transitório Oscilatório & $96 \%$ & $94 \%$ & $90 \%$ \\
\hline Elevação & $83 \%$ & $82 \%$ & $71 \%$ \\
\hline Elevação com Transitório Oscilatório & $97 \%$ & $94 \%$ & $91 \%$ \\
\hline Flutuação de Tensão & $97 \%$ & $93 \%$ & $69 \%$ \\
\hline Distorção Harmônica & $99 \%$ & $97 \%$ & $63 \%$ \\
\hline Distorção Harmônica com Afundamento & $98 \%$ & $96 \%$ & $82 \%$ \\
\hline Distorção Harmônica com Elevação & $99 \%$ & $99 \%$ & $97 \%$ \\
\hline Distorção Harmônica com Flutuação de & $100 \%$ & $100 \%$ & $100 \%$ \\
\hline Tensão & $96 \%$ & $84 \%$ & $64 \%$ \\
\hline Distorção Harmônica com Interrupção & $89 \%$ & $81 \%$ & $76 \%$ \\
\hline Impulso Transitório & $93 \%$ & $90 \%$ & $60 \%$ \\
\hline Interrupção & $91 \%$ & $83 \%$ & $23 \%$ \\
\hline Notch & $92 \%$ & $81 \%$ & $40 \%$ \\
\hline Spike & $91 \%$ & $87 \%$ & $36 \%$ \\
\hline Transitório Oscilatório & $94 \%$ & $90 \%$ & $68 \%$ \\
\hline Média & & & \\
\hline
\end{tabular}

Como foi citado no Capítulo 1, um dos objetivos desta dissertação, é testar a metodologia proposta sobre diferentes taxas de amostragem. Por isto, a Tabelas 6.9 apresenta um comparativo, em termos da média de acertos, entre cada uma das 5 árvores de decisão utilizando os três conjuntos de teste.

Tabela 6.9 - Desempenho comparativo da árvore de decisão sobre diferentes taxas de amostragem.

\begin{tabular}{|l|c|c|c|}
\hline & $\begin{array}{c}\text { Teste1 } \\
\text { (SNR 40 dB) }\end{array}$ & $\begin{array}{c}\text { Teste2 } \\
(\text { SNR 30 dB) }\end{array}$ & $\begin{array}{c}\text { Teste3 } \\
\text { (SNR 20 dB) }\end{array}$ \\
\hline 16 Amostras/Ciclo & $93 \%$ & $83 \%$ & $59 \%$ \\
\hline 32 Amostras/Ciclo & $95 \%$ & $85 \%$ & $63 \%$ \\
\hline 64 Amostras/Ciclo & $94 \%$ & $85 \%$ & $64 \%$ \\
\hline $\mathbf{1 2 8}$ Amostras/Ciclo & $94 \%$ & $87 \%$ & $67 \%$ \\
\hline 256 Amostras/Ciclo & $94 \%$ & $90 \%$ & $68 \%$ \\
\hline
\end{tabular}




\subsubsection{Resultados para um sinal com tamanho de dez ciclos}

Na sequência, propôs-se a analisar o desempenho da árvore de decisão para classificação dos distúrbios de QEE que apresentam uma duração de 10 ciclos. Para construir o conjunto de treinamento e teste são gerados, sobre 5 taxas de amostragem, 100 estudos de casos para cada um dos 15 distúrbios e, para cada caso é inserido 6 diferentes tipos de ruído ( $45 \mathrm{~dB}, 40 \mathrm{~dB}, 35 \mathrm{~dB}, 30 \mathrm{~dB}, 25 \mathrm{~dB}, 20 \mathrm{~dB}$ ), totalizando-se então 3500 estudos de casos.

Esses dados são divididos de forma que, para treinamento da árvore, são utilizados os sinais que apresentam relação sina/ruído de $45 \mathrm{~dB}, 35 \mathrm{~dB}, 25 \mathrm{~dB}$ e adicionamento do sinal sem a presença de ruído. Já para teste são utilizados os sinais que apresentam nível de ruído de $40 \mathrm{~dB}, 30 \mathrm{~dB}$ e $20 \mathrm{~dB}$.

Desse modo, são construídas 5 árvores de decisão, cada uma sendo responsável por classificar, respectivamente, os sinais obtidos sobre 16 amostras/ciclo, 32 amostras/ciclo, 64 amostras/ciclo, 128 amostras/ciclo e 256 amostras/ciclo. As tabelas 6.10 à 6.14 , apresentam o desempenho de cada árvore de decisão, sobre diferentes níveis de ruído. 
Tabela 6.10 - Desempenho da Árvores de Decisão utilizando os distúrbios adquiridos com taxa de amostragem de 16 amostras/ciclo e duração de 10 ciclos.

\begin{tabular}{|l|c|c|c||}
\hline \multirow{2}{*}{ Distúrbio } & \multicolumn{3}{|c|}{$\mathbf{1 6}$ Amostras/Ciclo } \\
\cline { 2 - 4 } & SNR 40 dB & SNR 30 dB & SNR 20 dB \\
\hline Afundamento & $93 \%$ & $72 \%$ & $24 \%$ \\
\hline Elevação & $100 \%$ & $100 \%$ & $40 \%$ \\
\hline Flutuação de Tensão & $98 \%$ & $94 \%$ & $17 \%$ \\
\hline Distorção Harmônica & $90 \%$ & $71 \%$ & $21 \%$ \\
\hline Impulso Transitório & $97 \%$ & $76 \%$ & $64 \%$ \\
\hline Interrupção & $98 \%$ & $85 \%$ & $29 \%$ \\
\hline Notch & $50 \%$ & $63 \%$ & $5 \%$ \\
\hline Spike & $98 \%$ & $77 \%$ & $6 \%$ \\
\hline Transitório Oscilatório & $96 \%$ & $92 \%$ & $41 \%$ \\
\hline Distorção Harmônica com Afundamento & $94 \%$ & $87 \%$ & $67 \%$ \\
\hline Distorção Harmônica com Elevação & $100 \%$ & $100 \%$ & $77 \%$ \\
\hline Distorção Harmônica com Flutuação de & $93 \%$ & $73 \%$ & $60 \%$ \\
\hline Tensão & $94 \%$ & $87 \%$ & $58 \%$ \\
\hline Distorção Harmônica com Interrupção & $96 \%$ & $89 \%$ & $60 \%$ \\
\hline Afundamento Com Transitório Oscilatório & $100 \%$ & $94 \%$ & $95 \%$ \\
\hline Elevação com Transitório Oscilatório & $\mathbf{9 3 \%}$ & $\mathbf{8 4 \%}$ & $\mathbf{4 4 \%}$ \\
\hline Média & & & \\
\hline
\end{tabular}

Tabela 6.11 - Desempenho da Árvores de Decisão utilizando os distúrbios adquiridos com taxa de amostragem de 32 amostras/ciclo e duração de 10 ciclos.

\begin{tabular}{|l|c|c|c|}
\hline \multirow{2}{*}{ Distúrbio } & \multicolumn{3}{|c|}{ 32 Amostras/Ciclo } \\
\cline { 2 - 4 } & SNR 40 dB & SNR 30 dB & SNR 20 dB \\
\hline Afundamento & $95 \%$ & $83 \%$ & $49 \%$ \\
\hline Elevação & $100 \%$ & $100 \%$ & $94 \%$ \\
\hline Flutuação de Tensão & $99 \%$ & $96 \%$ & $78 \%$ \\
\hline Distorção Harmônica & $100 \%$ & $89 \%$ & $34 \%$ \\
\hline Impulso Transitório & $99 \%$ & $93 \%$ & $85 \%$ \\
\hline Interrupção & $100 \%$ & $92 \%$ & $86 \%$ \\
\hline Notch & $80 \%$ & $77 \%$ & $2 \%$ \\
\hline Spike & $100 \%$ & $96 \%$ & $29 \%$ \\
\hline Transitório Oscilatório & $98 \%$ & $84 \%$ & $12 \%$ \\
\hline Distorção Harmônica com Afundamento & $94 \%$ & $88 \%$ & $71 \%$ \\
\hline Distorção Harmônica com Elevação & $100 \%$ & $100 \%$ & $99 \%$ \\
\hline Distorcão Harmônica com Flutuação de & $90 \%$ & $79 \%$ & $58 \%$ \\
\hline Tensão & $98 \%$ & $91 \%$ & $83 \%$ \\
\hline Distorção Harmônica com Interrupção & $96 \%$ & $91 \%$ & $81 \%$ \\
\hline Afundamento Com Transitório Oscilatório & $100 \%$ & $100 \%$ & $98 \%$ \\
\hline Elevação com Transitório Oscilatório & $\mathbf{9 7 \%}$ & $\mathbf{9 1 \%}$ & $\mathbf{6 4 \%}$ \\
\hline Média & & \\
\hline
\end{tabular}


Tabela 6.12 - Desempenho da Árvores de Decisão utilizando os distúrbios adquiridos com taxa de amostragem de 64 amostras/ciclo e duração de 10 ciclos.

\begin{tabular}{|l|c|c|c|}
\hline \multirow{2}{*}{ Distúrbio } & \multicolumn{3}{|c|}{$\mathbf{6 4}$ Amostras/Ciclo } \\
\cline { 2 - 4 } & SNR 40 dB & SNR 30 dB & SNR 20 dB \\
\hline Afundamento & $92 \%$ & $86 \%$ & $23 \%$ \\
\hline Elevação & $98 \%$ & $95 \%$ & $27 \%$ \\
\hline Flutuação de Tensão & $98 \%$ & $88 \%$ & $62 \%$ \\
\hline Distorção Harmônica & $95 \%$ & $91 \%$ & $43 \%$ \\
\hline Impulso Transitório & $96 \%$ & $87 \%$ & $55 \%$ \\
\hline Interrupção & $98 \%$ & $87 \%$ & $51 \%$ \\
\hline Notch & $95 \%$ & $91 \%$ & $4 \%$ \\
\hline Spike & $94 \%$ & $85 \%$ & $52 \%$ \\
\hline Transitório Oscilatório & $94 \%$ & $80 \%$ & $2 \%$ \\
\hline Distorção Harmônica com Afundamento & $98 \%$ & $93 \%$ & $85 \%$ \\
\hline Distorção Harmônica com Elevação & $99 \%$ & $99 \%$ & $92 \%$ \\
\hline Distorção Harmônica com Flutuação de & $93 \%$ & $87 \%$ & $55 \%$ \\
\hline Tensão & $99 \%$ & $96 \%$ & $82 \%$ \\
\hline Distorção Harmônica com Interrupção & $97 \%$ & $89 \%$ & $90 \%$ \\
\hline Afundamento Com Transitório Oscilatório & $97 \%$ & $96 \%$ & $100 \%$ \\
\hline Elevação com Transitório Oscilatório & $\mathbf{9 6 \%}$ & $\mathbf{9 0 \%}$ & $\mathbf{5 5 \%}$ \\
\hline Média & &
\end{tabular}

Tabela 6.13 - Desempenho da Árvores de Decisão utilizando os distúrbios adquiridos com taxa de amostragem de 128 amostras/ciclo e duração de 10 ciclos.

\begin{tabular}{|l|c|c|c|}
\hline \multirow{2}{*}{ Distúrbio } & \multicolumn{3}{|c|}{$\mathbf{1 2 8}$ Amostras/Ciclo } \\
\cline { 2 - 4 } & SNR 40 dB & SNR 30 dB & SNR 20 dB \\
\hline Afundamento & $94 \%$ & $89 \%$ & $61 \%$ \\
\hline Elevação & $100 \%$ & $95 \%$ & $87 \%$ \\
\hline Flutuação de Tensão & $97 \%$ & $89 \%$ & $73 \%$ \\
\hline Distorção Harmônica & $93 \%$ & $91 \%$ & $87 \%$ \\
\hline Impulso Transitório & $96 \%$ & $83 \%$ & $55 \%$ \\
\hline Interrupção & $98 \%$ & $94 \%$ & $66 \%$ \\
\hline Notch & $96 \%$ & $91 \%$ & $80 \%$ \\
\hline Spike & $99 \%$ & $92 \%$ & $96 \%$ \\
\hline Transitório Oscilatório & $98 \%$ & $90 \%$ & $99 \%$ \\
\hline Distorção Harmônica com Afundamento & $99 \%$ & $97 \%$ & $57 \%$ \\
\hline Distorção Harmônica com Elevação & $100 \%$ & $100 \%$ & $73 \%$ \\
\hline Distorção Harmônica com Flutuação de & $95 \%$ & $91 \%$ & $58 \%$ \\
\hline Tensão & $95 \%$ & $97 \%$ & $24 \%$ \\
\hline Distorção Harmônica com Interrupção & $96 \%$ & $95 \%$ & $40 \%$ \\
\hline Afundamento Com Transitório Oscilatório & $99 \%$ & $97 \%$ & $53 \%$ \\
\hline Elevação com Transitório Oscilatório & $\mathbf{9 7 \%}$ & $\mathbf{9 3} \%$ & $\mathbf{6 7 \%}$ \\
\hline Média & &
\end{tabular}


Tabela 6.14 - Desempenho da Árvores de Decisão utilizando os distúrbios adquiridos com taxa de amostragem de 256 amostras/ciclo e duração de 10 ciclos.

\begin{tabular}{|l|c|c|c|}
\hline \multirow{2}{*}{ Distúrbio } & \multicolumn{3}{|c|}{256 Amostras/Ciclo } \\
\cline { 2 - 4 } & SNR 40 dB & SNR 30 dB & SNR 20 dB \\
\hline Afundamento & $95 \%$ & $80 \%$ & $49 \%$ \\
\hline Elevação & $99 \%$ & $95 \%$ & $47 \%$ \\
\hline Flutuação de Tensão & $99 \%$ & $96 \%$ & $44 \%$ \\
\hline Distorção Harmônica & $96 \%$ & $93 \%$ & $52 \%$ \\
\hline Impulso Transitório & $95 \%$ & $90 \%$ & $79 \%$ \\
\hline Interrupção & $95 \%$ & $96 \%$ & $63 \%$ \\
\hline Notch & $98 \%$ & $91 \%$ & $80 \%$ \\
\hline Spike & $98 \%$ & $92 \%$ & $52 \%$ \\
\hline Transitório Oscilatório & $93 \%$ & $94 \%$ & $24 \%$ \\
\hline Distorção Harmônica com Afundamento & $98 \%$ & $98 \%$ & $77 \%$ \\
\hline Distorção Harmônica com Elevação & $100 \%$ & $99 \%$ & $98 \%$ \\
\hline Distoção Harmônica com Flutuação de & $95 \%$ & $94 \%$ & $64 \%$ \\
\hline Tensão & $100 \%$ & $97 \%$ & $83 \%$ \\
\hline Distorção Harmônica com Interrupção & $96 \%$ & $91 \%$ & $79 \%$ \\
\hline Afundamento Com Transitório Oscilatório & $98 \%$ & $97 \%$ & $92 \%$ \\
\hline Elevação com Transitório Oscilatório & $\mathbf{9 7 \%}$ & $\mathbf{9 4 \%}$ & $\mathbf{6 6 \%}$ \\
\hline Média & & \\
\hline
\end{tabular}

\subsection{Considerações Finais}

O capítulo apresentou inicialmente as definições a respeito do classificador baseado em árvore de decisão, evidenciando-se as heurísticas que são utilizadas no desenvolvimento dos algoritmos responsáveis pelo processo de indução de uma árvore de decisão.

Por fim foi apresentado os resultados obtidos com a utilização do classificador baseado em árvore de decisão. Os resultados mostram que a árvore de decisão consegue detectar padrões das características que são utilizadas como entrada, relacionando estes padrões com o distúrbio equivalente. É importante ressaltar que a árvore conseguiu uma boa classificação tanto para um sinal que representa uma janela de tamanho igual a um ciclo como para um sinal com tamanho igual a 10 ciclos. 


\section{Conclusões e Trabalhos Futuros}

Este trabalho representa o estudo de um método compacto, que possa ser empregado para detecção dos distúrbios que afetam o sistema elétrico de potência. Adicionalmente é proposto um classificador baseado em árvore de decisão que realiza classificação estes distúrbios.

Para isto, foi proposto, uma metodologia que emprega cálculos simples no domínio do tempo, junto com a Transformada de Fourier, para extração das características dos sinais de tensão do sistema elétrico. Portanto, pode-se dizer que o método se diverge das metodologias convencionais, as quais extraem características do sinal somente a partir dos dados obtidos com a utilização de uma ferramenta de pré-processamento.

Ainda respeitando a simplicidade da metodologia, foi também desenvolvido um método de detecção que utiliza dois blocos, os quais cada um recebe de entrada respectivamente a característica RMS e THD. A partir da entrada cada bloco consegue inferir na presença ou não do distúrbio em uma janela analisada, com base em uma regra.

Com relação a classificação das janelas, o vetor de características extraídas do sinal é introduzido no classificador baseado em árvore de decisão sendo este responsável por identificar 15 distúrbios de QEE

É importante comentar que os dados utilizados para testar a metodologia foram obtidos de um banco de dados que armazena os distúrbios de qualidade de 
energia em 5 diferentes frequências de amostragem $(960 \mathrm{~Hz}, 1920 \mathrm{~Hz}, 2840 \mathrm{~Hz}, 7680$ $\mathrm{Hz}$ e $15360 \mathrm{~Hz}$ ). Os sinais que foram inseridos no banco de dados foram modelados por meio de equações paramétricas.

Pelos resultados, observa-se que a metodologia proposta consegue classificar de forma eficiente e rápida eventos de qualidade de energia. No entanto o desempenho do classificador diminui à medida que aumenta o ruído no sinal de entrada. Estas classificações errôneas estão intimamente relacionadas ao fato de os distúrbios possuírem características semelhantes em suas formas de onda.

Portanto, esta aplicação mostra que a extração de características utilizando cálculos compactos (no tempo) consegue obter peculiaridades distintivas de todos os distúrbios, aumentando-se então a precisão do classificador.

É importante comentar que, apesar de o processo de extração de características fornecerem grande auxílio aos classificadores, faz-se ainda necessário investigar novas características que possam ser calculadas e que possam contribuir ainda mais para o processo de classificação dos distúrbios.

Para os trabalhos futuros pretende-se determinar os parâmetros ótimos a serem utilizados em cada bloco do método de detecção. Pretende-se também a aplicação de outras arquiteturas de classificação de padrão, a fim de compara-las com as árvores de decisão. Por fim pretende-se utilizar a metodologia proposta em dados reais do sistema elétrico de potência. 


\section{Referências Bibliográficas}

ABDELSALAM, A. A.; ELDESOUKY, A. A.; SALLAM, A. A. Characterization of power quality disturbances using hybrid technique of linear Kalman filter and fuzzy-expert system. Electric Power Systems Research, v. 83, n. 1, p. 41-50, fev. 2012.

ADDISON, P. S. The illustrated wavelet transform handbook: introductory theory and applications in science, engineering, medicine and finance. [s.l.] Institute of Physics Publishing, 2002. p. 353

ANEEL. PRODIST (Procedimentos de Distribuição de Energia Elétrica no Sistema Elétrico Nacional) - - Módulo 8: Qualidade da Energia Elétrica, 2012.

BISWAL, B. et al. Classification of power quality data using decision tree and chemotactic differential evolution based fuzzy clustering. Swarm and Evolutionary Computation, v. 4, p. 12-24, jun. 2012.

BISWAL, B.; DASH, P.; PANIGRAHI, B. Power quality disturbance classification using fuzzy $C$-means algorithm and adaptive particle swarm optimization. IEEE Transactions on Industrial Electronics, v. 56, n. 1, p. 212-220, 2009.

$\mathrm{CHO}$, S. et al. Time-Frequency Analysis of Power-Quality Disturbances via the Gabor - Wigner Transform. v. 25, n. 1, p. 494-499, 2010.

COMMITTEE, D. IEEE Std 1159 ${ }^{\text {TM }}$-2009, IEEE Recommended Practice for Monitoring Electric Power Quality. [s.I.] IEEE, 2009. v. 2009p. c1 -81

DECANINI, J. G. M. S. et al. Detection and classification of voltage disturbances using a Fuzzy-ARTMAP-wavelet network. Electric Power Systems Research, v. 81, n. 12, p. 2057-2065, dez. 2011.

DUGAN, R. C. et al. Electrical Power Systems Quality. 3. ed. New York: McGrawHill Education, 2002.

ERIŞTI, H.; UÇAR, A.; DEMIR, Y. Wavelet-based feature extraction and selection for classification of power system disturbances using support vector machines. Electric Power Systems Research, v. 80, n. 7, p. 743-752, jul. 2010.

GARGOOM, A. M. et al. Automatic Classification and Characterization of Power Quality Events. v. 23, n. 4, p. 2417-2425, 2008. 
GRANADOS-LIEBERMAN, D. et al. Techniques and methodologies for power quality analysis and disturbances classification in power systems: a review. IET Generation, Transmission \& Distribution, v. 5, n. 4, p. 519, 2011.

HALMENSCHLAGER, C. Um algoritmo para induçao de árvores e regras de decisão. [s.I.] Universidade Federal do Rio Grande do Sul, 2002.

HOOSHMAND, R.; ENSHAEE, A. Detection and classification of single and combined power quality disturbances using fuzzy systems oriented by particle swarm optimization algorithm. Electric Power Systems Research, v. 80, n. 12, p. 15521561, dez. 2010.

HOOSHMAND, R.; ENSHAEE, A. Detection and classification of single and combined power quality disturbances using fuzzy systems oriented by particle swarm optimization algorithm. Electric Power Systems Research, v. 80, n. 12, p. 15521561, dez. 2010.

HUANG, N. et al. Power quality disturbances classification based on S-transform and probabilistic neural network. Neurocomputing, v. 98, p. 12-23, dez. 2012.

JAYASREE, T.; DEVARAJ, D.; SUKANESH, R. Power quality disturbance classification using Hilbert transform and RBF networks. Neurocomputing, v. 73, n. 7-9, p. 1451-1456, mar. 2010.

JI, T. Y. et al. Disturbance detection, location and classification in phase space. IET Generation, Transmission \& Distribution, v. 5, n. 2, p. 257, 2011.

LEE, C.-Y.; SHEN, Y.-X. Optimal Feature Selection for Power-Quality Disturbances Classification. IEEE Transactions on Power Delivery, v. 26, n. 4, p. 2342-2351, out. 2011.

MADRI, W. Análise Exploratória de Dados. Londrina, 2011. [Apostila do Curso de Especialização "Lato Sensu" em Estatística - Universidade Estadual de Londrina.

MALANGE, F. C. V. Rede Neuro-Fuzzy-Wavelet para Detecção e Classificação de Anomalias de Tensão em Sistemas Elétricos de Potência. 2010. Tese (Doutorado em Engenharia Eletrica) - Faculdade de Engenharia, UNESP, Campus Ilha Solteira. 2010.

MANIMALA, K.; SELVI, K.; AHILA, R. Optimization techniques for improving power quality data mining using wavelet packet based support vector machine.

Neurocomputing, v. 77, n. 1, p. 36-47, fev. 2012.

MASOUM, M. A. S.; JAMALI, S.; GHAFFARZADEH, N. Detection and classification of power quality disturbances using discrete wavelet transform and wavelet networks. IET Science, Measurement \& Technology, v. 4, n. 4, p. 193, 2010.

MEHER, S. K.; PRADHAN, A. K. Fuzzy classifiers for power quality events analysis. Electric Power Systems Research, v. 80, n. 1, p. 71-76, jan. 2010. 
MISHRA, S. et al. Detection and Classification of Power Quality Disturbances Using S-Transform and Probabilistic Neural Network. v. 23, n. 1, p. 280-287, 2008.

OLESKOVICZ, M. et al. Power quality analysis applying a hybrid methodology with wavelet transforms and neural networks. International Journal of Electrical Power \& Energy Systems, v. 31, n. 5, p. 206-212, 2009.

OPPENHEIM, A. V; SCHAFER, R. W.; BUCK, J. R. Discrete Time Signal Processing. Prentice Hall, 1999. v. 1999

PANIGRAHI, B. K.; DASH, P. K.; REDDY, J. B. V. Hybrid signal processing and machine intelligence techniques for detection, quantification and classification of power quality disturbances. Engineering Applications of Artificial Intelligence, v. 22, n. 3, p. 442-454, 2009.

PANIGRAHI, B.; PANDI, V. Optimal feature selection for classification of power quality disturbances using wavelet packet-based fuzzy k-nearest neighbour algorithm. Generation, Transmission \& Distribution, v. 3, n. April 2008, p. 296306, 2009.

PIRES, V. F.; AMARAL, T. G.; MARTINS, J. F. Power quality disturbances classification using the 3-D space representation and PCA based neuro-fuzzy approach. Expert Systems with Applications, v. 38, n. 9, p. 11911-11917, 2011.

QUINLAN, R. J. C4.5: Programs for Machine Learning. Sao Francisco, CA: Mateo: Morgan Kaufmann Publishers, 1993.

RODRÍGUEZ, A. et al. Rule-based classification of power quality disturbances using S-transform. Electric Power Systems Research, v. 86, p. 113-121, 2012.

SAINI, M. K.; KAPOOR, R. Classification of power quality events - A review.

International Journal of Electrical Power \& Energy Systems, v. 43, n. 1, p. 11-19, 2012.

SALEM, M. E.; MOHAMED, A.; SAMAD, S. A. Rule based system for power quality disturbance classification incorporating S-transform features. Expert Systems with Applications, v. 37, n. 4, p. 3229-3235, 2010.

SANTOSO, S.; POWERS, E. J.; GRADY, W. M. Electric power quality disturbance detection using wavelet transform analysis. Time-Frequency and Time-Scale Analysis, 1994., Proceedings of the IEEE-SP International Symposium on. p. 166-169, 1994.

SHANNON, E. C. A Mathematical Theory of Communication. Bell System Technical Jornal, v. 27, 1948.

SMITH, S, W. The Scientist and Engineer's Guide to Digital Signal Processing. California, 1997. 
UYAR, M.; YILDIRIM, S.; GENCOGLU, M. T. An expert system based on Stransform and neural network for automatic classification of power quality disturbances. Expert Systems with Applications, v. 36, n. 3, p. 5962-5975, abr. 2009.

WITTEN, I. H.; FRANK, E. Data Mining: Pratical Machine Learning Tools and Techiques. 3. ed. Boston: Morgan Kaufmann Publishers, 2011.

ZHANG, M.; LI, K.; HU, Y. A real-time classification method of power quality disturbances. Electric Power Systems Research, v. 81, n. 2, p. 660-666, fev. 2011. 